\title{
Enhanced Clearing of Wound Related Pathogenic Bacterial Biofilms Using Protease-Functionalized Antibiotic Nanocarriers
}

\author{
Paul J. Weldrick, ${ }^{a}$ Matthew J. Hardman ${ }^{b}$ and Vesselin N. Paunov ${ }^{a *}$ \\ ${ }^{a}$ Department of Chemistry and Biochemistry, University of Hull, Hull, UK; \\ ${ }^{b}$ Centre for Atherothrombosis and Metabolic Disease, Hull York Medical School, Hull, UK.
}

\begin{abstract}
KEYWORDS: Biofilms, nanogels, protease, Alcalase 2.4 L FG, ciprofloxacin, Staphylococcus aureus, Pseudomonas aeruginosa, Klebsiella pneumoniae
\end{abstract}

\begin{abstract}
Biofilms are prevalent in chronic wounds and once formed are very hard to remove which is associated with poor outcomes and high mortality rates. Biofilms are comprised of surface-attached bacteria embedded in an extracellular polymeric substance (EPS) matrix, which confers increased antibiotic resistance and host immune evasion. Therefore, disruption of this matrix is essential to tackle the biofilm embedded bacteria. Here we propose a novel nanotechnology to do this, based on protease-functionalized nanogel carriers of antibiotics. Such active antibiotic nanocarriers, surface coated with the protease Alcalase $2.4 \mathrm{~L} \mathrm{FG}$, "digest" their way through the biofilm EPS matrix, reach the buried bacteria and deliver a high dose of antibiotic directly on their cell walls which overwhelms their defenses. We demonstrated their effectiveness against six wound biofilm forming bacteria, Staphylococcus aureus, Pseudomonas aeruginosa, Staphylococcus epidermidis, Klebsiella pneumoniae, Escherichia coli and Enterococcus faecalis. We confirmed a six-fold decrease in the biofilm mass, and a substantial reduction in bacterial cell density using fluorescence, atomic force and scanning electron microscopy. Additionally, we showed that co-treatments of ciprofloxacin and Alcalase-coated Carbopol nanogels led to a 3-log reduction in viable biofilm forming cells when compared to ciprofloxacin treatments alone. Encapsulating an equivalent concentration of ciprofloxacin into the Alcalse-coated nanogel particles boosted their antibacterial effect much further, reducing the bacterial cell viability to below detectable amounts after 6 hours of treatment. The Alcalase-coated nanogel particles were non-cytotoxic to human adult keratinocyte cells (HaCaT), inducing a very low apoptotic response in these cells. Overall, we demonstrated that the Alcalase-coated nanogels loaded with a cationic antibiotic elicit very strong biofilm clearing effects against wound associated biofilm forming pathogenic bacteria. This nanotechnology approach has the potential to become a very powerful treatment of chronically infected wounds with biofilm forming bacteria.
\end{abstract}

\section{INTRODUCTION}

Biofilms are microbial communities surrounded by a structure referred to as extracellular polymeric substance (EPS), composed of biopolymers such as exopolysaccharides, nucleic acids, lipids, and proteins. ${ }^{1}$ The EPS matrix is highly hydrated, with occasional hydrophobic regions, such as areas containing cellulose. ${ }^{2}$ Combined, these substances form a structured matrix, allowing bacteria to effectively adhere to a range of surfaces. ${ }^{3}$ The formation of biofilms begins when surface-attached bacterial cells secrete EPS which allows complex communal tertiary microcolony structures to form. ${ }^{4}$ Biofilms are commonly surface-attached with one layer of cells in direct contact with the substratum, however, they can be found in flocs in which biofilms are formed around cells without contact with a substratum. ${ }^{5}$ The EPS matrix provides effective protection of the bacteria within the biofilm to a wide array of environmental factors, such as antimicrobial agents and a host immune response molecules. $^{6,7}$ Biofilms confer benefits to the cells within, in quenching antimicrobial agents which would kill planktonic cells. ${ }^{8}$ The biofilm is able to impair the diffusion of antimicrobial agents through the EPS and lower local concentration, thus increasing the tolerance of the cells to the most chemicals. ${ }^{9}$ An example of tolerance is the neutralization of toxic metal ions such as copper which is complexed to the polysaccharides of the EPS. ${ }^{10,11}$ Biofilm infections in humans with species which show high resistance to treatment may result in chronic infections. ${ }^{16}$ Opportunistic pathogens such as, Staphylococcus, Pseudomonas and Klebsiella genus', can form biofilms on acute and chronic dermal wounds, impairing wound healing, and potentially leading to sepsis. ${ }^{17}$ This effect can lead to increased patient mortality and morbidity in regard to biofilm infection. ${ }^{18,19}$ Nanoparticles (NPs) have been investigated for their anti-biofilm properties. Ag-Au nanocomposite particles, CuONPs, $\mathrm{Mg}(\mathrm{OH})_{2}$ NPs, silica NPs 
and $\mathrm{Au}$ NPs have shown high efficacy in this regard. $21,22,12,64,13$ Borovicka et al. ${ }^{37,45,46}$ developed photothermal colloid antibodies based on bioimprints that can selectively kill microbial cells by cell shape recognition. Au NPs in conjunction with heat produced with laser irradiation can effectively disrupt biofilms. ${ }^{23}$ Taking advantage of the antimicrobial effect of Ag has led to the novel use of bioglass which incorporates surface reacted $\mathrm{Ag}$ and has been shown to have effective anti-biofilm use. ${ }^{24}$ Enzymatic biofilm degradation has also been investigated, e.g. the use of hydrolases, amylases, and proteases. ${ }^{25}$ The principle of disrupting the biofilm network using enzymatic lysis, rather than directly attacking the cells themselves has the advantage of not relying on the biocidal action of tradition antimicrobials, and as such do not place a direct evolutionary pressure on the bacteria to develop resistance. ${ }^{26}$ All components of the EPS matrix have been investigated for the removal of biofilms, these include DNases, glycosidases, and proteases. ${ }^{27}$ An examples of a glycosidases is dispersin B produced by Aggregatibacter actinomycetemcomitans, has been demonstrated as being effective against $S$. epidermidis and S. aureus biofilms. ${ }^{28,29}$ Glycoside hydrolase alginate lyase and DNase NucB has also proved effective against $P$. aeruginosa and E. coli biofilms respectively. ${ }^{30,31}$ Proteases (EC
3.4) are present in all life forms, providing a wide variety of metabolic and physiological functions, including signal transduction, apoptosis, cell division, blood pressure regulation, and many more. ${ }^{32}$ Protease have previously been investigated for their anti-biofilm potential, both as small molecules (e.g. ficin) and bacterial-derived Bacillus proteases (AprBp and GseBp). ${ }^{33,34}$ Ironically, bacteria have become a useful source of anti-biofilm proteases. ${ }^{35,36}$ Proteases have two unique properties which make them an excellent enzyme choice for degrading biofilms. Their ability to hydrolyze EPS matrix proteins and adhesins (allowing a biofilm to attach to a solid surface and bacteria-bacteria adhesion) give them a distinct advantage over other anti-biofilm enzymes. ${ }^{1}$ Additionally, they may disrupt intercellular communication by lysis of type I signal peptidase, as shown in $S$. aureus. ${ }^{39}$ Proteases have also been shown to have potential in improving wound healing by degrading the biofilm EPS which may be interfering with the normal wound healing process. ${ }^{40,41}$ Serine Esp based protease obtained from $S$. epidermidis and elastase LasB from $P$. aeruginosa have been shown to reduce biofilm formation in $S$. aureus, providing further evidence of their efficacy and usefulness in biofilm treatment options. ${ }^{42}$

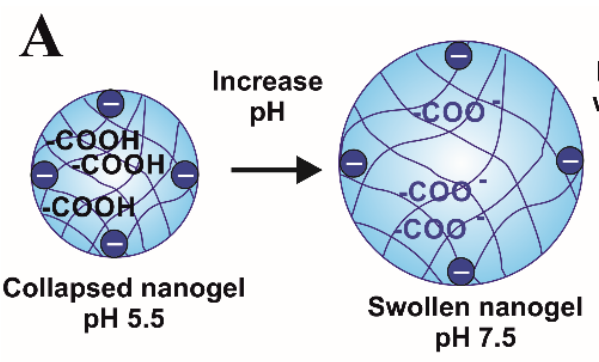

pH 7.5

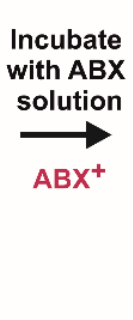 swollen nanogel pH 7.5

ABX-loaded

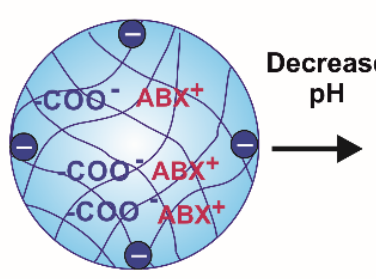

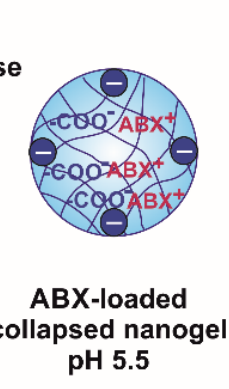

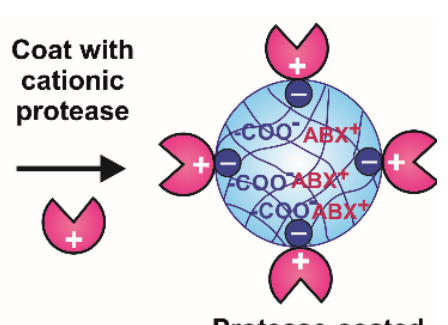

Protease-coated ABX-loaded collapsed nanogel
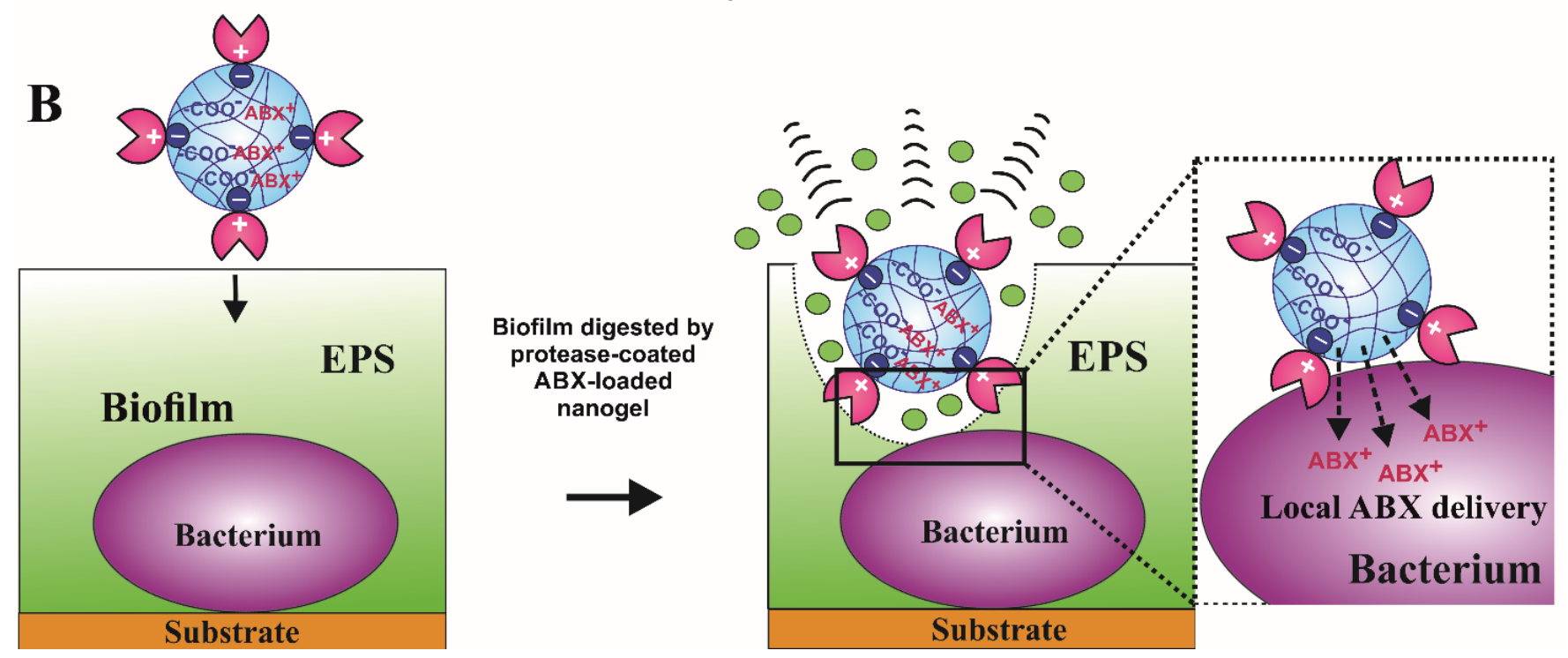

Figure 1. (A) Schematic for the loading of the Carbopol Aqua SF1 nanogel with antibiotic $\left(\mathrm{ABX}^{+}\right)$followed by surface coating with protease (Alcalase 2.4 L FG). (B) Diagram of the mechanism of action of the Carbopol Aqua SF1-Alcalase 2.4 L FG nanogel particles on biofilms adhered to a substrate. Alcalase $2.4 \mathrm{~L} \mathrm{FG}$ acts as a hydrolases cleaving peptide chains. It also acts as an esterase, enabling it to catalyze stereo-selective hydrolysis of some esters including carboxylic esters and amino esters, see Figure $\mathbf{S 1}$ for illustration. 
In addition to the evidence that exogenous protease degrade biofilms, it has been shown that in the natural selfinduced disassembly of biofilms, bacteria induce expression of extracellular proteases to cleave matrix proteins. ${ }^{44}$ Some of these extracellular proteases include sigB and sarA, which have all been shown to reduce biofilm capacity in S. aureus. ${ }^{47}$ Novozymes $®$ (Denmark) produce a wide array of enzymes produced by Bacillus spp. (Gram-positive, rodshaped, spore-forming bacteria) which have applications in industry and biopharmaceutical ingredients, many with useful activity properties as mentioned above. ${ }^{38}$ It has been demonstrated that immobilization of proteases can increase their stability, reusability, and increase their tolerance of environmental stresses. ${ }^{48}$ Covalent bonding, ionic interactions, entrapment/encapsulation in a polymer or inorganic matrices and hydrophobic adsorption have previously been demonstrated as methods to immobilize enzymes. ${ }^{49}$ Although immobilization can improve the enzyme activity, stability and storage life, there is also the possibility of enzyme rigidification, particularly in strong covalent techniques, which reduce the effective activity of the enzyme. ${ }^{50}$ Nanoparticle carriers such as chitosan beads and soybean fibers have been shown to be useful biocompatible carriers for proteins and also increase the activity of Alcalase. ${ }^{51,52}$

In this study, we investigated the use of Carbopol Aqua SF1 nanogels as a substrate to immobilize a Serine endo-peptidase proteases, namely Alcalase 2.4 L FG (Figure 1 illustrates the process). Polyacrilic acid co-polymer nanogels have cross-linked polymer chains which due to the abundance of $\mathrm{COOH}$ groups confer an anionic charge upon their surface and interior. ${ }^{53}$ These nanogel particles have shown good biocompatibility and have been found to be effective in encapsulating cationic antimicrobials such as chlorhexidine digluconate, and tetracycline and lincomycin hydrochloride. ${ }^{54,55}$ Nanocarrier-based antibiotic delivery provides an opportunity to increase the effectiveness of therapeutic agents by specifically targeting bacteria due to their anionic cell wall ${ }^{54,55}$ (e.g. utilizing cationic coatings of the nanogel such as PDAC and bPEI), localizing the drug whilst reducing the unintended damaging effect on neighboring tissue. Since Alcalase $2.4 \mathrm{~L} \mathrm{FG}$ has a very high isoelectric point, it is positively charged at neutral $\mathrm{pH}$. We took advantage of the negative surface charge of Carbopol Aqua SF1 nanogel particles to electrostatically immobilize Alcalase 2.4 L FG on their surface. We investigated the stability of Alcalase 2.4 L FG coated Carbopol Aqua SF1 nanoparticles, and evaluated their potential anti-biofilm use on skin associated pathogens which are known to produce biofilms. Additionally, we investigated the potential synergistic effect of antibiotic co-treatments and encapsulations within the nanogel using ciprofloxacin hydrochloride, combined with further surface coating of the loaded nanogel with Alcalase 2.4 L FG. Our study demonstrates that there is a strong synergistic clearing effect of these novel dual functionalized nanogels on biofilms of a range of pathogenic bacteria.

\section{EXPERIMENTAL SECTION}

\section{Materials}

Carbopol Aqua SF1 nanogel (30 wt $\%$ aqueous suspension) was provided by Lubrizol, USA. Six American Type Culture Collection (ATCC) bacterial species were used in this study. Staphylococcus aureus subsp. aureus Rosenbach (ATCC® $29213^{\mathrm{TM}}$ ), Pseudomonas aeruginosa (Schroeter) Migula (ATCC $\AA 27853^{\mathrm{TM}}$ ), Staphylococcus epidermidis (Winslow and Winslow) Evans (ATCC® $35984^{\mathrm{TM}}$ ), Klebsiella pneumoniae subsp. pneumoniae (Schroeter) Trevisan (ATCC $35657^{\mathrm{TM}}$ ), Escherichia coli (Migula) Castellani and Chalmers (ATCC $® 25922^{\mathrm{TM}}$ ), and Enterococcus faecalis (Andrewes and Horder) Schleifer and Kilpper-Balz (ATCC® $51299^{\mathrm{TM}}$ ). Mueller-Hilton Broth (MHB), Mueller-Hilton Agar (MHA) were supplied by Oxoid, UK. Alcalase 2.4 L FG EC number; 3.4.21.62 was kindly provided by Novozymes, Denmark. Alcalase 2.4 L FG is a Serine endo-peptidase (mainly subtilisin A) which performs stereo-selective hydrolysis of amino esters and selective esters. Alcalase also efficiently hydrolyses amino esters which include heterocyclic amino esters. Optimal conditions for usage are $30-65^{\circ} \mathrm{C}$ and $\mathrm{pH} 7-9$. Its enzymatic activity is $2.4 \mathrm{AU}-\mathrm{A} / \mathrm{g}$. The protein concentration of Alcalase $2.4 \mathrm{~L} \mathrm{FG}$ was $55 \mathrm{mg} / \mathrm{mL}$, determined by a NanoDrop $^{\text {TM }}$ Lite Spectrophotometer (Thermo Scientific, UK). Millipore Express PLUS Membrane Filter paper $(0.22$ $\mu \mathrm{m}$ pore size, hydrophilic polyethersulfone, $47 \mathrm{~mm}$ diameter), Ciprofloxacin hydrochloride ( $\geq 98.0 \%)$, Acridine Orange base (75\%) and Resazurin Sodium salt (75\%) were purchased from Sigma-Aldrich, UK. Resazurin Sodium salt was used for cell metabolic in situ assays and diluted in Dulbecco's Phosphate Buffered Saline (DPBS) (Gibco, Fisher Scientific, UK) at a concentration of $0.015 \mathrm{wt} / \mathrm{vol} \%$. HaCaT cells were obtained from AddexBio, T0020001, USA. DMEM and FBS were obtained from Gibco, UK, L-Glutamine and Trypsin EDTA by BioWhittaker, UK. A Pierce ${ }^{\text {TM }}$ Protease Assay Kit (Thermo Scientific, USA) was used to characterize the Alcalase 2.4 L FG activity. A MTT colorimetric survival and proliferation kit (Millipore Corp, USA) was used for HaCaT cell viability experiments and ANNEXIN V apoptosis detection Kit I (BD Pharmogen, USA) was used to measure apoptosis after treatments. Deionized water purified by reverse osmosis and ion exchange with a Milli-Q water system (Millipore, USA) was used in all our studies. Its surface tension was $71.9 \mathrm{mN} \mathrm{m}^{-1}$ at $25^{\circ} \mathrm{C}$, with measured resistivity higher than $18 \mathrm{M} \Omega \mathrm{cm}^{-1}$. Consumable plasticware used in the study were purchased from Sarstedt (UK), Thermo Scientific (UK), or CytoOne (UK) unless otherwise stated.

Synthesis of Alcalase-coated nanogel particles. Carbopol Aqua SF1 (30 wt\%) was diluted into $0.6 \mathrm{wt} \%$ by pipetting 2 $\mathrm{mL}$ of the stock suspension (30 wt\%) and diluting with deionized water to a final volume of $100 \mathrm{~mL}$. This suspension was sonicated for $15 \mathrm{~min}$ using 2 second on/off pulsing to allow effective dispersion. Droplets $0.25 \mathrm{M} \mathrm{HCl}$ was added to the suspension to reduce the $\mathrm{pH}$ to 5.5 . A $0.6 \mathrm{wt} \%$ solution of Alcalase L FG 2.4 was created by diluting $0.6 \mathrm{~mL}$ of the stock liquid enzyme solution and diluting with deionized water to a final volume of $100 \mathrm{~mL}$. The $0.6 \mathrm{wt} \%$ Alcalase 
solution was sonicated for 15 min to prevent aggregation. $25 \mathrm{~mL}$ of the $0.6 \mathrm{wt} \%$ Carbopol Aqua SF1 suspension and 25 $\mathrm{mL}$ of the $0.6 \mathrm{wt} \%$ Alcalase L FG 2.4 solution were mixed together for $30 \mathrm{~min}$ at $\mathrm{pH} 5.5$ with constant stirring to allow the cationic enzyme to electrostatically bind to the anionic Carbopol NPs. After mixing the suspension was centrifuged at $4000 \mathrm{rpm}$ for $15 \mathrm{~min}$ the pellet was washed trice with deionized water and then dispersed into $50 \mathrm{~mL}$ of fresh deionized water. Droplets of acetate buffer solution were used to maintain the dispersion at $5.5 \mathrm{pH}$. The supernatant was retained for analysis to determine the surface functionalization efficiency by UV-Vis absorption measurement. The particle size and zeta potential distribution of the Carbopol-Alcalase NPs were measured using a Malvern Zetasizer as described below. Prior to measurement, and use of the nanogels in treatments, the $0.6 \mathrm{wt} \%$ Carbopol- $0.6 \mathrm{wt} \%$ Alcalase dispersion was sonicated for $5 \mathrm{~min}$ to remove aggregation and diluted into deionized water to the appropriate concentration.

Preparation of ciprofloxacin-loaded nanogel. The principle of encapsulating a cationic antibiotic (as a hydrochloride salt) is based on the swelling and deswelling cycle of the Carbopol Aqua SF1 at different pH. ${ }^{53}$ Briefly, a $100 \mathrm{~mL}$ of $0.6 \mathrm{wt} \%$ aqueous dispersion of the nanogel was prepared, this was then adjusted to $\mathrm{pH} 7.5$ by adding droplets of $0.25 \mathrm{M} \mathrm{NaOH}$ whilst been stirred. The dispersion was then warmed to $37^{\circ} \mathrm{C}$. An aliquot of $0.0032 \mathrm{wt} \%$ ciprofloxacin hydrochloride aqueous dispersion was prepared by weighing $3.2 \mathrm{mg}$ of the antibiotic (ABX = ciprofloxacin) powder, diluting into $100 \mathrm{~mL}$ of deionized water and then warming to $37^{\circ} \mathrm{C}$. The $100 \mathrm{~mL} \mathrm{ABX}$ solution was then added to the $\mathrm{pH} 7.5$ nanogel dispersion and shaken for 30 $\min$ at $37{ }^{\circ} \mathrm{C}$ to allow the antibiotic cations to diffuse into and electrostatically bind in the cores of the swollen nanogel particles. The $\mathrm{pH}$ of the ABX-Carbopol solution was then reduced to pH 5.5 using droplets of $0.25 \mathrm{M} \mathrm{HCl}$ whilst being stirred for another $30 \mathrm{~min}$. The ABX-Carbopol suspension was then centrifuged at $4000 \mathrm{rpm}$ for $15 \mathrm{~min}$, and the supernatant was removed and retained for encapsulation efficiency analysis. The pellet was washed twice with deionized water and re-dispersed into $100 \mathrm{~mL}$ of deionized water. The $\mathrm{pH}$ was then increased to 7.5 by gradually adding droplets of $0.25 \mathrm{M} \mathrm{NaOH}$ and the solution was gently stirred overnight. The final ABX-Carbopol nanogel solution was reduced to pH 5.5 using acetate buffer solution. The particle size and zeta potential distribution of the ATX-Carbopol dispersion were measured using a Malvern Zetasizer Nano ZS as described above. Coating of the ciprofloxacin encapsulated Carbopol NPs with Alcalase 2.4 L FG was performed as described above.

Characterization of free Alcalase, Alcalase-nanogel and Alcalase-coated Ciprofloxacin-loaded nanogel. All hydrodynamic diameter and zeta potential measurements were performed using a Malvern Zetasizer Nano ZS. The isoelectric point of Alcalase L FG 2.4; $10 \mathrm{~mL}$ of $0.02 \mathrm{wt} \%$ aqueous solution Alcalase aliquots were created at a range of $\mathrm{pH}$ 5 to 12 using droplets of either $0.25 \mathrm{M} \mathrm{HCl}$ or $0.25 \mathrm{M} \mathrm{NaOH}$. Afterwards, the aliquots were sonicated for $15 \mathrm{~min} .1 \mathrm{~mL}$ of each aliquot was added to a quartz cuvette and the zeta potential measured using a ZEN1002 dip cell at a refractive in- dex of 1.45 and absorption of 0.001 as per Malvern Instruments protein refractive index manual. Measurements were performed at $25{ }^{\circ} \mathrm{C}$ and data represented as the mean of 3 repeats.

Hydrodynamic diameter and zeta potential of Alcalasenanogel and Alcalase-nanogel loaded with Ciprofloxacin. $50 \mathrm{~mL}$ of pH $5.50 .6 \mathrm{wt} \%$ Carbopol- $0.6 \mathrm{wt} \%$ Alcalase $\mathrm{L}$ FG 2.4 NPs and 0.6 wt\% Carbopol-0.0032 wt\% ciprofloxacin- $0.6 \mathrm{wt} \%$ Alcalase-nanogel dispersions were prepared as described above. Aliquots of $0.6 \mathrm{wt} \%$ Carbopol were mixed with varying concentrations of Alcalase L FG 2.4 (range; $0.000625 \mathrm{wt} \%$ to $0.6 \mathrm{wt} \%)$. The hydrodynamic diameter and zeta potential were measured at $25{ }^{\circ} \mathrm{C}$ using a quartz cuvette at a RI of 1.336 and absorbance of 1.000 as determined by Al-Awady et al. ${ }^{53}$ Each measurement was repeated 3 times and data presented as the mean. The UV-Visible spectrum of 0.05 wt $\%$ Carbopol, $0.05 w t \%$ Alcalase $2.5 \mathrm{~L} \mathrm{FG}$ and 0.05 wt\% Carbopol with 0.05 wt\% Alcalase 2.4 L FG coating. Samples were measured at pH 5.5 by adjustment with acetate buffer solution. The absorbance was measured between $220 \mathrm{~nm}$ and $1000 \mathrm{~nm}$ using a FLUOstar Omega spectrophotometer, BMP Labtech. The Alcalase coating efficiency of the Carbopol NPs was examined by UV-Vis analysis of the supernatant produced during the synthesis as described above. The absorbance of the supernatant was measured at $500 \mathrm{~nm}$ using a spectrophotometer (FLUOstar Omega spectrophotometer, BMP Labtech).

Protease activity of free Alcalase vs. nanogel-immobilized Alcalase. The activity of free Alcalase 2.4 L FG vs Alcalase 2.4 L FG-Carbopol Aqua SF1 NPs was investigated by measuring the cleavage of succinylated casein in the presence of 0.2 wt $\%$ Alcalase, or 0.2 wt $\%$ Alcalase- 0.2 wt $\%$ Carbopol NPs at varying $\mathrm{pH}$, temperature, and over time. $10 \mathrm{mg}$ of lyophilized succinylated casein was dissolved in $1 \mathrm{~mL}$ of acetate buffer ( $\mathrm{pH}$ 5.5), PBS (pH 7.5), or BupH Borate buffer (pH 8.5). For the purpose of the temperature and time experiments acetate buffer was used for all measurements, mimicking the buffer used in the NP preparation. $100 \mu \mathrm{L}$ of this solution was added to a 96-well plate, and $100 \mu \mathrm{L}$ of buffer was added to bring the total volume to $200 \mu \mathrm{L}$ in each well. $100 \mu \mathrm{L}$ of plane buffer was used as a blank. $50 \mu \mathrm{L}$ of either free Alcalase 2.4 L FG vs. Alcalase 2.4 L FG-Carbopol Aqua SF1 NPs was added to the wells. The activity of the samples was measured at different $\mathrm{pH}$ (using buffers above) for $30 \mathrm{~min}$ at room temperature, over time $(30 \mathrm{mins}$ to 24 $\mathrm{hr}$ ) at room temperature, or at different temperatures (30 ${ }^{\circ} \mathrm{C}, 37^{\circ} \mathrm{C}$, and $45^{\circ} \mathrm{C}$ ) for $30 \mathrm{~min} .100 \mu \mathrm{L}$ of trinitrobenzenesulfonic acid was dissolved in $14.9 \mathrm{~mL}$ of appropriate buffer to create a TNBSA working solution. Succinylated casein in the presence of proteases is cleaved at the peptide bonds revealing primary amine groups. TNBSA reacts with these groups to produce an orange-yellow product of which the absorbance can be measured at $450 \mathrm{~nm}$ informing of protease activity of the samples. The protease activity of the free protease vs nanogel-coated protease were measured at specific time points by adding $50 \mu \mathrm{L}$ of the TNBSA solution to the wells and incubating for $20 \mathrm{~min}$. Then, the absorbance of the wells was measured at $450 \mathrm{~nm}$ subtracting the absorbance from the blank wells. 
A
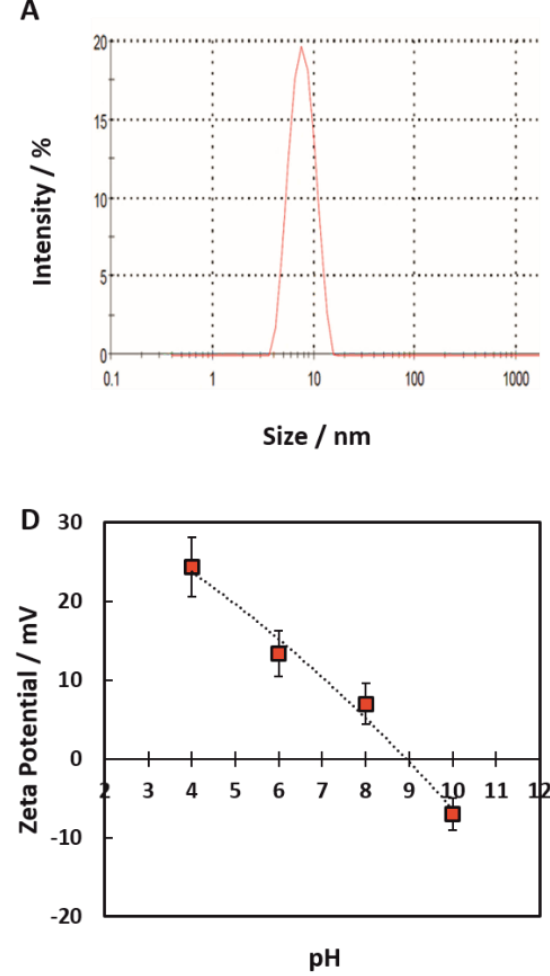
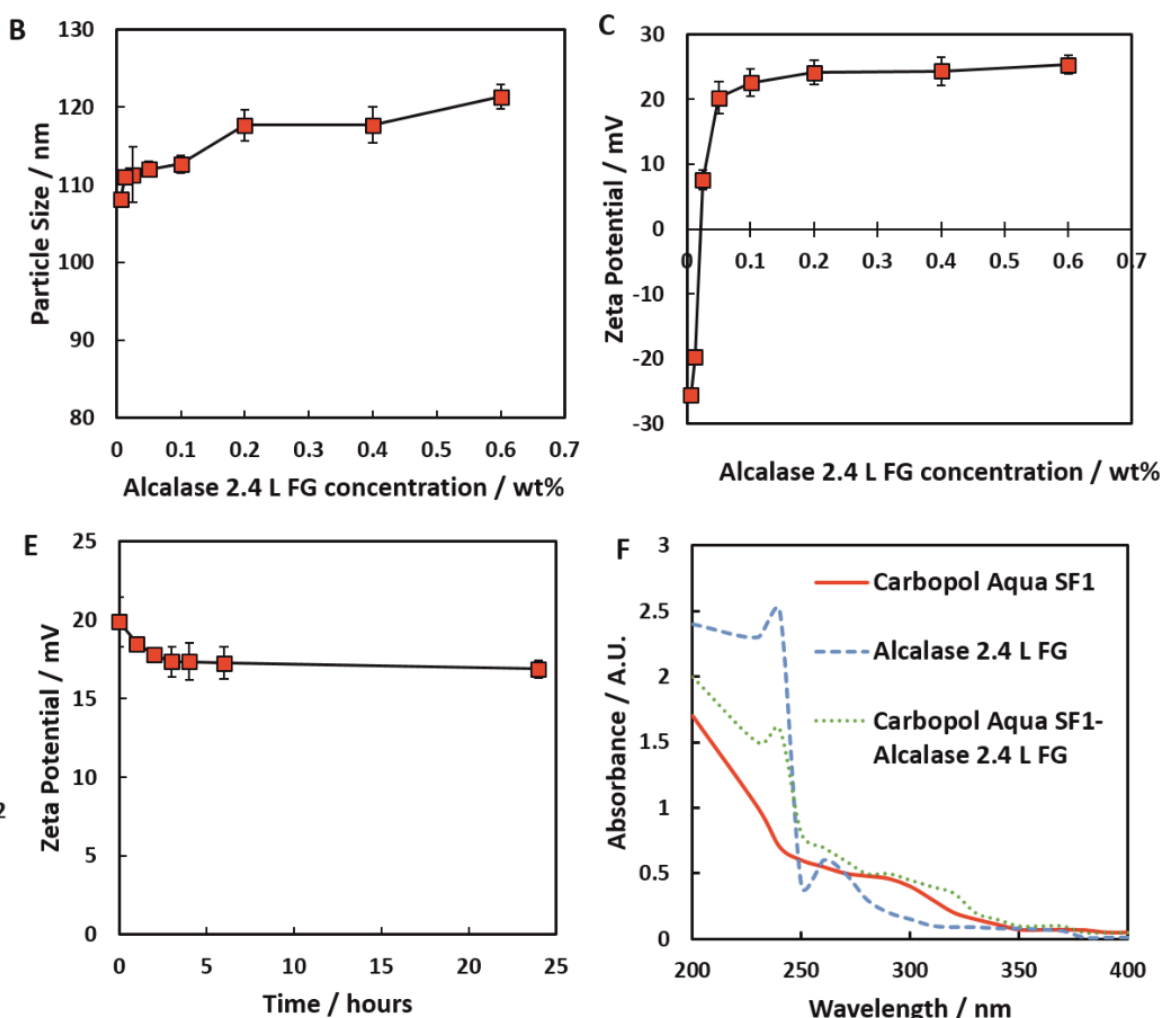

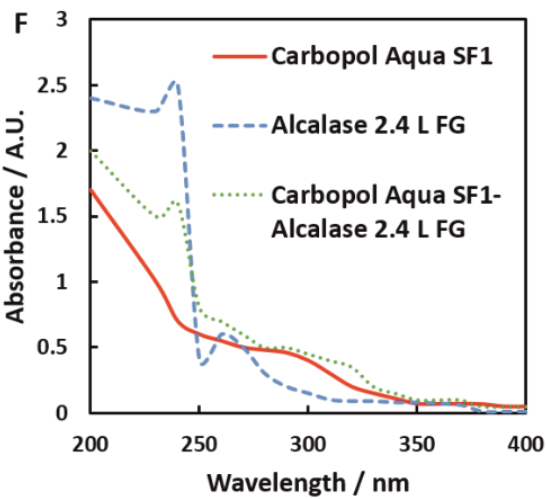

Figure 2. (A) Hydrodynamic diameter and (D) isoelectric point of $0.6 \mathrm{wt} \%$ Alcalase $2.4 \mathrm{~L}$ FG measured using a Malvern zetasizer Nano $\mathrm{ZS}$ at $25^{\circ} \mathrm{C}$. Each value represents a triple replicate with \pm S.D. (B) The mean particle hydrodynamic diameter and (C) mean zeta potential of Alcalase 2.4 L FG coated Carbopol nanogel particles measured at pH 5.5 (acetate buffered saline) with various concentrations of Alcalase mixed with an equal wt\% of Carbopol Aqua SF1 NPs. (E) The zeta potential of $0.6 \mathrm{wt} \%$ Alcalase $2.4 \mathrm{~L} \mathrm{FG}$ coated "empty" $0.6 \mathrm{wt} \%$ Carbopol nanogel particles at pH 5.5 (adjusted with acetate buffered saline) measured at various time intervals after preparation. The refractive index of either particles was taken as 1.336. Each value represents average triplicate measurements with error bars representing the \pm S.D. The lines are guides to the eye. (F) The UV-Visible spectrum of $0.05 \mathrm{wt} \%$ Carbopol (red line), 0.05 wt\% Alcalase $2.5 \mathrm{~L} \mathrm{FG}$ (Blue line) and $0.05 \mathrm{wt} \%$ Carbopol with $0.05 \mathrm{wt} \%$ Alcalase $2.4 \mathrm{~L}$ FG coating (green line). Samples were measured at pH 5.5 adjusted by acetate buffer. The absorbance was measured between 220 and $1000 \mathrm{~nm}$ using a FLUOstar Omega spectrophotometer.

This data was used to assess the relative protease activity of the free Alcalase 2.4 L FG vs Alcalase 2.4 L FG-Carbopol Aqua SF1 nanogels at different experimental conditions.

Bacterial culture and biofilm producing assessment. Frozen ATCC species were prepared onto MHA plates according to manufacturer's instructions. Overnight $(\mathrm{O} / \mathrm{N})$ cultures were prepared by incubating a single colony scraped from the MHA stock plates into $10 \mathrm{~mL}$ of MHB for $16 \mathrm{hr}$ at $37^{\circ} \mathrm{C}$ with $140 \mathrm{rpm}$ shaking (Stuart Orbital Incubator $\mathrm{S} 1500$ ). For biofilm assays, $\mathrm{O} / \mathrm{N}$ cultures were adjusted to $0.5 \mathrm{McF}$ arland standard by diluting the $\mathrm{O} / \mathrm{N}$ culture into $0.85 \mathrm{w} / \mathrm{v} \%$ sterile saline until an optical density of $0.08-0.12$ at $625 \mathrm{~nm}\left(1-2 \times 10^{8} \mathrm{CFU} / \mathrm{mL}\right)$ was obtained using a spectrophotometer (FLUOstar Omega spectrophotometer, BMP Labtech). These adjusted bacterial saline suspensions were then diluted 1:150 into MHB to yield starting concentrations between $5 \times 10^{5}-1 \times 10^{6}$ colony forming units per $\mathrm{mL}$ (CFU mL ${ }^{-1}$ ). All 6 ATCC species used in this study have previously been confirmed as biofilm producers, however, to validate this, a simple qualitative biofilm formation assessment was performed. $2 \mathrm{~mL}$ of MHB was placed into glass test tubes and inoculated with a single colony of bacteria from culture plates. The test tubes where incubated for 24 $\mathrm{hr}$ at $37^{\circ} \mathrm{C}$. Afterward, the culture media was decanted and the test tubes washed with PBS (pH 7.4), and left to dry for $30 \mathrm{~min} .0 .1 \mathrm{wt} \%$ Crystal Violet was used to stain cells adhered to the glass tubes for $5 \mathrm{~min}$, before being washed away with deionized water. The test tubes where then left to dry in an inverted position for $2 \mathrm{hr}$. Biofilm formation was considered positive when a visible film lined the wall and the bottom of the tube. Ring formation at the liquid interface was not indicative of biofilm formation. The formation of biofilm by staining of the adhered cells was scored as either 0 -absent, 1-weak, 2-moderate or 3-strong, as performed by Christensen et al. ${ }^{56}$

Zeta potential of bacteria treated with free Alcalase and Alcalase-coated nanogel. Bacterial species were cultured as described in as described above. The bacterial suspension was then centrifuged for $10 \mathrm{~min}$ at $5000 \mathrm{rpm}$ and the 
supernatant discarded. The pellet was washed twice with deionized water and finally resuspended into $10 \mathrm{~mL}$ of 0.2 wt $\%$ Alcalase or 0.2 wt $\%$ Alcalase- 0.2 wt $\%$ Carbopol Aqua SF1 in deionized water. The samples were incubated at room temperature with gentle mixing for $10 \mathrm{~min}$ or $1 \mathrm{hrs}$. Afterwards, a $1 \mathrm{~mL}$ aliquot of this suspension was added to a quartz cuvette and the mean zeta potential distribution was measured using the Dipstick probe and a Malvern Zetasizer Nano ZS (Malvern Instruments, UK). The refractive index was 1.384 , the absorption 1.000 , and the temperature was $25^{\circ} \mathrm{C}$ for all measurements.

Biofilm staining with Crystal Violet and Congo Red. A standard 96-well microtiter biofilm formation plate assay was performed using crystal violet and Congo Red dyes (modified from 0'Toole, 2011). ${ }^{57}$ Crystal Violet staining: 1 $\mathrm{mL}$ of $5 \times 10^{5}-1 \times 10^{6} \mathrm{CFU} / \mathrm{mL}$ of $0 / \mathrm{N}$ bacterial culture was pipetted into 48 -well TC-treated plates and incubated at 37 ${ }^{\circ} \mathrm{C}$ for $24 \mathrm{hrs}$ in static conditions. After incubation, the plates were washed twice by submerging in deionized water to remove any remaining media and suspended cells. The plate was then shaken dry and left to air dry for 15 mins at room temperature. $1 \mathrm{~mL}$ of MHB supplemented with Carbopol-Alcalase synthesized NPs treatment was added to the wells and incubated for $24 \mathrm{hrs}$ at $37{ }^{\circ} \mathrm{C}$ in static conditions. The plates were then washed vigorously by submersion in deionized water to remove excess treated media and suspended cells. The plate was then shaken to remove any liquid droplets and left to dry for $15 \mathrm{mins}$ at room temperature. $1 \mathrm{~mL}$ of $0.1 \mathrm{wt} \%$ Crystal Violet solution was added to each well and incubated at room temperature for 15 mins. The plates were then washed thoroughly by submersion in deionized water and blotted with paper towels to remove excess dye and water. The plate was left to dry for $2 \mathrm{hrs}$ at room temperature. $1 \mathrm{~mL}$ of $30 \mathrm{wt} \%$ acetic acid was added to each well for 15 min to solubilize to the Crystal Violet. $125 \mu \mathrm{L}$ of this solution was transferred to a fresh 96well plate and the absorbance measured at $570 \mathrm{~nm}$ with 30 wt\% acetic acid used as a blank measurement. Congo Red staining: As described above, 48-well plate biofilms were formed and treated with $1 \mathrm{~mL}$ of MHB supplemented Carbopol-Alcalase nanogel suspension. After the treatment, the enzyme-infused MHB media was removed and the 48well plate washed thoroughly by submerging in water. The plate was then shaken to remove liquid droplets and left to dry for 15 mins at room temperature. $125 \mu \mathrm{L}$ of $0.005 \mathrm{wt} \%$ Congo Red was added to each well and left to stain the amyloid protein complexes for 15 mins. The 96 -well plate was then washed thoroughly again by submersion in deionized water and blotted with paper towels to remove excess Congo red dye and water. The plate was left to dry for $2 \mathrm{hrs}$ at room temperature. $125 \mu \mathrm{L}$ of $30 \%$ ethanol was added to each well for 15 mins to solubilize to the Congo Red dye. 125 $\mu \mathrm{L}$ of this solution was transferred to a fresh 96 -well plate and the absorbance measured at $550 \mathrm{~nm}$ with $30 \%$ ethanol used as a blank sample.

Membrane Colony Biofilm NP and Ciprofloxacin treatment. To test the effects of Alcalase-Carbopol nanogel and ciprofloxacin co-treatments on biofilms a filter membrane method was employed. $2 \mathrm{~cm}^{2}$ Millipore Express PLUS Membrane Filter paper sections were placed on to MHA. An overnight culture was adjusted to $1 \times 10^{5} \mathrm{CFU} / \mathrm{mL}$ in saline and $20 \mu \mathrm{L}$ of this culture added as a droplet to the center of the filter paper. The sample was then incubated for 24 hours at $37{ }^{\circ} \mathrm{C}$ to allow a colony biofilm to form. After $24 \mathrm{hrs}$ the membranes were placed onto fresh agar plates ( $3 \mathrm{~mm}$ deep) into a 6-well plate and $1 \mathrm{~mL}$ of treatment added to each well. The plate was gently shaken in the incubator during treatment. $1 \mathrm{~mL}$ of deionized water was considered the growth control. 0.6 wt\% Carbopol, 0.6 wt\% Alcalase 2.4 L FG in deionized water, and 0.6 wt\% Carbopol-0.6 wt\% Alcalase 2.4 L FG NPs were used as treatments to the measure their effect on the cell viability. Additionally, ciprofloxacin hydrochloride was added separately and as a co-treatment with the Carbopol-Alcalase NPs at a range of 0 to $32 \mu \mathrm{g} / \mathrm{mL}$ $(0.0032 \mathrm{wt} \%)$. Equivalent concentrations of encapsulated ciprofloxacin tested as a comparison. After $24 \mathrm{hrs}$ of treatment, the membrane filter paper was peeled from the agar wells and placed in to sample tube with $1 \mathrm{~mL}$ of fresh MHB and $2 \mathrm{~cm}$ of sterile glass beads. Each sample was vortexed for 30 secs at high speed to disintegrate the biofilm and inoculated the MHB with cells. The drop plate enumeration method was used to measure cell viability in CFU/mL. To measure the viability of cells within the biofilms, 10 -fold dilutions were made in fresh MHB, $10 \mu \mathrm{L}$ droplets were placed on to MHA plates and grown for $24 \mathrm{hrs}$ at $37{ }^{\circ} \mathrm{C}$. CFUs were counted from the last two droplets which contained a countable amount of colonies ( 3 to 30 colonies per $10 \mu \mathrm{L}$ drop) and averaged.

Resazurin Sodium Salt in situ bacterial metabolic activity assay. After the 24-hr membrane colony biofilm NP treatment, as described above, each membrane biofilm was carefully removed from the agar plate using sterile tweezers at the corner of the membrane. The membrane biofilm was allowed to air dry in sterile conditions for $15 \mathrm{~min}$ and then placed onto a dry sterile Petri dish. $20 \mu \mathrm{L}$ of $0.015 \mathrm{wt} \%$ Resazurin Sodium Salt was added and incubated for $30 \mathrm{~min}$ at $37^{\circ} \mathrm{C}$ to visualize the metabolically active cells within the biofilm (modified from Wilkinson et al.58). Images were captured using an 8MP digital camera and the percentage of cell metabolic activity calculated using ImageJ v1.52a.

Biofilm formation assay on a glass surface. An overnight culture of each species was adjusted to 0.5 McFarland standard. $10 \mu \mathrm{L}$ of the adjusted culture was placed into a Petri plate containing a glass slide and $10 \mathrm{~mL}$ of $\mathrm{MHB}$ and incubated for $48 \mathrm{hrs}$ at $37^{\circ} \mathrm{C}$ allowing the bacterial species to form a glass slide adhered biofilm. After $24 \mathrm{hrs}$ the glass slide was washed with deionized water to remove any remaining planktonic cells, and the media was replaced with $10 \mathrm{~mL}$ of fresh MHB supplemented with $0.6 \mathrm{wt} \%$ Carbopol, 0.6 wt\% Alcalase L FG, and 0.6 wt\% Carbopol-0.6 wt\% Alcalase 2.4 L FG. Un-supplemented media was considered the control. The glass biofilms were incubated for a further 24 hrs at $37^{\circ} \mathrm{C}$. Post treatment, the glass slides were washed with deionized water. $100 \mu \mathrm{L} 0.2 \mathrm{wt} \%$ Acridine Orange (AO) was added to the Petri dish and incubated at room temperature for 5 mins in darkness with gentle shaking to reduce photobleaching. After incubation, the slides were washed 
three times with deionized water and allowed to air dry for 15 mins. The slides were examined using an Olympus BX51 fluorescent microscope with DP70 digital camera.

Atomic force microscopy (AFM). AFM images of the airdried biofilms were obtained using a Dimension Icon scanning probe microscope (Bruker, USA) using tapping mode. The biofilms were prepared and treated as described above in the glass surface biofilm formation assay. Post treatment, the glass slide biofilms were washed gently with deionized water, and the biofilm fixed in $1 \mathrm{wt} \%$ aqueous glutaraldehyde for 2 hrs by submersion. After fixation, the slide was washed three times with deionized water and left to air dry inside an enclosed container. TESPA-V2 probes (Bruker, USA) with a nominal length of $127 \mu \mathrm{m}$ and a tip radius of 7 $\mathrm{nm}$ were used, the images obtained at 512 lines/scan at a $0.25 \mathrm{~Hz}$ scan rate. Images were acquired in height (topography) and the analyzed using Nanoscope Analysis v.1.7. (Bruker, USA).

TEM images of Alcalase-nanogel and SEM images of the treated biofilms. SEM images of membrane colony biofilms were obtained. Post treatment the membrane was gently removed from the agar using sterile tweezers and placed onto a $7 \mathrm{~mm}$ diameter circular glass slide and adhered using Carbon discs. The excess membrane was trimmed from the edges of the glass slide using sterile scissors. The biofilm was gently washed with deionized water to remove excess media and treatment. The biofilms were then fixed in a 1 wt $\%$ glutaraldehyde PBS buffer solution for $1 \mathrm{hr}$ at room temperature. After fixation, the biofilms were washed 3 times gently with deionized water to remove excess glutaraldehyde. The samples were then dehydrated in $50 \% / 75 \% / 90 \%$ and absolute ethanol solutions for 30 min per each ethanol concentration. The absolute ethanol was dried using liquid $\mathrm{CO}_{2}$ at its critical point using an E3000 Critical Point Dryer (Quorum Technologies, UK) and then coated in $10 \mathrm{~nm}$ carbon layer. Samples were imaged with variable pressure 100-micron aperture at $40 \mathrm{~Pa}$. EHT $20 \mathrm{kV}$, probe current $100 \mathrm{pA}$. Images were captured with Zeiss smartSEM software (Zeiss Evo-60 SEM, Germany). TEM images of bare Carbopol Aqua NPs, free Alcalase 2.4 L FG protease, and Alcalase 2.4 L FG coated Carbopol Aqua SF1 nanogels were obtained by placing a droplet of the suspended sample onto carbon-coated copper grids (EM Solutions, UK) and allowed to adhere for $2 \mathrm{~min}$. The grid was quickly rinsed with deionized water and negatively stained with $1 \mathrm{wt} \%$ aqueous uranyl acetate. This was again quickly rinsed with deionized water, allowed to dry in air and then imaged with a Gatan Ultrascan 4000 digital camera attached to the Jeol 2010 TEM 2010 electron microscope (Jeol, Japan) running at $120 \mathrm{kV}$.

EDX data was collected via an Oxford Instruments Nanoanalysis X-Max 65-T detector and INCA software.

Cytotoxicity and apoptotic stasis of HaCaT spontaneously transformed keratinocytes from histological normal skin after treatment with nanogel, Alcalase and Alcalase-nanogels. HaCaT cells were cultured in T75 flask using DMEM supplemented with 10\% FBS and 1\% L-glutamine under humidified conditions at $37{ }^{\circ} \mathrm{C}, 5 \% \mathrm{CO}_{2}$. When a confluency of $80 \%$ was achieved, determined by visualization with an optical microscope, passaging was performed to ensure that the cells remained in the exponential phase for experimentation. Passaging was performed by removing spent media, washing in DPBS and incubating with $1 \times$ trypsin EDTA at $37{ }^{\circ} \mathrm{C} 5 \% \mathrm{CO}_{2}$ for 5 min until the cells were detached in suspension. The trypsin EDTA was then neutralized with a $1: 1$ volumetric ratio of fresh DMEM and gently centrifuged at $400 \mathrm{rpm}$ for $4 \mathrm{~min}$, the supernatant was aspirated, and the pellet was re-suspended in DMEM (supplemented as above) at a $1: 6$ ratio and transferred into a fresh T75 flask. Experimental cells were diluted in fresh DMEM, supplemented with $2 \%$ FBS and 1\% L-glutamine and seeded at $5 \times 104$ in $100 \mu \mathrm{L}$ media, were placed into 96 -well plate wells and incubated for 24 hours at $37^{\circ} \mathrm{C} 5 \% \mathrm{CO}_{2}$. The medium was then removed and the cells and replaced with $100 \mu \mathrm{L}$ of treatment infused DPBS. The treatments with only DPBS were used as a control, $0.6 \mathrm{wt} \%$ Carbopol, $0.6 \mathrm{wt} \%$ free Alcalase, and 0.6 wt $\%$ Alcalase - 0.6 wt\% Carbopol nanogel were used as treatments. DPBS was used so DMEM peptones did not interfere with the true activity of the Alcalase. Treatments were performed for 1, 6, and 24 hrs time points. A colorimetric (MTT) cell survival and proliferation assay kit was used to measure cell viability. Treatment culture was aspirated away and the cells washed for $2 \mathrm{~min}$ with fresh DPBS. $100 \mu \mathrm{L}$ of fresh DMEM was added after which $100 \mu \mathrm{L}$ of MTT reagent (50\% 3-(4,5-dimethylthiazol-2yl)2,5-diphenyl tetrasodium bromide and 50\% PBS) was added. This was incubated in the same conditions for $2 \mathrm{hrs}$ until intracellular purple formazan crystals were visible under a light microscope. After $2 \mathrm{hrs}, 100 \mu \mathrm{L}$ of color development reagent in isopropanol with $0.04 \mathrm{M} \mathrm{HCl}$ was added for $1 \mathrm{hr}$, allowing the cells to lyse and the formazan crystal to be solubilized to a homogenous blue solution. The absorbance of the blue solution was read at $570 \mathrm{~nm}$ on a plate reader and subtracted from a blank of media only. These data were calculated into cell count data using the BeerLambert extinction coefficient law using absorbance values from a fixed number of cells in media. The HaCaT cell viability assay was repeated in three independent experiments. The induction apoptosis was investigated using a FITC Annexin $\mathrm{V}$ staining kit according to manufactures instructions. Apoptosis was measured after $24 \mathrm{hrs}$ exposure to $0.6 \mathrm{wt} \%$ Alcalase-0.6 wt\% Carbopol nanogel. Briefly, post treatment the cells were washed twice with DPBS and detached from the 96-well surface using a mini-cell scraper and re-suspended in $1 \mathrm{X}$ binding buffer at a concentration of $1 \times 10^{6}$ cells $\mathrm{mL}^{-1} .5 \mu \mathrm{L}$ of FITC Annexin V and $5 \mu \mathrm{L}$ of Propidium Iodide (PI) solution to $100 \mu \mathrm{L}$ of the cell suspension. The cells were then incubated at room temperature for 15 mins in darkness with gentle shaking. After incubating, $400 \mu \mathrm{L}$ of $1 \mathrm{X}$ binding buffer was added to the cell samples which were then placed quantified by flow cytometry (BD FACSCalibur, USA). The Annexin V fluorescence was measured using a FITC-FL1 detector, and PI measured using a FL2 phycoerythrin signal detector. The experiment was ended after 10,000 cells were counted, the data was analyzed by a dot plot scatter and percentages of live, dead, and apoptotic cells determined by cell quadrating. 


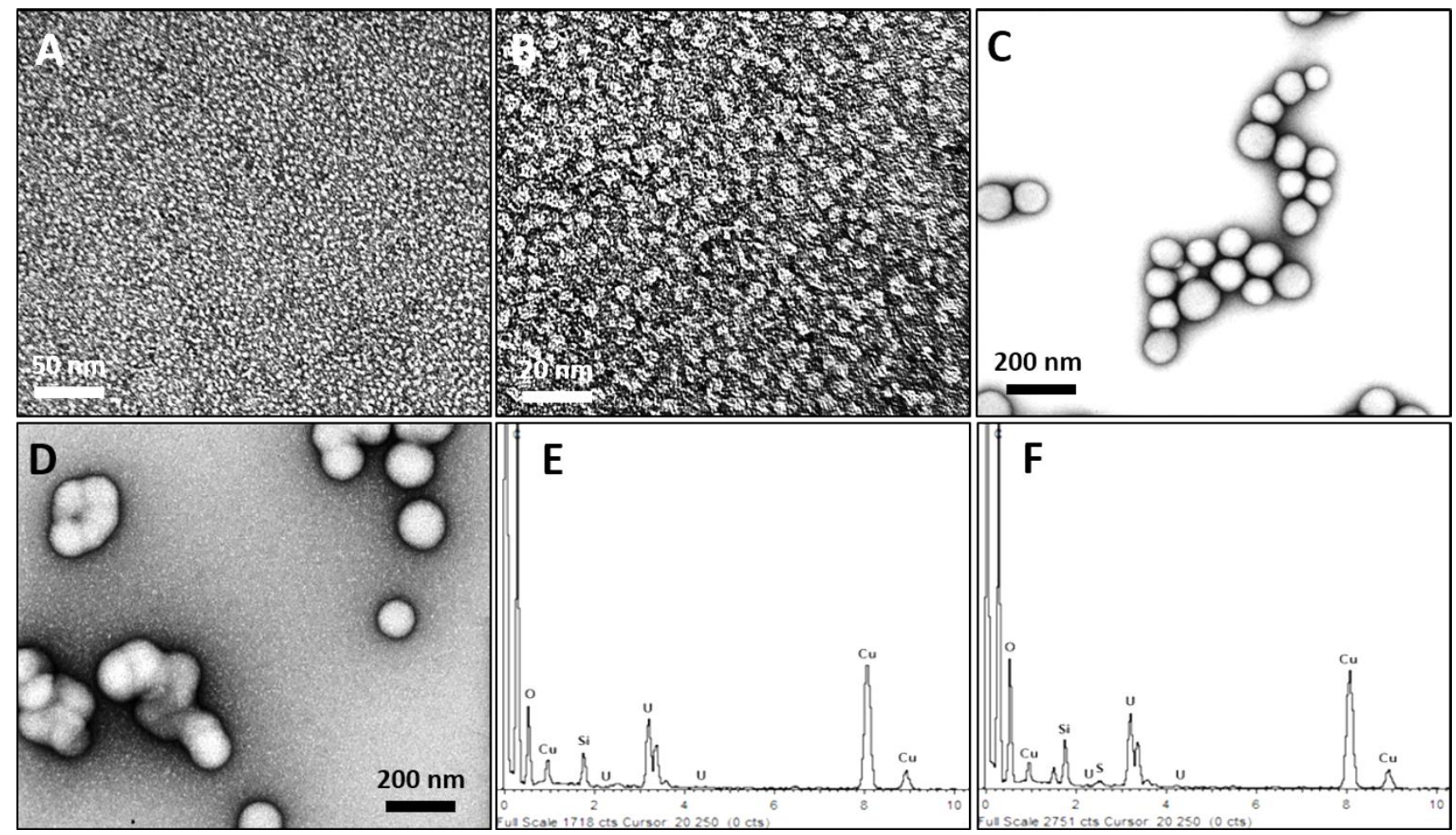

Figure 3. (A-B) TEM images of $0.6 \mathrm{wt} \%$ Alcalase $2.4 \mathrm{~L}$ FG samples counterstained in 1 wt\% uranyl acetate for 1 min during preparation. (C) TEM images of $0.6 \mathrm{wt} \%$ "empty" Carbopol Aqua SF1 nanogel particles; (D) TEM images of the nanoparticles after coating with $0.6 \mathrm{wt} \%$ Alcalase $2.5 \mathrm{~L}$ FG. Partial aggregation has occurred during the sample evaporation. All samples were counter-stained in $1 \mathrm{wt} \%$ uranyl acetate for 1 min during preparation. TEM images were obtained using a JEM 2010 (JOEL, Japan) at 120kV, and a Gatan Ultrascan 4000 digital camera. (E) EDX spectra of 0.6 wt\% Carbopol Aqua SF1 nanoparticles and (F) 0.6 wt\% Carbopol Aqua SF1 nanogel particles coated with 0.6 wt\% Alcalase 2.4 L FG. A Nanoanalysis X-Max 65-T detector and INCA software were used to produce the elemental analysis spectra.

Statistical analysis. Data were expressed as average values \pm standard deviations of the mean. P-values of less than 0.05 were considered significant. All Student's $t$-tests were performed in GraphPad v7.0.4.

\section{RESULTS AND DISCUSSION}

Coating and immobilization of Alcalase 2.4 L FG on to Carbopol Aqua SF1 nanogel particles. A colloidal suspension of Carbopol Aqua SF1 was chosen as an appropriate nanocarrier for investigating the immobilization Alcalase 2.4 L FG protease on their surface. The lightly cross-linked carboxylic groups confer a net anionic surface charge corresponding to a zeta-potential of approximately $-30 \mathrm{mV}$ at a $\mathrm{pH}$ of 5.5. This allows it to be used as a substrate to immobilize the cationic protein on its surface. We chose to limit this suspension to $0.6 \mathrm{wt} \%$ to prevent the aggregation of the nanogel particles. Alcalase $2.4 \mathrm{~L} \mathrm{FG}$ has a diameter of $\sim 8 \mathrm{~nm}$ as shown from the dynamic light scattering size distribution and TEM micrographs (see Figure $2 \mathrm{~A}$ and $3 \mathrm{~A}-\mathrm{B}$, respectively). Data in Figure 2D shows that Alcalase 2.4 L FG has an isoelectric point of $\sim 9$ and a pH 5.5 has a zeta potential of $\sim+18 \mathrm{mV}$. This allows a successful ionic interaction between the anionic Carbopol NPs and the cationic Alcalase 2.4 L FG. Figure 2C shows the bare 0.6 wt\% Carbopol NPs have a hydrodynamic diameter of approximately $110 \mathrm{~nm}$, however, when coated with 0.6 wt\% Alcalase 2.4 L FG (Figure 2D) the particles mean diameter is increased to approximately $120 \mathrm{~nm}$. Figure 2B confirms this through measurement of the hydrodynamic diameter of the Alcalase-coated collapsed nanogel particles. Figure S2 (ESI) shows a comparison between the bare Carbopol and Alcalase coated Carbopol nanogels. It can be seen that by increasing the concentration of the Alcalase, the coated Carbopol NPs average particle size also increases. This can be seen in the TEM images on Figure 3D, where the corona of the collapsed nanogel particles can be seen coated with a "halo" of the Alcalase protein molecules. The successful coating of the Alcalase on the Carbopol NPs was also confirmed using UV-Vis spectrophotometry. Figure 2F shows that Alcalase has a distinct absorption peak at $\sim 245 \mathrm{~nm}$, however, the bare Carbopol shows no such peak. When the Alcalase has coated the Carbopol particles, a small peak also at $\sim 245 \mathrm{~nm}$ can be seen, indicating the Carbopol and Alcalase have ionically interacted and formed a composite Alcalase-coated Carbopol particles. Figure S3 (ESI) shows each of the formulations visually. The stability of the Alcalase-coated Carbopol nanogel particles was also investigated. 
Figure $2 \mathrm{E}$ shows that over $24 \mathrm{hrs}$, the zeta potential was stable in the range between $16-20 \mathrm{mV}$. This indicates the Alcalase remains electrostatically deposited in the nanogel particles over $24 \mathrm{hrs}$, indicating that it is a stable carrier for immobilization of the enzyme during treatment. Additionally, we investigated the EDX spectra of the bare and coated Alcalase-nanogels using samples prepared for TEM. (see Figure 3E-F). The EDX spectra are similar, however, a sulfur peak can be seen in the coated sample spectra, which is not present in the uncoated nanogel. The bare nanogel formulation contains only $\mathrm{C}, \mathrm{O}$, and $\mathrm{N}$, so the presence of $\mathrm{S}$, an element commonly found in protein indicates that the protein has electrostatically bound to the Carbopol nanogel particles. Fourier Transform Infra-Red spectroscopy (FTIR) was used to investigate the composition of the Carbopol/Alcalase/Ciprofloxacin NPs at a range of $600 \mathrm{~cm}^{-1}$ to $4000 \mathrm{~cm}^{-}$ 1 (Figure S4, ESI). Carbopol Aqua SF1 shows a strong peak at $3350 \mathrm{~cm}^{-1}$. This indicates stretching vibrations of $\mathrm{O}-\mathrm{H}$ and intermolecular hydrogen bonding. Strong peaks are also seen at $3005 \mathrm{~cm}^{-1}$ and $1698 \mathrm{~cm}^{-1}$ correlating to strong stretching of aliphatic $\mathrm{C}-\mathrm{H}$ and strong vibration of carbonyl $(\mathrm{C}=0)$ bonds. Peaks at $1000 \mathrm{~cm}^{-1}$ and $1195 \mathrm{~cm}^{-1}$ indicate coupling between in-plane $\mathrm{O}-\mathrm{H}$ bending and $\mathrm{C}-\mathrm{O}$ stretching of neighboring carboxyl groups. Alcalase 2.4 L FG shows weak peaks at $2950 \mathrm{~cm}^{-1}$ and $3001 \mathrm{~cm}^{-1}$, which are characteristic of amino acid with aromatic side chains e.g. tyrosine, tryptophan and phenylalanine. The peak at $1753 \mathrm{~cm}^{-1}$ indicates strong $\mathrm{C}=0$ stretching, attributed to $\mathrm{C}=0$ bond adjacent to secondary amide (peptide) bond. The peak at 1156 $\mathrm{cm}^{-1}$ shows strong $\mathrm{C}-\mathrm{O}-\mathrm{H}$ group stretching, present in the amino acids serine and tyrosine. Ciprofloxacin hydrochloride shows a peak at $1451 \mathrm{~cm}^{-1}$ attributed to the strong vibration of $\mathrm{C}-\mathrm{H}$ bonds. The peak $1255 \mathrm{~cm}^{-1}$ is associated with the aromatic C-F group present on ciprofloxacin. Peak 801 $\mathrm{cm}^{-1}$ is interpreted as tetra-substituted benzene ring derivatives, present on the ciprofloxacin chemical structure. The tightly packed range of peaks between $600 \mathrm{~cm}^{-1}$ to $1450 \mathrm{~cm}$ 1 indicates an array of substituted groups associated with the ciprofloxacin chemical structure. Ciprofloxacin encapsulated Carbopol, coated with Alcalase contains peaks associated with the individual components. The peak at 3358 $\mathrm{cm}^{-1}$ shows stretching vibrations of $\mathrm{O}-\mathrm{H}$ and intermolecular hydrogen bonding, this is analogous to Carbopol alone. The peak at $1721 \mathrm{~cm}^{-1}$ provides evidence strong $\mathrm{C}=0$ stretching, attributed to $\mathrm{C}=\mathrm{O}$ bond adjacent to secondary amide (peptide) bond, present in this formulation due to the coating effect on the Carbopol surface. High density peaks at 600 $1000 \mathrm{~cm}^{-1}$ again are similar to ciprofloxacin alone, which indicates that a variety of substituted groups associated with the ciprofloxacin being present within the Carbopol. The elemental analysis of Carbopol Aqua SF1, Alcalase 2.4 L FG and Ciprofloxacin alone, and Ciprofloxacin-loaded Carbopol nanogel coated with Alcalase 2.4 L FG was performed using a CHN Analyzer (Carlo Erba 1108) (Table S6, ESI). The formulated nanogel particles where centrifuged for $15 \mathrm{~min}$ at $4000 \mathrm{rpm}$. The supernatant was discarded and the pellet washed 3 times with deionized water. The precipitate was further dried overnight at room temperature under vacuum. The data shows the \% value of $\mathrm{C}, \mathrm{H}, \mathrm{N}$ and $\mathrm{S}$ for the above materials. Carbopol alone contained only $\mathrm{C}$ and $\mathrm{H}$, which is consistent with polyacrylic acid polymers. Oxygen is present in all samples but not analyzed. Alcalase contained $\mathrm{C}, \mathrm{H}$, and $\mathrm{N}$, present in all amino acids, additionally it contained $0.48 \% \mathrm{~S}$, which is present in the amino acids methionine and cysteine. This is confirmed by the EDX results in Figure 3F. Ciprofloxacin contains $\mathrm{C}, \mathrm{H}$ and N.

The formulation of $0.6 \mathrm{wt} \%$ Carbopol Aqua SF-1-0.0032 wt\% Ciprofloxacin-0.6 wt\% Alcalase 2.4 L FG nanogel contained all elements analyzed, confirming that the Alcalase had been successful retained on the Carbopol during preparation. EDX spectra of the $0.6 \mathrm{wt} \%$ Carbopol- $0.0032 \mathrm{wt} \%$ Ciprofloxacin- 0.6 wt\% Alcalase nanogel, and the individual components was performed on SEM prepared samples (Figure S5, ESI). It can be seen that the formulation contains both sulfur and fluorine peaks, characteristic of Alcalase and ciprofloxacin respectively. This provides evidence the formulated nanogel has successfully encapsulated ciprofloxacin and is coated with Alcalase. Alcalase 2.4 L FG was chosen as a potential protease to degrade biofilms due to its favorable activities (see Figure S6, ESI). It is highly active and stable between $\mathrm{pH}$ 6-9 in wide temperature range between $30-65^{\circ} \mathrm{C}$. Table S1 (ESI) also shows its optimal usage conditions are between $30-65^{\circ} \mathrm{C}$ and $\mathrm{pH}$ 7-9 (Novozymes ${ }^{\circledR}$ data). These properties make it an ideal choice of bacterial biofilms which are grown at $37{ }^{\circ} \mathrm{C}$ and can grow at either acidic or basic conditions. ${ }^{59}$

Protease activity of free Alcalase vs. Alcalase-nanogel. Enzyme catalytic potential is affected by several factors. We investigated the effect of $\mathrm{pH}$, temperature and time on the free enzyme, and the surface immobilized Alcalase on the Carbopol nanogel particles (Figure S7, ESI). The effect of $\mathrm{pH}$ was investigated at 5.5, 7.5, and 8.5. As seen in Figure S7A, a higher $\mathrm{pH}$ increases the activity of the free Alcalase, and Alcalase-nanogel substantially. There is only a marginal difference between the protease performances of each sample, which is likely due to the gentle electrostatic attraction between the anionic Carbopol nanogel particles, and the cationic protease in this $\mathrm{pH}$ range, having little effect on the enzymes tertiary structure. Covalent enzyme immobilization methods have been shown to cause a decrease in protease activity for this reason. ${ }^{60} \mathrm{~A}$ similar trend is observed when measuring the effect of temperature (Figure S7B) on the activity of the free and immobilized Alcalase. Its activity broadly increased at physiological and higher temperatures, a common feature of biologically derived enzymes, but there is very little difference in performance between the samples. This data is in agreement with the enzyme ac-

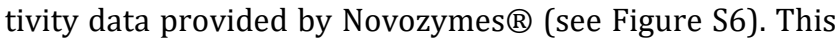
provides further evidence the Carbopol nanogel immobilization technique is exerting little influence on the enzyme activity. Figure S7C examines the effect time has the activity of the free and immobilized samples. As like $\mathrm{pH}$ and temperature there is only a small difference in activity, particularly up until $6 \mathrm{hr}$. At the $24 \mathrm{hrs}$ time point, the immobilized Alcalase-Carbopol nanogel show and increased activity compared to the free counterpart. 
S. aureus
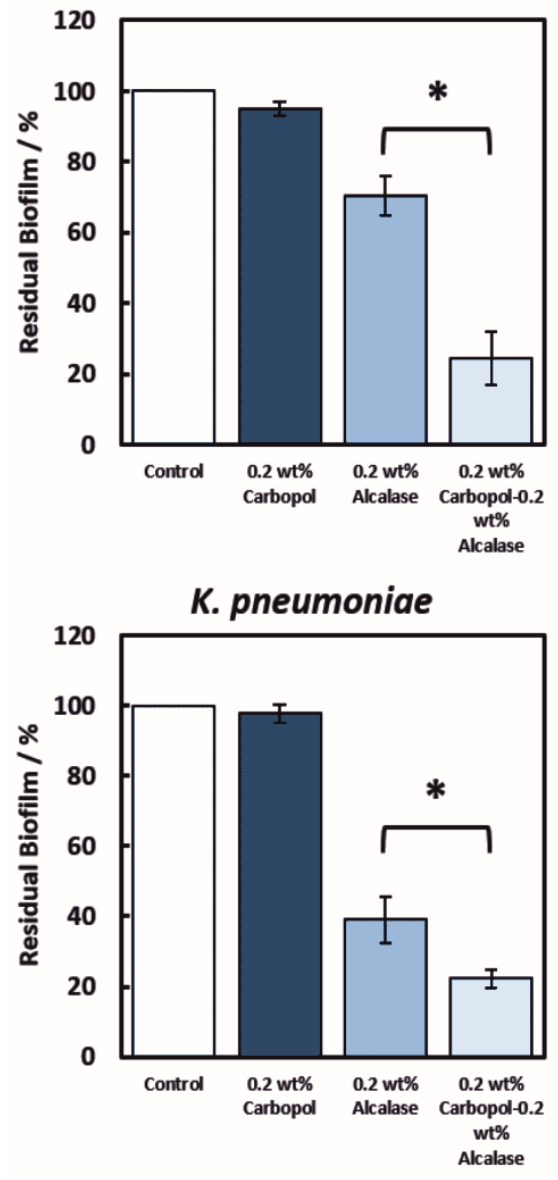

P. aeruginosa

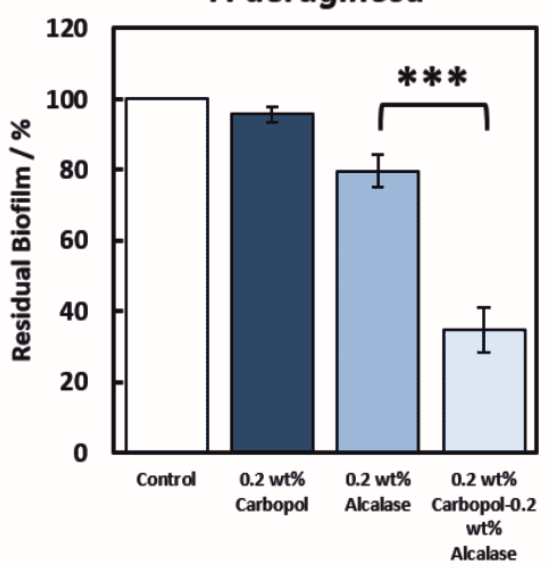

E. coli

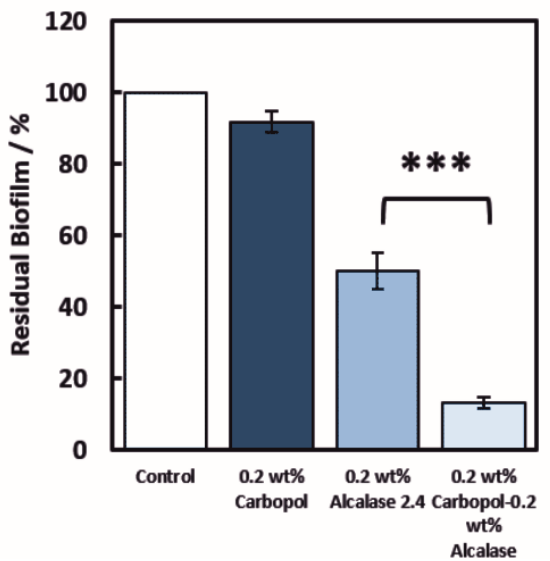

S. epidermidis

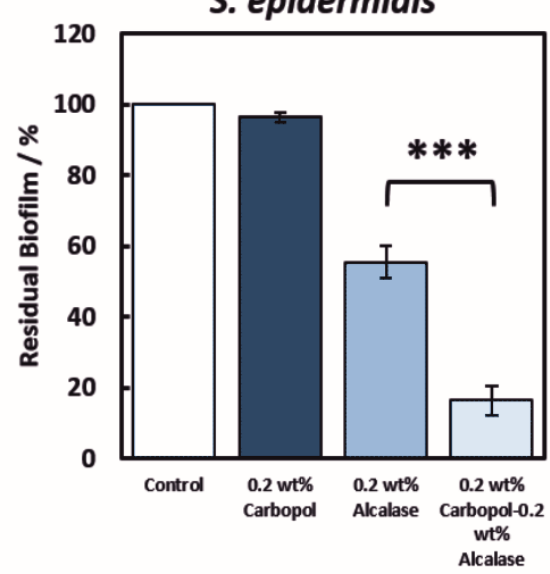

E. faecalis

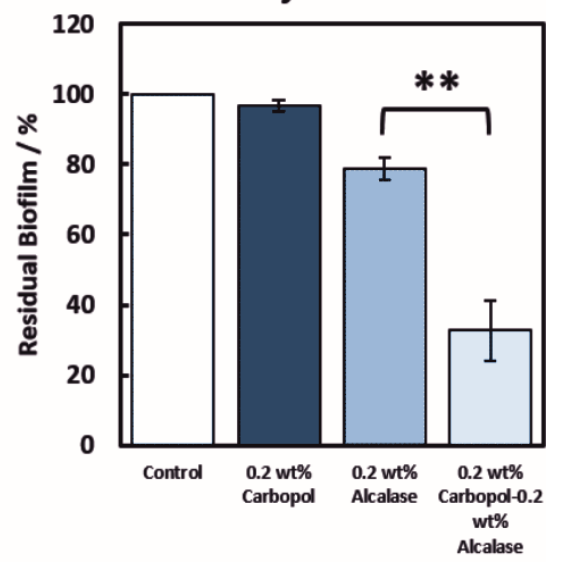

Figure 4. The ability of $0.2 \mathrm{wt} \%$ Alcalase $2.4 \mathrm{~L}$ FG and $0.2 \mathrm{wt} \%$ Carbopol-0.2 wt\% Alcalase $2.4 \mathrm{l}$ FG to disrupt biofilms. Bacteria were cultured in MHB broth for $24 \mathrm{hrs}$ at $37^{\circ} \mathrm{C}$ to form a biofilm. The excess media and suspended cells were washed away and the remaining mature biofilm incubated for $24 \mathrm{hrs}$ in supplemented MHB. After the treatment, the residual biofilms were quantified using Crystal Violet staining. Tests were performed in triplicates $(\mathrm{N}=3$ with $\pm \mathrm{S}$.D). Statistical analysis shown in Table S3 (ESI). $\mathbf{P}<0.05$ is considered significant. $* \mathbf{P}<0.05$, $* * \mathbf{P}<0.01$, ***P $<0.001$.

This indicated that over time the Alcalase-nanogel can outperform the free Alcalase at equivalent concentration. However, it is concluded from this data that the immobilization progress is not allowing the enzyme functionalized nanogel to perform better due to any intrinsic property the Carbopol is inferring, but rather the nanogel allow the enzyme to concentrate and localize at key anionic structures of the biofilm, such as the cell wall, or biofilm surface adherence proteins. ${ }^{61}$

Qualitative biofilm producing capability assessment of representative ATCC bacterial species. Before assessment of the Alcalase 2.4 L FG coated Carbopol NPs on biofilms, the ability of the six types of bacteria to produce biofilms was investigated. A simple glass tube Crystal Violet staining assay was used to assess their adherence to a smooth glass surface after 24 hrs of growth. Table S2 (ESI) shows that all six species were able to adhere to the glass tube. The adhered cells and biofilm was relatively scored based on the concentration of Crystal Violet dye retained after washing with deionized water. Figure S8 (ESI) shows the blue/purple coating of the glass over the area in which the bacterial cells were cultivated and adhered to the glass wall in a biofilm. S. aureus, $P$. aeruginosa, and $S$. epidermidis were shown to have strong adherence. K. pneumoniae and E. coli showed moderate adherence, and finally, E. faecalis was shown to have a weaker adherence. Staphylococcal, Pseudomonas, Escherichia, and Enterococcus species have all been previously shown to form biofilms. A Congo Red agar culture method, first demonstrated by Freeman et al., ${ }^{62}$ was also performed (see Figure S9, ESI). This uses a highly nutritional agar supplemented with sucrose, encouraging the production of exopolysaccharides. Biofilm producing species produce black colonies, which can be seen on the $S$. $a u$ reus, $P$. aeruginosa, and $S$. epidermidis species. However, this was not expressed so well on the K. pneumoniae, E. coli, and $E$. faecalis species, although there was some darkening of the colonies. The sensitivity and the exact mechanism of the production of the black colonies is not well understood, and as it has been suggested by Freeman et al. ${ }^{62}$ that it may be due to the presence of secondary metabolites. 
S. aureus
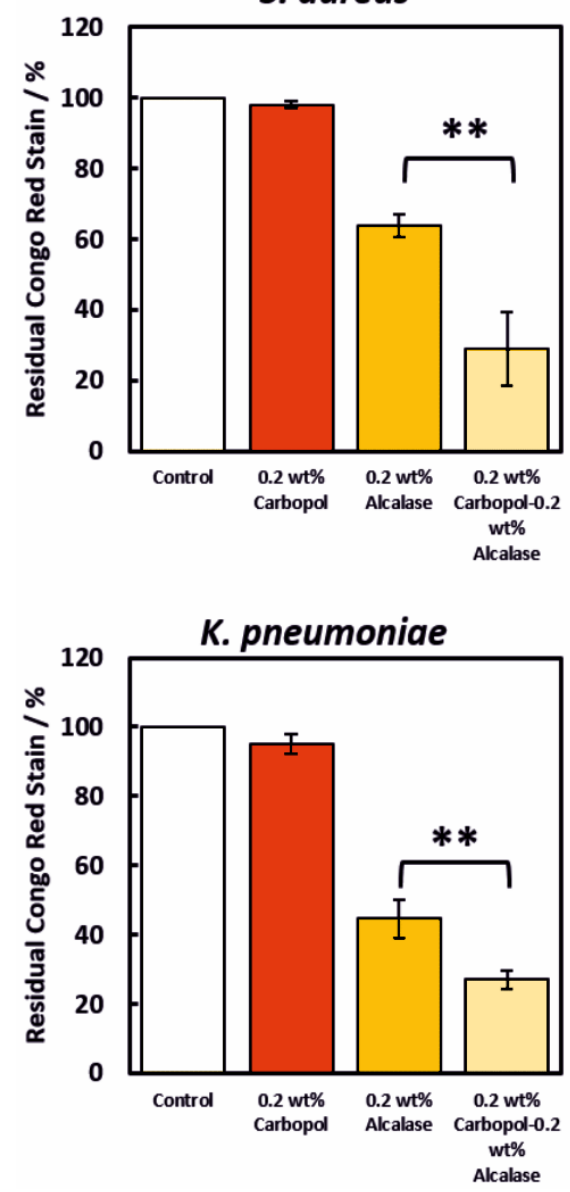

P. aeruginosa

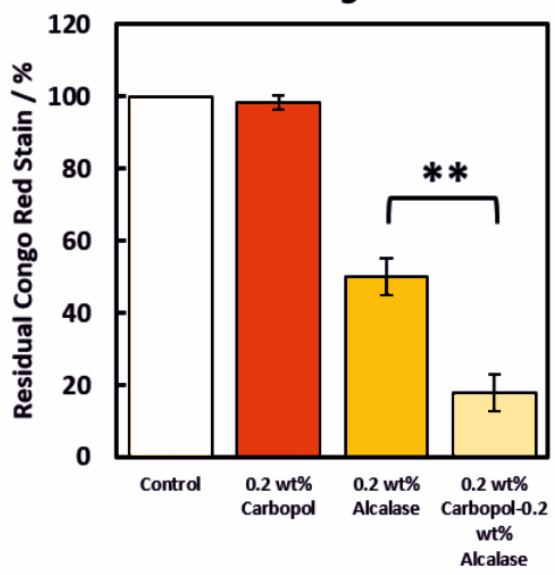

E. coli

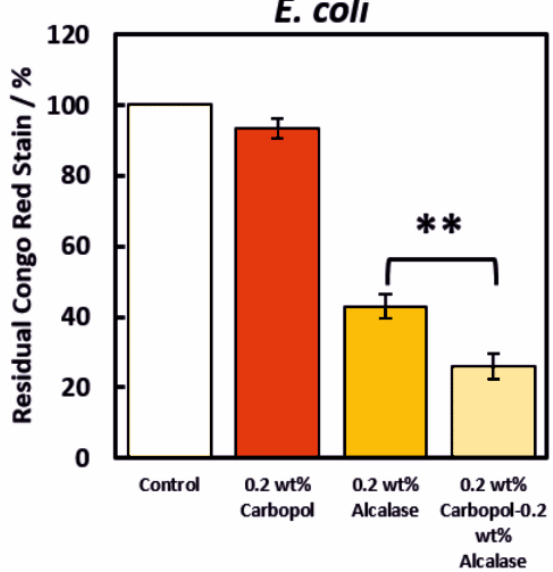

S. epidermidis

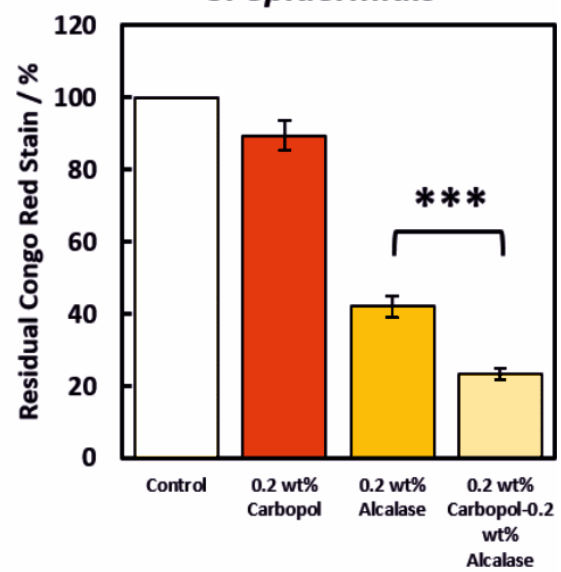

E. faecalis

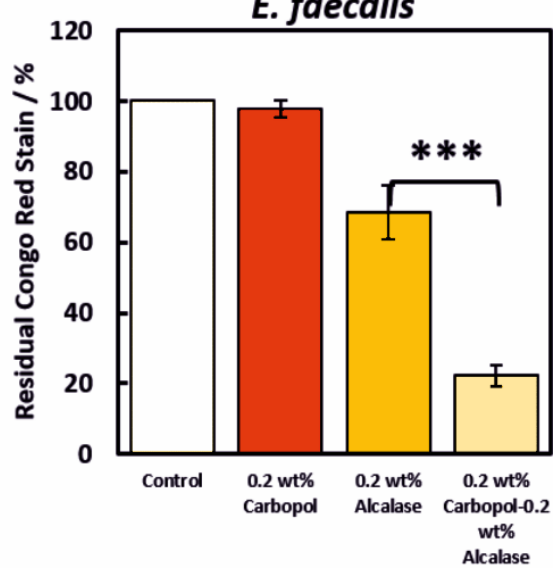

Figure 5. The ability of $0.2 \mathrm{wt} \%$ Alcalase 2.4 L FG and $0.2 \mathrm{wt} \%$ Carbopol Aqua SF1-0.2 wt\% Alcalase 2.4 I FG to disrupt matrix protein by hydrolysis. Bacteria were cultured in MHB broth for $24 \mathrm{hrs}$ at $37^{\circ} \mathrm{C}$ to form a biofilm. The excess media and suspended cells were washed away and the remaining mature biofilm incubated for $24 \mathrm{hrs}$ in supplemented MHB. After treatment, the residual biofilms were quantified using Congo Red staining. Tests were performed in triplicates $(\mathrm{N}=3$ with \pm S.D). Statistical analysis shown in Table S4 (ESI). $P<0.05$ is considered significant. $* P<0.05, * * P<0.01, * * * P<0.001$.

We therefore, have referred to the Crystal Violet tube method which shows that all six species are biofilm producers.

Biofilm disruption by Alcalase-coated nanogel particles. Proteolytic enzymes have previously been used, particularly in wound healing applications, as agents to remove necrotic tissue and cell debris. $33,63,65,66$ We investigated if $\mathrm{Al}$ calase 2.4 L FG coated Carbopol nanogels were able to disrupt the biofilms formed by the species described above. Biofilms were formed by culturing the bacterial species in TC-coated 48 -well plates for $24 \mathrm{hr}$ at $37^{\circ} \mathrm{C}$ in static conditions. After $24 \mathrm{hrs}$, the media was removed and the biofilms adhered to the well plates were washed to remove any remaining planktonic cells. Fresh culture media was supplemented with 0.2 wt\% Carbopol, 0.2 wt\% Alcalase, and 0.2 wt\% Alcalase coated Carbopol nanogel, un-supplemented media was used as a control. 0.1 wt\% Crystal Violet was used to stain the adhered cells and biofilm matrix, before being solubilized in $30 \%$ acetic acid. The absorbance was taken to quantify the residual biofilm mass. Figure 4 shows that bare $0.2 \mathrm{wt} \%$ Carbopol nanogel showed very little biofilm disruption capability, approximately a $5 \%$ reduction in biofilm mass. $0.2 \mathrm{wt} \%$ free Alcalase showed a marked improvement in biofilm mass reduction. This ranged from around $80 \%$ to $40 \%$ residual biofilm left, with $P$. aeruginosa and $K$. pneumoniae showing the least and most reduction in biofilm mass respectively. Interestingly, across all six species the $0.2 \mathrm{wt} \%$ Alcalase coated $0.2 \mathrm{wt} \%$ Carbopol nanogel showed a much greater reduction in biofilm mass compared to the free Alcalase enzyme. This ranged from around 35\% to $15 \%$ residual biofilm mass compared to the control. In $S$. aureus, $P$. aeruginosa, S. epidermidis, E. coli, and E. faecalis there was an over $50 \%$ decrease in the biofilm mass compared to the free Alcalase alone. K. pneumoniae showed a $20 \%$ decrease in the biofilm mass compared to the free $\mathrm{Al}-$ calase. Figure S10 (ESI) shows visually the reduction in Crystal Violet staining on the biofilms after treatment. To test the hydrolysis of the biofilm matrix, particularly the protein content, the same experiment was performed using 0.005 wt\% Congo Red to stain the biofilm. 


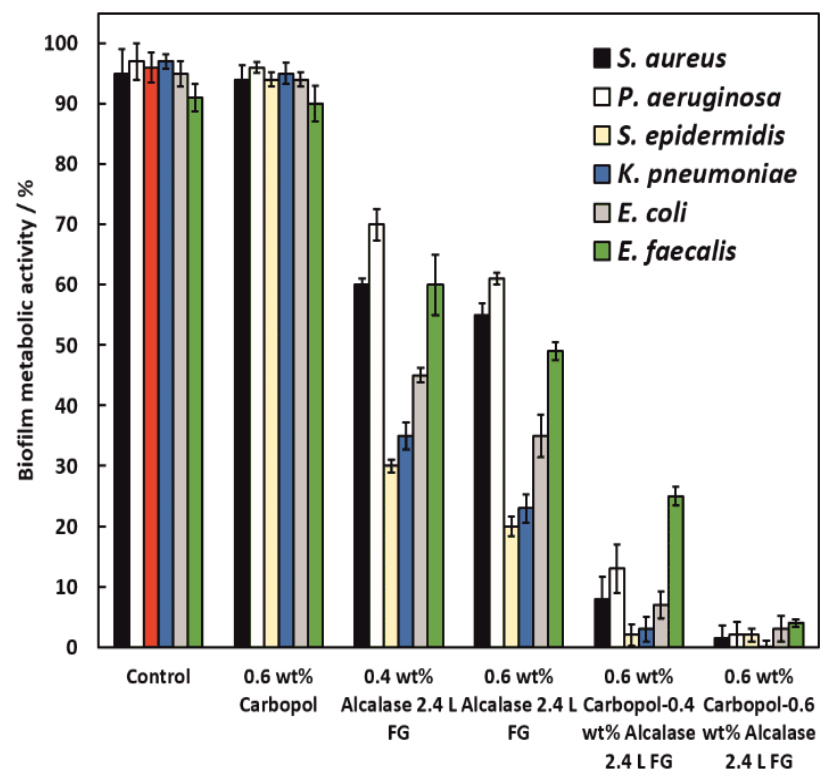

Figure 6. Resazurin sodium salt in situ bacterial biofilm assay. Membrane biofilms were grown for $24 \mathrm{hrs}$ at $37{ }^{\circ} \mathrm{C} .20$ $\mu \mathrm{L}$ of treatment was applied as a droplet to the surface of the biofilm and left to incubate for $24 \mathrm{hr}$. $20 \mu \mathrm{l}$ of 0.015 wt \% Resazurin sodium salt was added and incubated for 30 minutes. Images were captured using an DP70 8MP digital camera and the percentage of biofilm showing metabolic activity calculated using ImageJ.

This was solubilized in $30 \%$ ethanol and the absorbance taken to quantify the intensity of the staining of the biofilms after treatment. Congo Red has previously been used to stain amyloidosis, an accumulation of proteins, in histology sections. Increased concentrations of protein result in a more intense red staining. Figure 5 shows a similar correlation between the reduction of the biofilm mass observed by Crystal Violet staining. $0.2 \mathrm{wt} \%$ Carbopol nanogel showed no reduction to very little reduction of the protein content (see Figure S11 (ESI) for visual images of Congo Red biofilm stains). Free $0.2 \mathrm{wt} \%$ Alcalase showed between a $40 \%$ to $60 \%$ residual protein content within the biofilms. However, $0.2 \mathrm{wt} \%$ Alcalase coated $0.2 \mathrm{wt} \%$ Carbopol shows a much more impressive reduction in protein content within the biofilm, between $25 \%$ and $15 \%$ residual protein compared to the control. This shows that the Alcalase coated nanogels are causing the degradation of the protein backbone of the biofilm. The immobilized Alcalase on Carbopol nanogel particles are likely resulting in an increase in enzyme stability and reduction in aggregation, allowing them to outperform their free enzyme counterparts.

Resazurin sodium salt in situ bacterial biofilm metabolic activity assay. Resazurin Sodium Salt assay was used to measure the metabolic activity of the bacterial cells within the biofilm. Biofilms of the six species were growth for 24 hrs on Membrane Filter paper sections placed on to
MHA. After 24 hrs of growth a biofilm was formed on the filter paper. The membrane biofilm was then transferred onto fresh MHA in a 6-well plate and submerged into treatment infused deionized water (Un-supplemented deionized water was used as the control). Treatments were increased to $0.4 \mathrm{wt} \%$ and $0.6 \mathrm{wt} \%$ Alcalase to investigate if higher concentrations of free Alcalase enzyme, and Alcalase-coated Carbopol nanogels would affect the viability of the cells within the biofilm after $24 \mathrm{hrs} 0.015 \mathrm{wt} \%$ Resazurin sodium salt was used to measure the metabolic activity of the cells within the biofilm by applying evenly to the surface of the biofilm. Resazurin sodium salt can be used as a metabolic activity assay by measuring the production of resorufin (fluorescent pink) created in the presence of cellular NADH. ${ }^{67}$ Only metabolically activity cells are able to reduce resazurin to resorufin. The development of resorufin on the biofilm was quantified to measure the metabolic activity of the biofilm after treatments. Figure 6 shows that $0.6 \mathrm{wt} \%$ Carbopol has no effect on the metabolic activity of the bacterial cells. 0.4 and 0.6 wt $\%$ free Alcalase was able to reduce the metabolic activity of cells within the biofilm by on average $60 \%$ to $40 \%$ across the six species. S. epidermidis showed by far the most decreased metabolic activity, $30 \%$ to $20 \%$ viability with 0.4 and $0.6 \mathrm{wt} \%$ free Alcalase treatment. P. aeruginosa and $E$. faecalis were able to tolerate the free enzyme treatments much better, reducing to approximately 60 to $50 \%$ after treatment with 0.4 and $0.6 \mathrm{wt} \%$ free Alcalase, respectively. In agreement with the 48 -well biofilms described above, the Alcalase-coated Carbopol nanogel performed much better than the equivalent concentration of the free Alcalase enzyme. In all six species, the $0.6 \mathrm{wt} \% \mathrm{Al}-$ calase $-0.6 \mathrm{wt} \%$ Carbopol nanogel were able to reduce the viability of the biofilms to approximately 4\%. Figure S13 (ESI) shows the intensity of the purple color of biofilm after treatment with $0.6 \mathrm{wt} \%$ Alcalase $-0.6 \mathrm{wt} \%$ Carbopol. This contrasts the control image which shows a pink color indicating the biofilm contains metabolically active cells.

S. aureus biofilm cellular viability after treatment with Alcalase-nanogel particles and co-treatment with free ciprofloxacin hydrochloride. Alcalase-coated Carbopol nanogel has been shown to reduce the biofilm mass, the protein concentration of biofilm matrix, and biofilm metabolic activity. We decided to investigate the viability of the cells with in the biofilms after treatment by CFU enumeration. S. aureus was chosen as the proxy biofilm producing bacterium for these experiments. S. aureus is considered one of the most prevalent pathogens in wound infection, ${ }^{70}$ and has been widely studied making it a good choice for further investigation. Biofilms were growth on filter membrane atop MHA and treated with $0.6 \mathrm{wt} \%$ bare Carbopol, $0.6 \mathrm{wt} \%$ free Alcalase, and $0.6 \mathrm{wt} \%$ Alcalase coated $0.6 \mathrm{wt} \%$ Carbopol in the same fashion as above. Additionally, we investigated the effect of co-treatment with the antibiotic ciprofloxacin as a free agent and equivalent concentrations of ciprofloxacin encapsulated into Carbopol. 

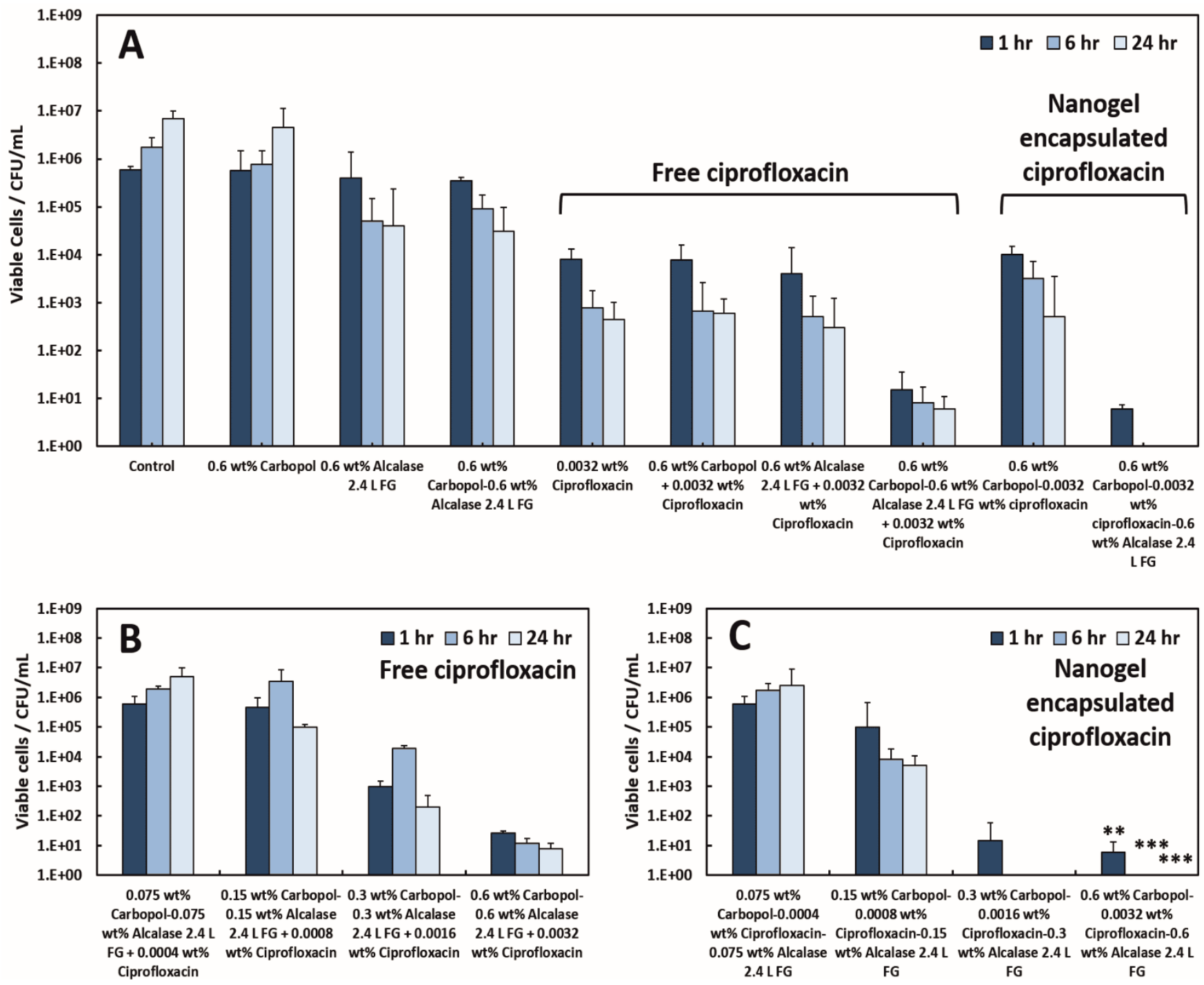

Figure 7. (A) S. aureus biofilm cellular viability after anti-biofilm treatments. CFU/mL of colony biofilms after timed exposure (1, 6, $24 \mathrm{hr}$ ) with a variety of Carbopol Aqua SF1, Alcalase 2.4 L FG, and ciprofloxacin formulations (co-treatment and encapsulated in Carbopol nanogel particles). The cell viability of $S$. aureus from the biofilm culture with (B) co treatments of ciprofloxacin and (C) treatments with encapsulated ciprofloxacin within Alcalase-coated Carbopol formulations at different dilutions at 1,6 and 24 hr time-points. The treatment solutions were diluted 2-fold from a starting concentration of $0.6 \mathrm{wt} \% \mathrm{Carbopol-0.6}$ wt $\%$ Alcalase-0.0032 wt \% ciprofloxacin (co-treatment or nanogel-encapsulated). Post-treatment, the colony biofilms were glass bead beaten in $1 \mathrm{~mL}$ of MHB with serial dilutions. The agar drop plate method was used to elucidate the CFU/mL. Statistical analysis shown in Table S8 (ESI). $P<0.05$ is considered significant. $* P<0.05$, **P $<0.01$, ***P $<0.001$.

We have previously demonstrated that antibiotics can be encapsulated into Carbopol and this confers an increased efficacy of the antimicrobials against target cells. ${ }^{55}$ Table S5 (ESI) shows that $75 \%$ of the ciprofloxacin encapsulated with the Carbopol was retained. The encapsulation efficiency was measured by analyzing the supernatant of the formulation immediately after centrifugation, the encapsulation efficiency was calculated using a standard calibration curve of absorption vs. known concentrations of ciprofloxacin (Figure S14, ESI). Post-encapsulation, the mean particle diameter was marginally increased by approximately $1 \mathrm{~nm}$ post encapsulation and there was no detectable change in zeta potential of the nanogel particles (Figure S15, ESI).
Previously, polyelectrolytes have been used to reverse the charge of nanogel and allowed an electrostatic adhesion to anionic surface of the bacteria. ${ }^{14,15,20}$ In this study, we used Alcalase to accomplish this goal to create a dual purpose nanocarrier able to effectively degrade the biofilm and simultaneously deliver concentrated doses of antibiotic localized directly on the cell wall. This strategy is known to work extremely well for planktonic bacteria, but so far this has never been tried for bacteria in a biofilm. The release kinetics of the nanogel-loaded ciprofloxacin hydrochloride was measured over $24 \mathrm{hr}$ (Figure S16, ESI) and as in previous studies the antibiotic was released slowly over a period of $24 \mathrm{hrs}$ after dilution of the stock suspension. 

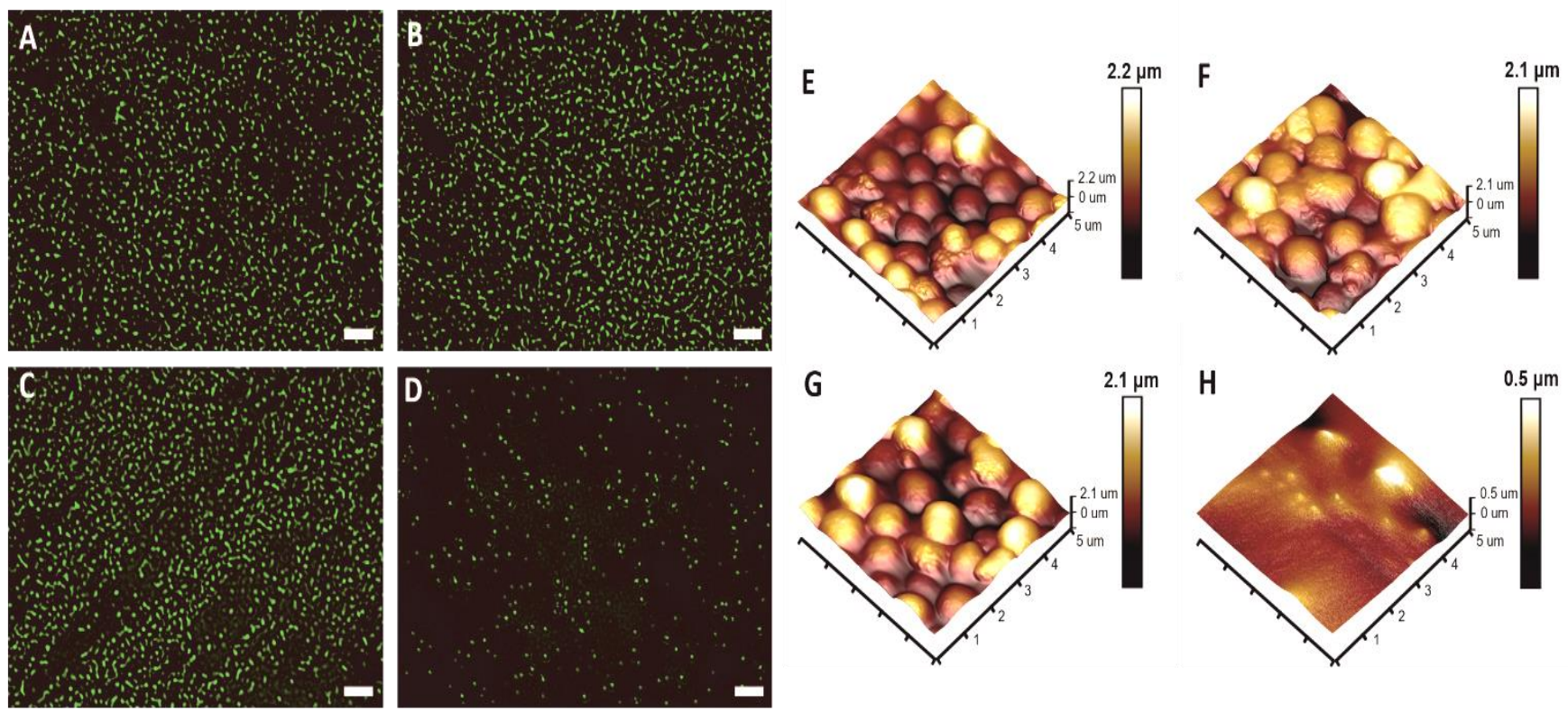

Figure 8. Fluorescent images of $S$. aureus biofilm formation, (A) represents an untreated control sample, (B) treatment with $0.6 \mathrm{wt} \%$ Carbopol, (C) $0.6 \mathrm{wt} \%$ Alcalase 2.4 L FG , and (D) 0.6wt\% Carbopol-0.6 wt\% Alcalase 2.4 L FG nanogel particles. Samples were stained with AO. White insert bar represents $5 \mu \mathrm{m}$. Tapping Mode Atomic force microscopy of 24-hr growth $S$. aureus biofilms cultured on glass slides. (E) shows biofilm growth control, (F) treatment with $0.6 \mathrm{wt} \%$ Carbopol, (G) $0.6 \mathrm{wt} \%$ Alcalase $2.4 \mathrm{~L}$ FG and (H) $0.6 \mathrm{wt} \%$ Carbopol-0.6 wt\% Alcalase $2.4 \mathrm{~L} \mathrm{FG}$ nanogel particles. Images were acquired in height (topography) and then analyzed using Nanoscope Analysis v.1.7. (Bruker). The area scanned is $5 \mu \mathrm{m}^{2}$ per image.

This facilitated the release of ciprofloxacin in close proximity to the $S$. aureus. Cell enumeration was performed after 1 , 6 , and $24 \mathrm{hr}$ of treatment. The treated biofilms were glass bead beaten and enumerated using the drop plate method. Ciprofloxacin was chosen as an appropriate co-treatment as it can be administered topically, orally, and intravenously. Figure S17 (ESI) shows that the $S$. aureus strain used in this study was susceptible to ciprofloxacin and had a MIC of 0.08 $\mu \mathrm{g} / \mathrm{mL}(0.000008 \mathrm{wt} \%)$. We chose $0.0032 \mathrm{wt} \%$ as this is the maximum concentration measured to be effective against $S$. aureus using the ETEST $®$ strips. This allowed a fair comparison of formulated vs. free ciprofloxacin at concentrations shown to be effective against $S$. aureus. Additionally, this concentration allows the nanocarrier colloidal stability to be maintained due to ciprofloxacin's low water solubility. Figure 7A shows that after seeding a membrane with $1 \times 10^{5}$ $\mathrm{CFU} / \mathrm{mL}$ for $24 \mathrm{hr}$ at $37^{\circ} \mathrm{C}$, the growth control continued to increase in cell density after a further 1,6 , and $24 \mathrm{hr}$ of growth. Treatment with 0.6 wt\% bare Carbopol showed little change in the $\mathrm{CFU} / \mathrm{mL}$ of biofilm. After treatment with $0.6 \mathrm{wt} \%$ free Alcalase, there was a reduction in viable cells within the S. aureus biofilm. There was little difference after $1 \mathrm{hr}$, but after $24 \mathrm{hr}$ the viable cell count was reduced to just under $1 \times 10^{5} \mathrm{CFU} / \mathrm{mL}$, very close to the concentration of cells the original membrane was seeded with.Surprisingly, after treatment with $0.6 \mathrm{wt} \%$ Alcalase $-0.6 \mathrm{wt} \%$ Carbopol NPs there was very little difference in the number of viable cells after each treatment time point. This is likely due to the Alcalase-Carbopol nanogel degrading the biofilm, but having very little effect on the bacterial cell viability, as there is no antibiotic in this treatment to act on the released bacteria. Treatment with $0.0032 \mathrm{wt} \%$ ciprofloxacin (higher than the MIC of $0.00008 \mathrm{wt} \%$ ) was used to measure the number of viable cells, after $24 \mathrm{hrs}$ of treatment the viable cells in the $S$. aureus biofilm had reduced from approximately $1 \times 10^{6}$ to $1 \times 10^{3}$. The cells within the biofilm are much less susceptible to antibiotics due to their poor penetration through the biofilm matrix. There was no real improvement when $0.0032 \mathrm{wt} \%$ ciprofloxacin is treated with $0.6 \mathrm{wt} \%$ Carbopol. This result is unsurprising due to the Carbopol nanogel alone demonstrating no ability to degrade the biofilm matrix. Again with $0.00032 \mathrm{wt} \%$ ciprofloxacin and $0.6 \mathrm{wt} \%$ free Alcalase there was no difference between the CFU/mL compared to the antibiotic alone. However, when the antibiotic is administered as a co-treatment with $0.6 \mathrm{wt} \% \mathrm{Al}-$ calase coated $0.6 \mathrm{wt} \%$ Carbopol NPs there was a reduction to $1 \times 10^{1}$. This indicates the cells in the biofilm have been destroyed due to the degradation of the biofilm matrix by the Alcalase-Carbopol nanogel allowing the ciprofloxacin to reach and penetrate the bacterial cells. This synergistic effect was enhanced further when the ciprofloxacin was delivered to the $S$. aureus in an encapsulated method, rather than as a separate co-treatment. After $6 \mathrm{hr}$ and $24 \mathrm{hr}$ of treatment with $0.0032 \mathrm{wt} \%$ ciprofloxacin encapsulated in $0.6 \mathrm{wt} \%$ Carbopol with $0.6 \mathrm{wt} \%$ Alcalase coating there were no viable bacteria found in the samples. This provides evidence that the dual functionality of the Alcalase-nanogel mediate biofilm degradation and the localized delivery of ciprofloxacin of this formulation is able to effectively clear the biofilms and kill all released bacterial cells. 

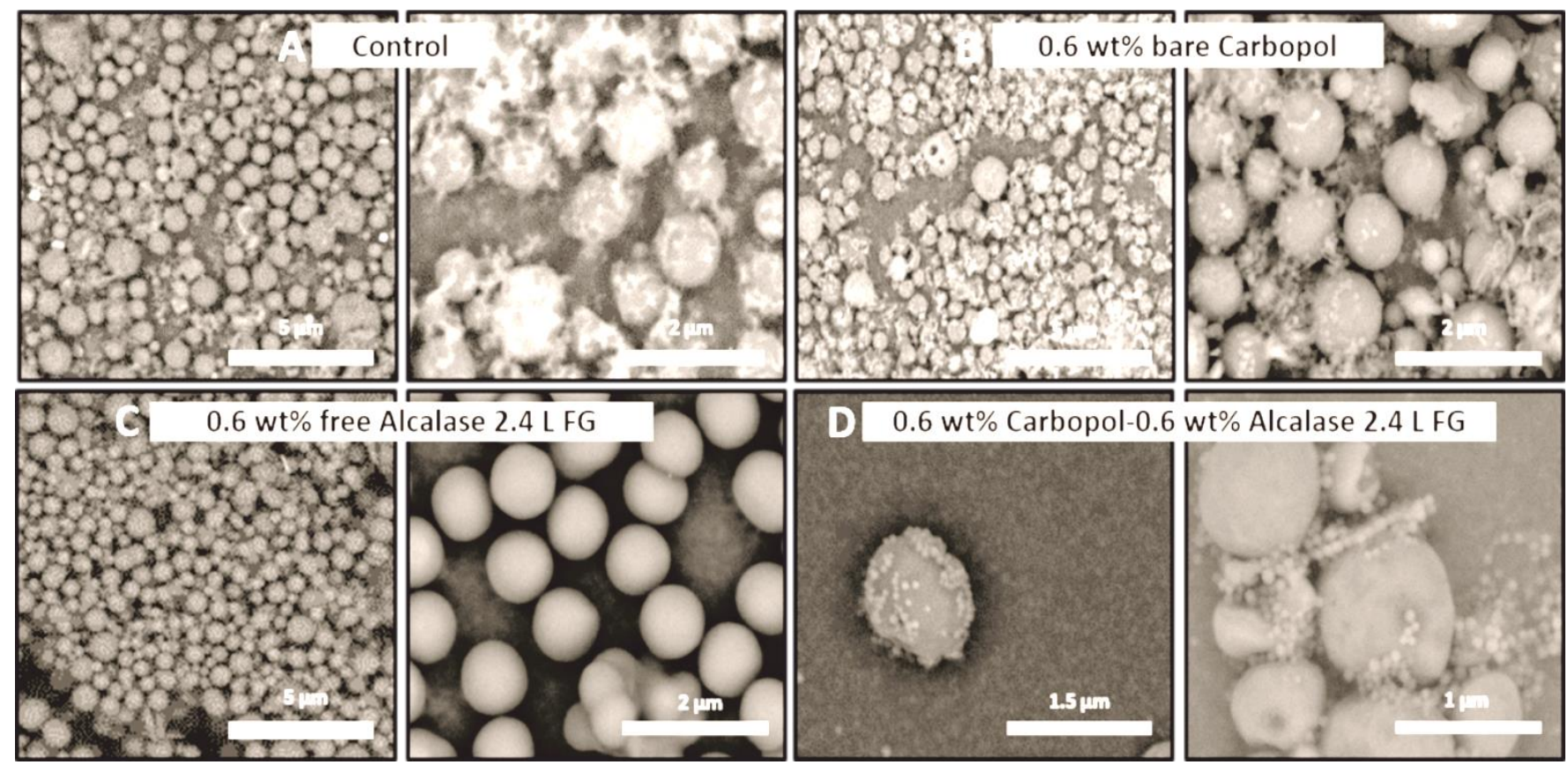

Figure 9. SEM images of $S$. aureus before (A) and after treatment with (B) 0.6 wt\% bare Carbopol nanogel, (C) 0.6 wt $\%$ free Alcalase 2.4 FG and (D) $0.6 \mathrm{wt} \%$ Alcalase $2.4 \mathrm{G}$ coated $0.6 \mathrm{wt} \%$ Carbopol nanogel. All samples were prepared for SEM imaging by drying and coated with $\sim 10 \mathrm{~nm}$ carbon layer. Samples were imaged using a Carl Zeiss Evo-60 (Germany) with a variable pressure $100 \mu \mathrm{m}$ aperture at $40 \mathrm{~Pa}$. EHT was $20 \mathrm{kV}$ with probe current of 100 pA. Images were captured with Zeiss smartSEM software.

Figure 7B shows that there is a correlation between the increasing of the concentration of free ciprofloxacin in the presence of equivalent amount of Alcalase-Carbopol NPs and the residual bacterial cell viability after treatment. Different dilutions of the treatments were prepared to measure this effect. A very low treatment concentration, 0.075 wt $\%$ Alcalase -0.075 wt $\%$ Carbopol +0.0004 wt $\%$ ciprofloxacin, showed very little effect after 1,6 , or $24 \mathrm{hrs}$. This is due to the likely ineffective degradation of the biofilm. However, as the concentration of the Alcalase-Carbopol NPs increased alongside the increased concentration of ciprofloxacin, CFU/mL was reduced to almost no viable cells. After $24 \mathrm{hrs}$ at the higher concentration of the formulation, there was very little difference in the CFU at the 1,6 , and $24 \mathrm{hr}$ time points, this indicates the Alcalase-coated nanogel particles are very fast acting, enabling the ciprofloxacin access to the cells quickly. Interestingly, at the mid-treatment concentrations $\mathrm{CFU} / \mathrm{mL}$ increased between $1 \mathrm{hr}$ and $6 \mathrm{hr}$, however a $24 \mathrm{hr}$ it had fallen below the first time point. This indicates the lower concentrations of Alcalase-Carbopol NPs are slower to effect the biofilms. $0.6 \mathrm{wt} \%$ Alcalase - $0.6 \mathrm{wt} \%$ Carbopol nanogel was found to be the most effective concentration to kill cells with in a biofilm when combined with the synergistic effect of ciprofloxacin. Figure 7C shows the results on the concentration dependence of the cell viability on the antibiotic treatment in experiments where the ciprofloxacin was encapsulated within the Carbopol nanogel, rather than being delivered separately as a co-treatment. We were able to show that there was a significant decrease in cell viability after 1, 6 and $24 \mathrm{hr}$ compared to when ciprofloxacin was administered separately at the same concentration. We attribute this to the highly localized release of ciprofloxacin from the adhered nanogel enhancing the effect of the antibiotic. Alcalase-functionalized Carbopol nanogel particles can be seen attached to the bacterial cell after the biofilm has been cleared away (Figure 9D) providing evidence of their ability of local delivery antibiotic directly to the bacterial cell wall.

Anti-biofilm efficacy of Alcalase-nanogel particles on $\boldsymbol{S}$. aureus biofilm structure. We also investigated how 0.6 wt $\%$ Alcalase -coated $0.6 \mathrm{wt} \%$ Carbopol nanogel affects the biofilm structure of $S$. aureus using fluorescence microscopy. S. aureus was allowed to adhere to a glass slide which has been submerged in this culture for $24 \mathrm{hr}$ at $37{ }^{\circ} \mathrm{C}$. After $24 \mathrm{hr}$ the media was removed and the glass slides washed to remove non-sessile cells. Supplemented fresh media containing $0.6 \mathrm{wt} \%$ Carbopol, $0.6 \mathrm{wt} \%$ free Alcalase, and 0.6 wt $\%$ Alcalase - 0.6 wt $\%$ Carbopol NPs was incubated for a further $24 \mathrm{hrs}$ covering the slides. Acridine Orange (AO) was used to visualize the remaining cells after treatment. AO is a cell-permeable nucleic acid selective fluorochrome dye. It can emit green light at $520 \mathrm{~nm}$ when intercalated with dsDNA. Figure 8A shows the growth control has a highly congested biofilm structure, the cells are highly packed which is consistent with biofilm formation. There is very little difference to the biofilm structure after treatment with $0.6 \mathrm{wt} \%$ bare Carbopol and $0.6 \mathrm{wt} \%$ free Alcalase (Figure $8 \mathrm{~B}, 8 \mathrm{C})$. The cells remain packed densely together, although there is a moderate reduction in the cell density 
when treated with free Alcalase. However, in Figure 8D, there is a marked reduction in the intensity of the AO fluorescence and a reduction in the cell density. The cells have much lower surface density. This suggests the disruption of the biofilm matrix by the Alcalase-Carbopol nanogel particles has allowed many of the cells to detach from the biofilm during treatment, or during the followed washing. For better understanding of the $S$. aureus biofilm structure, the same samples used for fluorescent analysis were imaged using AFM (Figure 8E-H). The AFM images again show how the 0.6 wt $\%$ Alcalase -0.6 wt $\%$ Carbopol NPs effectively remove the biofilm from the glass slide.

Figure 8E shows the tightly packed biofilm with staphylococcal cells of thickness approximately $1 \mu \mathrm{m}$; the cells appear to be in a multilayer due to the height sensor recording a maximum height of $2.2 \mu \mathrm{m}$. There was no clear differences in structure between the treatments of $0.6 \mathrm{wt} \%$ bare Carbopol nanogel and $0.6 \mathrm{wt} \%$ free Alcalase treatments (Figures $8 \mathrm{~F}$ and $8 \mathrm{G}$, respectively). There is only a very small reduction in the average thickness of the biofilm of $0.1 \mu \mathrm{m}$ which is insignificant. The AFM scans again show staphylococcal layer of approximately $1 \mu \mathrm{m}$ in a tightly packed fashion. In the control, 0.6 wt $\%$ bare Carbopol nanogel and 0.6 wt $\%$ free Alcalase there was no discernible difference in cellular morphology. The image in Figure $8 \mathrm{H}$, however, shows the biofilm structure has largely been removed, in the scanned region there were no obvious signs of cell adherence and the peak height was $0.5 \mu \mathrm{m}$ which is half the average diameter of an $S$. aureus cell. This results indicates that the cells have been removed during the Alcalase-Carbopol nanogel treatment, and washed away after treatment during the preparation of the glass slides for AFM microscopy. This correlates with the data obtained in the AO fluorescence microscopy images. Finally, we investigated the structure of the $S$. aureus biofilm using scanning electron microscopy (SEM). In this case, we used biofilms grown of filter membranes as this allowed feasible samples to be obtained for SEM analysis. The samples were prepared in the same manner as described in the cellular viability assays of biofilm grown $S$. aureus reported above. The biofilms were treated with $0.6 \mathrm{wt} \%$ bare Carbopol nanogel, $0.6 \mathrm{wt} \%$ free Alcalase, and 0.6 wt $\%$ Alcalase-coated 0.6 wt\% Carbopol nanogel particles. Un-supplemented media was considered the growth control. After the treatment, the biofilm membranes were gently removed from the agar using serial tweezers, however, instead of enumeration the membrane was washed in deionized water, fixed for $1 \mathrm{hr}$ in $1 \mathrm{wt} \%$ glutaraldehyde, dehydrated in ethanol and dried in liquid $\mathrm{CO}_{2}$ at critical point as described in the methods section. $10 \mathrm{~nm}$ of carbon coating was used to create a conductive layer over the biofilm, and reduce thermal damage during SEM imaging.

Figure 9 shows the SEM images after the treatments. The control sample shows the highly congested S. aureus biofilm. At higher magnification, the EPS within the matrix can also be seen adhered to the surface of the coccus cells and linked to other cells around, consistent with biofilm formation. This morphology is similar in the samples with 0.6 wt $\%$ free Carbopol nanogel treatments. The cell density remains highly analogous to the control sample and EPS matrix can be observed around the cells. The cells appear to also be in multilayer with cells atop one and other. Interestingly, in the sample treated with free $0.6 \mathrm{wt} \%$ Alcalase, the cellular morphology and density remain largely unchanged, however, there appears to be a distinct lack of EPS matrix coating and surrounding the cells. This indicates the Alcalase may have digested the biofilm matrix but left the cells largely untouched. Finally, the sample treated with the Alcalase-Carbopol NPs there is a clear reduction the cell density and additionally the biofilm EPS matrix has been degraded. The Alcalase-Carbopol nanogel particles can also be seen adhered to the surface of the $S$. aureus cells, due to the cationic protease molecules on the nanogel surface having an electrostatic attraction to the anionic surface of the bacterial cell wall. This data correlates to the images seen using fluorescence and atomic force microscopy, and confirms that the Alcalase-Carbopol nanogel particles are degrading the biofilm glycoprotein network.

Zeta potential of bacteria treated with free Alcalase and Alcalase-nanogel. We also investigated the effect the free Alcalase and the immobilized Alcalase on-Carbopol nanogel on the zeta potential of the bacterial species. The experiments on the cells were performed in suspension in allow zeta potential measurements by DLS. Figure S12 (ESI) indicates that all six species conferred a negative charge on their cells walls, with the Gram-negative generally having a stronger charge than the Gram-positive.

Across all six species, the free Alcalase showed a marginal reduction in the negative charge after 10 mins and $1 \mathrm{hr}$. This was likely due to the accumulation of protease on the cell wall. The charge difference was only slight between 10 mins and $1 \mathrm{hr}$, indicating the Alcalase protease had not built up and saturated the surface of the cells. In contrast, the Alcalase-Carbopol nanogel particles showed an increased reduction of the negative charge of the bacterial cells. On average, this was reduced by approximately 7-10 $\mathrm{mV}$ across the six species. This indicated a buildup of the cationic protease-coated nanogel carriers on the surface on the bacterial cells. The SEM images of S. aureus in Figure 9D also support this data, showing the Alcalase-Carbopol particles adhered to the bacterial cell wall. The experiments where stopped after $1 \mathrm{hr}$ due to the aggregation of the cells causing unreliable zeta potential measurements. Whilst these experiments are not indicative of the behavior of the cells in a biofilm, which will have a much more complex EPS matrix surrounding them, it does provide a valuable insight into the increased attraction of the Alcalase-Carbopol nanogel to the exposed bacterial cells, and therefore the likely increased affinity of these particles to protein structures within the biofilm matrix.

Comparison with standard treatments for biofilm forming bacteria. Currently, there is no Gold Standard when it comes to topically treating wound biofilms. There is universal agreement that mechanical debridement is the most effective way of remove biofilm infection, but this is not always possible and often results in regrowth of the biofilm creating a chronic infection. ${ }^{68,69,70}$ 

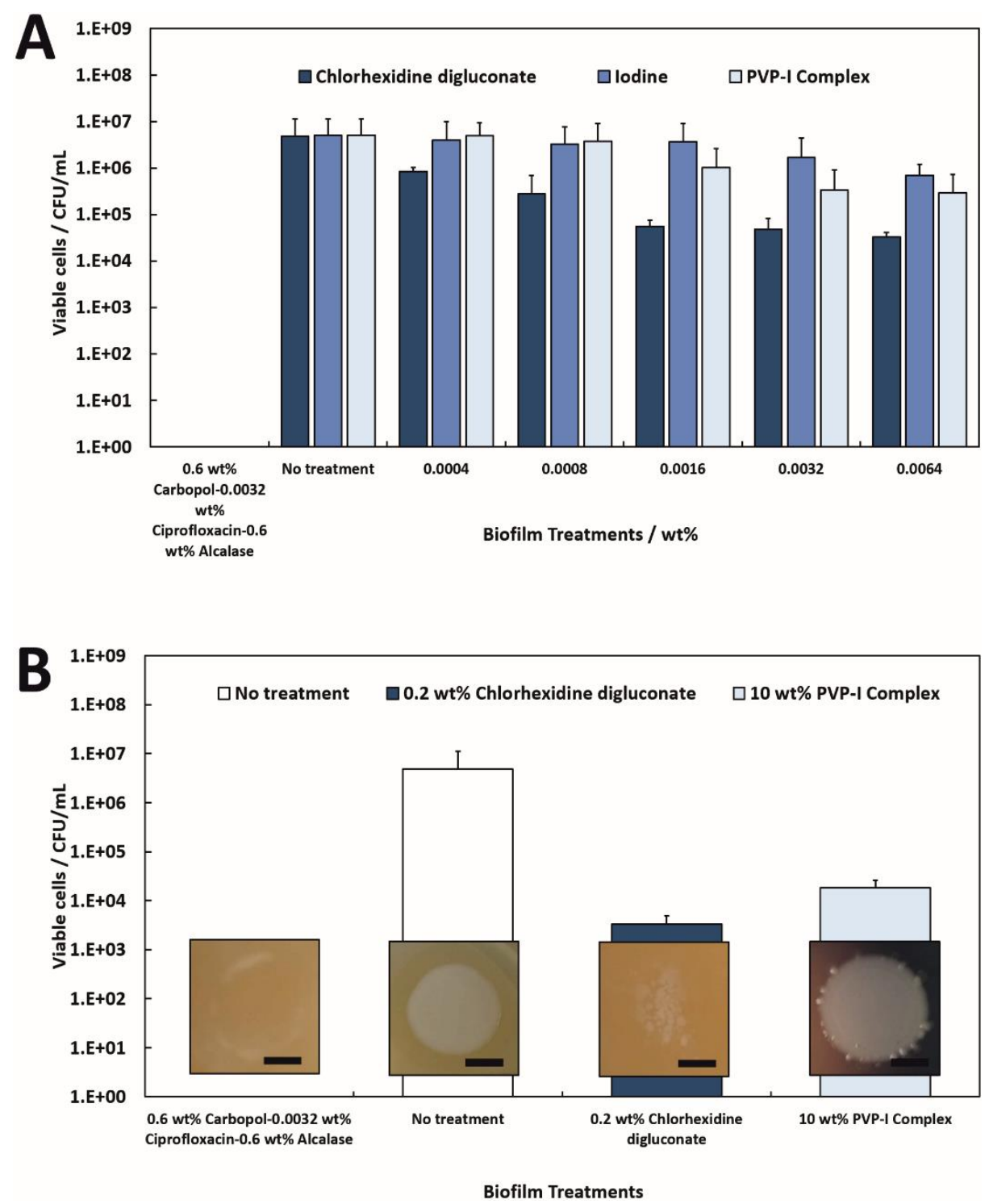

Figure 10. S. aureus biofilm cellular viability after 24 hours at different concentrations of alternative treatments. (A) Shows alternative biofilm treatments at 0 to $0.0062 \mathrm{wt} \%$ to compare to the active concentration of ciprofloxacin in the CarbopolAlcalase formulation. (B) Shows a comparison a comparison of the alternative biofilm treatments at concentrations used clinically. Biofilm treatments were $0.6 \mathrm{wt} \%$ Carbopol-0.0032 wt\% Ciprofloxacin-0.6 Alcalase, Chlorhexidine digluconsate, Iodine and Poly(vinylpyrrolidone)-Iodine (PVP-I). Post-treatment, the membrane biofilms were washed thrice and then glass bead beaten in $1 \mathrm{~mL}$ of MHB with serial dilutions. The agar drop plate method was used to elucidate the CFU/mL. Black scale bar in the biofilm pictures is $0.5 \mathrm{~cm}$.

Long term antibiotic treatment and topical antimicrobial treatments are other common options in treating biofilms. After decades of use, iodophore-based formulations such as Poly(vinylpyrrolidone)-Iodine (PVP-I) remain prevalent in wound biofilm treatments. ${ }^{71}$ Iodine based agents are effective antimicrobial agents, which are tolerated well by the body and offer a broad spectrum of activity. ${ }^{72}$ Additionally, they are able to penetrate biofilms, and no clinical evidence presently shows they have a negative effect on wound healing. ${ }^{73}$ Chlorohexidine is also often used to as a disinfectant on patients and is commonly found in formulations designed to reduce infection. However, it is not known to be effective against cells within biofilms. ${ }^{74}$ Figure 10 shows a comparison between 0.6 wt\% Carbopol- 0.0032 wt\% Ciprofloxacin- $0.6 \mathrm{wt} \%$ Alcalase nanogels against Iodine, PVP-I and chlorhexidine using the membrane biofilm model. The results show that at the concentrations similar to active agent in our formulation, ciprofloxacin, the alternative treatments are ineffective. This is likely due requirement of higher concentrations needed to be effective and the lack of penetration into the biofilm. 

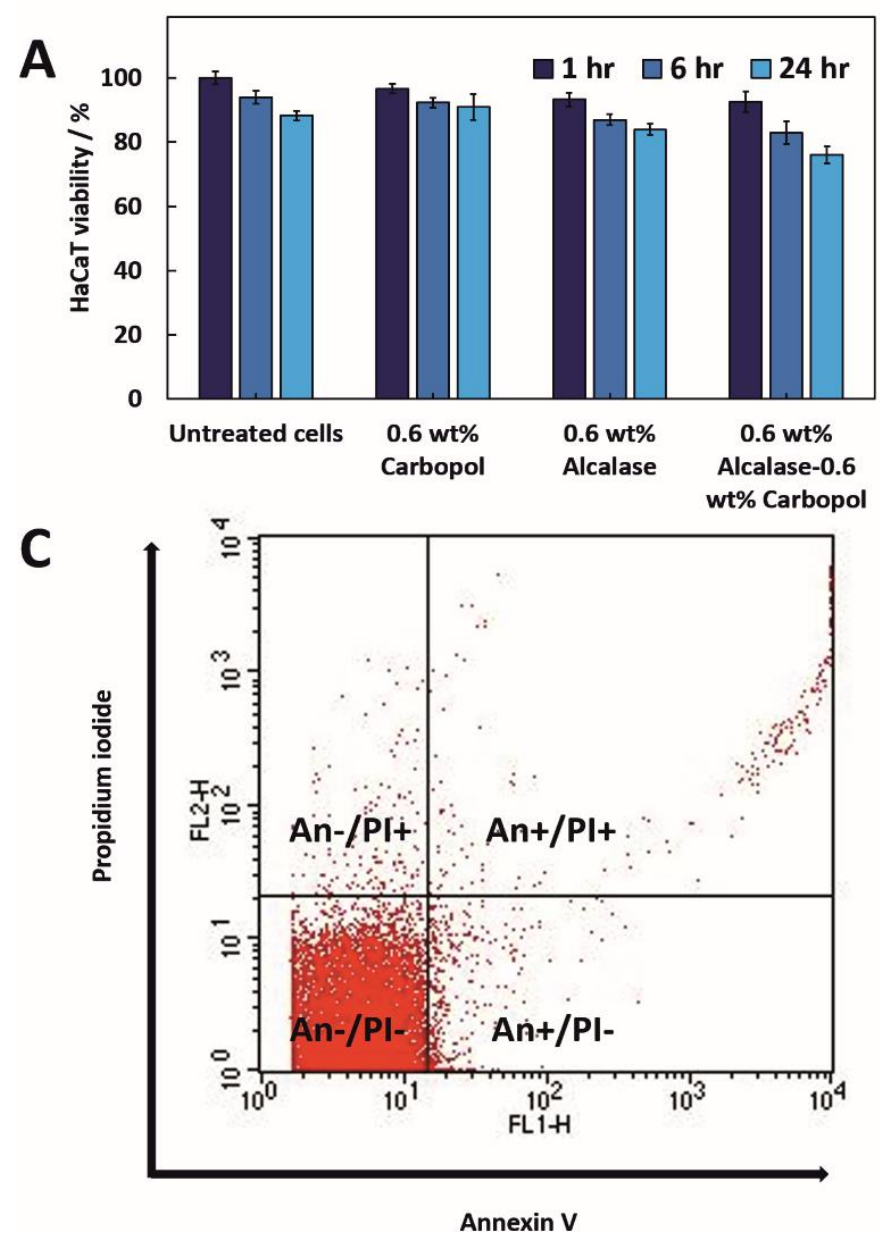
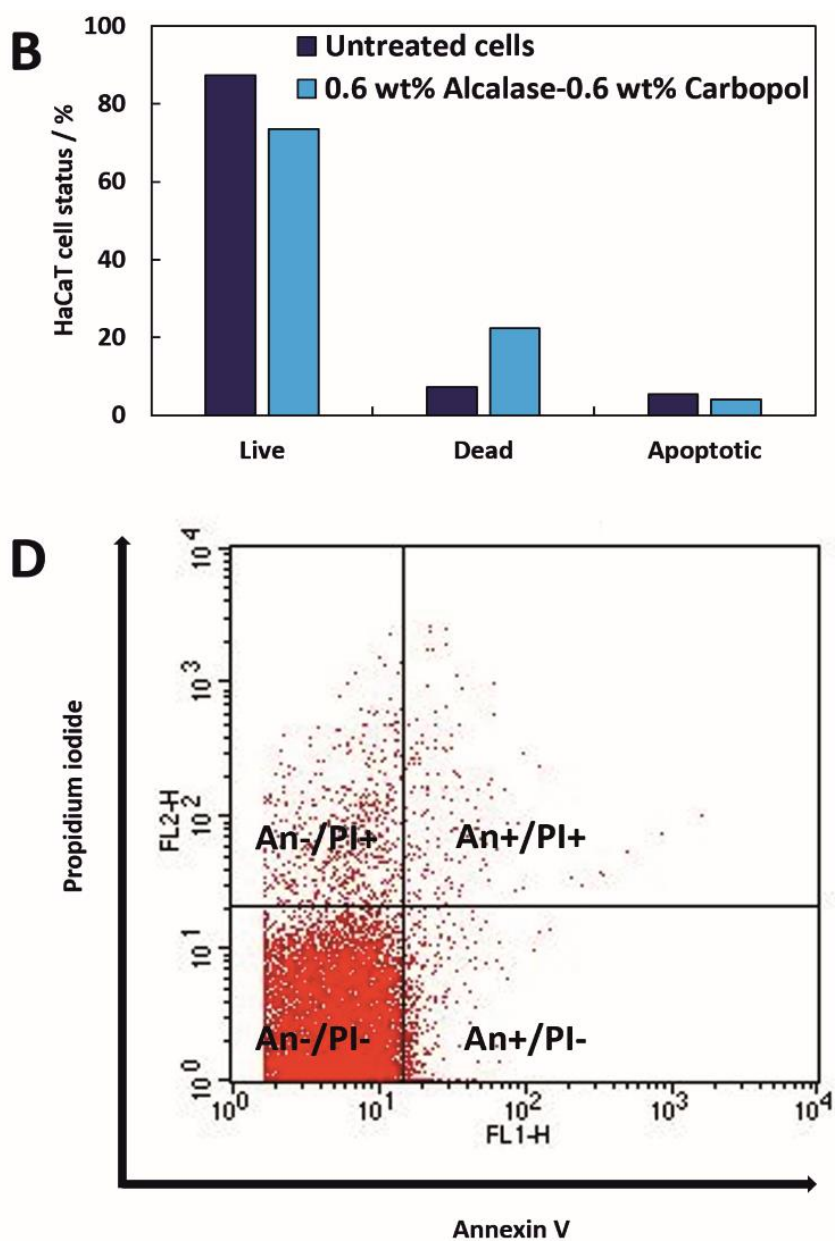

Figure 11. (A) HaCaT cell viability after comparative treatment with $0.6 \mathrm{wt} \%$ Carbopol Aqua SF1 nanogel, 0.6 wt\% Alcalase $2.4 \mathrm{~L} \mathrm{FG}$, and $-0.6 \mathrm{wt} \%$ Alcalase-coated $0.6 \mathrm{wt} \%$ Carbopol nanogel particles. Viability counts were performed at 1,6 , and 24 hr. (B) HaCaT cell status after $24 \mathrm{hr}$ untreated or $24 \mathrm{hr}$ of $0.6 \mathrm{wt} \%$ Alcalase- $0.6 \mathrm{wt} \%$ Carbopol treatment. (C) shows the dot plot distribution for untreated cells after $24 \mathrm{hr}$ and (D) shows the dot-plot distribution for $0.6 \mathrm{wt} \%$ Alcalase- $0.6 \mathrm{wt} \%$ Carbopol treatment after $24 \mathrm{hr}$. The experimental was ended after $10^{4}$ cells were counted after staining using a FITC Annexin staining kit. Figure S19 (ESI) shows the results for the $0.6 \mathrm{wt} \%$ Carbopol and $0.6 \mathrm{wt} \%$ Alcalase which were considered controls. Figure S20 (ESI) shows photographs of the HaCaT cells after $24 \mathrm{hr}$ treatment and Table S7 (ESI) shows the cell status after 24 hrs of treatment.

The quenching effective of the EPS is paramount in preserving cell viability within a biofilm. Additionally, we tested the effect of $0.2 \mathrm{wt} \%$ chlorhexidine, and $10 \mathrm{wt} \%$ PVP-I, concentrations which are commonly used clinically in wound cleaning and sterilization. ${ }^{73,75}$ Again, the results follow the same trend as the low concentrations, with neither agent able to fully eliminate the biofilm bacteria viability.

Cytotoxicity and apoptosis inducing ability of bare nanogel, free Alcalase, and Alcalase-nanogel on human cells. A preliminary human cell cytotoxicity experiment was performed on $\mathrm{HaCaT}$ cells to investigate if the bare Carbopol Aqua SF1, the free Alcalase 2.4 L FG, and the Alcalase 2.4 L FG-coated Carbopol Aqua SF1 nanogel particles were toxic to human cells. HaCaT cells are very good proxy for studying cytotoxicity of the treatment as they are human keratinocytes which are the same type of cells likely to be exposed to the formulation in chronic wound cells. Figure
$11 \mathrm{~A}$ shows that $0.6 \mathrm{wt} \%$ Carbopol showed only a marginal reduction in viable cells over 1,6 , and $24 \mathrm{hrs}$. This was also the case with $0.6 \mathrm{wt} \%$ free Alcalase $2.4 \mathrm{~L} \mathrm{FG}$, and Alcalase 2.4 L FG-coated $0.6 \mathrm{wt} \%$ Carbopol Aqua SF1 nanogels, the same formulations used in the anti-biofilm experiments. This indicates that the Alcalase-coated Carbopol nanogels confer only a slight increase in cytotoxicity towards the HaCaT cells, compared with the free enzyme and the bare nanogel. The data indicates that the enzyme concentration which provided effect anti-biofilm effect had very little impact on cell viability, providing evidence they may be appropriate for in vivo use in surface chronic wounds. Additionally, we investigated the effect the $0.6 \mathrm{wt} \%$ Alcalase- 0.6 wt $\%$ Carbopol nanogel particles on inducing apoptosis after 24 hrs treatment. An Annexin V-FITC staining kit was used to measure the induction of apoptosis using FACS (Fluorescence-activated cell sorting). Figure 11B shows that after 24 hrs exposure to the Alcalase-coated Carbopol nanogel there 
was approximately a $10 \%$ residual viable cells compared to untreated cells, which correlates well with the MTT viability data shown in Figure 11A. There is only a marginal difference in induced apoptosis (cells staining positive for Annexin and negative for PI). This indicates that the Alcalase 2.4 FG protease is not triggering apoptosis by way of the caspases cascade apoptosis pathway.

\section{CONCLUSIONS}

Our results confirm that protease Alcalase 2.4 L FG can disrupt the bacterial biofilm EPS matrix and reduce its biomass. The surface functionalization of Carbopol Aqua SF1 nanogels with this enzyme further boosts this effect on six wound biofilm associated pathogens reducing the biomass 6-fold compared to untreated biofilms. The efficacy of the Alcalase-coated Carbopol nanogel particles was confirmed using fluorescence, atomic force and scanning electron microscopy. Additionally, the application of Alcalase-Carbopol nanogels in a co-treatment with ciprofloxacin resulted in a 3-log reduction in viable cells counts compared to using of equivalent concentration of ciprofloxacin alone. When ciprofloxacin was encapsulated within Carbopol at equivalent concentrations to the free ciprofloxacin, there was a very significant further boost to the effectiveness of the antibiotic in this dual functionalized nanocarrier. These dual purpose Alcalase-coated antibiotic loaded nanogel particles provided effective treatment against $S$. aureus biofilms, with no detectable CFU after $6 \mathrm{hr}$ and $24 \mathrm{hr}$ treatment times. The Alcalase-Carbopol nanogels also showed negligible cytotoxicity and apoptosis inducing influence towards adult human keratinocytes. We conclude that the Alcalase-coated and ciprofloxacin loaded Carbopol nanogel carrier are an effective and apparently safe anti-biofilm formulation which could provide an alternative approach to treatment of external wound biofilms. We believe further investigation of the practical administration of Acalase-coated Carbopol nanogels loaded with antibiotics on biofilm infected wounds is required, where these nanogels could provide an advantageous tool for therapeutic anti-biofilm treatments and fight against antimicrobial resistance.

\section{ASSOCIATED CONTENT}

In the enclosed electronic supplementary information (ESI) we present the following additional data: (i) Schematic of the enzymatic degradation of peptide bonds in proteins by Alcalase 2.4 L FG; (ii) Comparison between bare Carbopol NPs and Alcalase coated Carbopol Aqua SF1 NPs; (iii) Photographs of Carbopol Aqua SF1, Alcalase 2.4 L FG, and Carbopol Aqua SF1-0.6 Alcalase 2.4 L FG NPs; (iv) Fourier transform infra-red (FTIR) spectra of Carbopol Aqua SF1, Alcalase 2.4 L FG, Ciprofloxacin and Carbopol encapsulated Ciprofloxacin coated with Alcalase NPs; (v) EDS spectra of Carbopol Aqua SF1, Alcalase 2.4 L FG, Ciprofloxacin and 0.6 wt\% Carbopol-0.0032 wt\% Ciprofloxacin-0.6 wt\% Alcalase NPs; (vi) Alcalase enzymatic characteristics; (vii) Enzymatic characteristics of Alcalase; (viii) Biofilm visual score; (ix) Relative activity of free Alcalase vs Alcalase-Carbopol; (x) Qualitative tube method of biofilm formation detection photographs; (xi) Congo Red Agar (CRA) biofilm detection method photographs; (xii) Photographs of 48-well plate biofilms after Crystal Violet staining and washing/drying; (xiii) Photographs of 48-well plate biofilms after Congo Red staining and washing/drying; (xiv) Crystal Violet staining statistical analysis; (xv) Congo Red staining statistical analysis; (xvi) The zeta potential of treated bacterial cells; (xvii) Photographs of $S$. aureus biofilms surface after treated with Resazurin Sodium Salt reagent; (xviii) The concentration of ciprofloxacin encapsulated into 0.6 wt\% Carbopol Aqua SF1 nanogel; (xix) Standard calibration graphs of the absorption vs concentrations of ciprofloxacin hydrochloride; (xx) The size and zeta potential of $0.6 \mathrm{wt} \%$ Carbopol, $0.6 \mathrm{wt} \%$ Carbopol encapsulating $0.0032 \mathrm{wt} \%$ ciprofloxacin and $0.6 \mathrm{wt} \%$ Carbopol encapsulating 0.0032 wt\% ciprofloxacin with 0.6 wt\% Alcalase coating; (xxi) Ciprofloxacin release kinetics; (xxii) Ciprofloxacin MIC ETEST®; (xxiii) Calibration curve of HaCaT cells; (xxiv) HaCaT cell status after 24 hours of treatment; (xxv) Photographs of HaCaT cells; (xxvi) Elemental analysis of Carbopol Aqua SF1, Alcalase 2.4 L FG, Ciprofloxacin, and Ciprofloxacin-loaded Carbopol nanogel coated with Alcalase 2.4 L FG; (xxvii) Cell status of HaCaT cells measured using FITC Annexin staining kit and FACS; (xxviii) Statistical analysis of free ciprofloxacin vs encapsulated ciprofloxacin

\section{AUTHOR INFORMATION}

Corresponding Author

* Phone +44 1482 465660. Email : V.N.Paunov@hull.ac.uk

\section{ORCID}

Paul J. Weldrick: $\quad$ 0000-0002-1791-5659

Matthew J. Hardman: 0000-0002-6423-5074

Vesselin N. Paunov: 0000-0001-6878-1681

\section{Author Contributions}

The manuscript was written through contributions of all authors. All experiments were performed by P.J.W. All authors have given approval to the final version of the manuscript.

\section{Funding Sources}

P. J. W. acknowledges the University of Hull for the PhD studentship as part of its Advanced Wound Care PhD cluster.

\section{ACKNOWLEDGMENTS}

P. J. W. acknowledges the University of Hull for the PhD studentship as part of its Advanced Wound Care PhD cluster. The authors would like to thank SEM technician Tim Dunstan and TEM technician Ann Lowry (University of Hull) with their assistance during this project. 


\section{ABBREVIATIONS}

EPS, extracellular polymeric substance: MHB, Mueller Hilton Broth: MHA, Mueller Hilton agar: CFU, colony forming unit: SEM, Scanning electron microscope: TEM, Transmission electron microscope: AFM, Atomic force microscope.

\section{REFERENCES}

(1) Leroy, C.; Delbarre, C.; Ghillebaert, F.; Compere, C.; Combes, D. Effects Of Commercial Enzymes On The Adhesion Of A Marine Biofilm-Forming Bacterium. Biofouling 2008, 24, 11-22.

(2) Choong, F.; Bäck, M.; Fahlén, S.; Johansson, L.; Melican, K.; Rhen, M.; Nilsson, K.; Richter-Dahlfors, A. Real-Time Optotracing Of Curli And Cellulose In Live Salmonella Biofilms Using Luminescent Oligothiophenes. npj Biofilms and Microbiomes 2016, 2, 16024.1-11.

(3) Kostakioti, M.; Hadjifrangiskou, M.; Hultgren, S. Bacterial Biofilms: Development, Dispersal, And Therapeutic Strategies In The Dawn Of The Postantibiotic Era. Cold Spring Harbor Perspectives in Medicine 2013, 3, a 010306.1-21

(4) Richards, J.; Melander, C. Controlling Bacterial Biofilms. ChemBioChem 2009, 10, 2287-2294.

(5) Kim, L.; Pagaling, E.; Zuo, Y.; Yan, T. Impact Of Substratum Surface On Microbial Community Structure And Treatment Performance In Biological Aerated Filters. Applied and Environmental Microbiology, 2013, 80, 177-183.

(6) Algburi, A.; Comito, N.; Kashtanov, D.; Dicks, L.; Chikindas, M. Erratum For Algburi Et Al., Control Of Biofilm Formation: Antibiotics And Beyond. Applied and Environmental Microbiology, 2017, 83, 2508-2516.

(7) Domenech, M.; Ramos-Sevillano, E.; García, E.; Moscoso, M.; Yuste, J. Biofilm Formation Avoids Complement Immunity And Phagocytosis Of Streptococcus Pneumoniae. Infection and Immunity, 2013, 81, 2606-2615.

(8) Sharma, D.; Misba, L.; Khan, A. Antibiotics Versus Biofilm: An Emerging Battleground In Microbial Communities. Antimicrobial Resistance \& Infection Control, 2019, 8, 76.1-10. DOI: 10.1186/s13756-019-0533-3.

(9) Singh, S.; Singh, S.; Chowdhury, I.; Singh, R. Understanding The Mechanism Of Bacterial Biofilms Resistance To Antimicrobial Agents. The Open Microbiology Journal 2017, 11, 53-62.

(10) Nocelli, N.; Bogino, P.; Banchio, E.; Giordano, W. Roles Of Extracellular Polysaccharides And Biofilm Formation In Heavy Metal Resistance Of Rhizobia. Materials, 2016, 9, 418.1-19.

(11) Gupta, P.; Diwan, B. Bacterial Exopolysaccharide Mediated Heavy Metal Removal: A Review On Biosynthesis, Mechanism And Remediation Strategies. Biotechnology Reports, 2017, 13, 58-71.

(12) Halbus, A.; Horozov, T.; Paunov, V. Controlling The Antimicrobial Action Of Surface Modified Magnesium Hydroxide Nanoparticles. Biomimetics 2019, 4, 41.

(13) Halbus, A.; Horozov, T.; Paunov, V. Self-Grafting Copper Oxide Nanoparticles Show A Strong Enhancement Of Their Anti-Algal And Anti-Yeast Action. Nanoscale Adv. 2019, 1, 23232336.

(14) Al-Obaidy, S.; Halbus, A.; Greenway, G.; Paunov, V. Boosting The Antimicrobial Action Of Vancomycin Formulated In Shellac Nanoparticles Of Dual-Surface Functionality. Journal of Materials Chemistry B 2019, 7, 3119-3133.

(15) Halbus, A.; Horozov, T.; Paunov, V. Strongly Enhanced Antibacterial Action Of Copper Oxide Nanoparticles With Boronic
Acid Surface Functionality. ACS Applied Materials \& Interfaces 2019, 11, 12232-12243.

(16) Yang, L.; Liu, Y.; Wu, H.; Song, Z.; Høiby, N.; Molin, S.; Givskov, M. Combating Biofilms. FEMS Immunology \& Medical Microbiology 2012, 65, 146-157.

(17) Donlan, R. Biofilms: Microbial Life On Surfaces. Emerging Infectious Diseases, 2002, 8, 881-890.

(18) Costerton, J.; Stewart, P.; Greenberg, E. Bacterial Biofilms: A Common Cause Of Persistent Infections. Science 1999, 284, 1318-1322.

(19) Rogers, S.; Huigens, R.; Cavanagh, J.; Melander, C. Synergistic Effects Between Conventional Antibiotics And 2-Aminoimidazole-Derived Antibiofilm Agents. Antimicrobial Agents and Chemotherapy 2010, 54, 2112-2118.

(20) Al-Obaidy, S.; Greenway, G.; Paunov, V. Dual-Functionalised Shellac Nanocarriers Give A Super-Boost Of The Antimicrobial Action Of Berberine. Nanoscale Advances, 2019, 1, 858-872.

(21) Newase, S.; Bankar, A. Synthesis Of Bio-Inspired Ag-Au Nanocomposite And Its Anti-Biofilm Efficacy. Bulletin of Materials Science 2017, 40, 157-162.

(22) Markowska, K.; Grudniak, A.; Wolska, K. Silver Nanoparticles As An Alternative Strategy Against Bacterial Biofilms. Acta Biochimica Polonica 2013, 60, 523-530.

(23) Pastore, C. Piercing The Biofilm. Nature Nanotechnology 2018, 13, 1092-1092.

(24) Wilkinson, H.; Iveson, S.; Catherall, P.; Hardman, M. A Novel Silver Bioactive Glass Elicits Antimicrobial Efficacy Against Pseudomonas Aeruginosa And Staphylococcus Aureus In An Ex Vivo Skin Wound Biofilm Model. Frontiers in Microbiology 2018, 9, 1450.

(25) Singh, R.; Kumar, M.; Mittal, A.; Mehta, P. Microbial Enzymes: Industrial Progress In 21St Century. 3 Biotech 2016, 6, 174.

(26) Blackledge, M.; Worthington, R.; Melander, C. Biologically Inspired Strategies For Combating Bacterial Biofilms. Current Opinion in Pharmacology 2013, 13, 699-706.

(27) Kaplan, J. Biofilm Dispersal: Mechanisms, Clinical Implications, And Potential Therapeutic Uses. Journal of Dental Research 2010, 89, 205-218.

(28) Donelli, G.; Francolini, I.; Romoli, D.; Guaglianone, E.; Piozzi, A.; Ragunath, C.; Kaplan, J. Synergistic Activity Of Dispersin B And Cefamandole Nafate In Inhibition Of Staphylococcal Biofilm Growth On Polyurethanes. Antimicrobial Agents and Chemotherapy 2007, 51, 2733-2740.

(29) Darouiche, R.; Mansouri, M.; Gawande, P.; Madhyastha, S. Antimicrobial And Antibiofilm Efficacy Of Triclosan And Dispersinb(R) Combination. Journal of Antimicrobial Chemotherapy 2009, 64, 88-93.

(30) Alkawash, M.; Soothill, J.; Sshiller, N. Alginate Lyase Enhances Antibiotic Killing Of Mucoid Pseudomonas Aeruginosa In Biofilms. APMIS 2006, 114, 131-138.

(31) Nijland, R.; Hall, M.; Burgess, J. Dispersal Of Biofilms By Secreted, Matrix Degrading, Bacterial Dnase. PLoS ONE 2010, 5 , e15668.

(32) Theron, L.; Divol, B. Microbial Aspartic Proteases: Current And Potential Applications In Industry. Applied Microbiology and Biotechnology 2014, 98, 8853-8868.

(33) Baidamshina, D.; Trizna, E.; Holyavka, M.; Bogachev, M.; Artyukhov, V.; Akhatova, F.; Rozhina, E.; Fakhrullin, R.; Kayumov, A. Targeting Microbial Biofilms Using Ficin, A Nonspecific Plant Protease. Scientific Reports 2017, 7, 46068. DOI: $10.1038 /$ srep46068. 
(34) Mitrofanova, O.; Mardanova, A.; Evtugyn, V.; Bogomolnaya, L.; Sharipova, M. Effects Of Bacillus Serine Proteases On The Bacterial Biofilms. BioMed Research International 2017, 2017, 110.

(35) Singh, S.; Bajaj, B. Medium Optimization For Enhanced Production Of Protease With Industrially Desirable Attributes Frombacillus Subtilisk-1. Chemical Engineering Communications 2014, 202, 1051-1060.

(36) Singh, S.; Bajaj, B. Bioprocess Optimization For Production Of Thermoalkali-Stable Protease Frombacillus Subtilisk-1 Under Solid-State Fermentation. Preparative Biochemistry and Biotechnology 2016, 46, 717-724.

(37) Borovička, J.; Metheringham, W.; Madden, L.; Walton, C.; Stoyanov, S.; Paunov, V. Photothermal Colloid Antibodies For Shape-Selective Recognition And Killing Of Microorganisms. J. Amer. Chem. Soc. 2013, 135, 5282-5285.

(38) Veloorvalappil, J.; Robinson, B.; Selvanesan, P.; Sasidharan, S.; Kizhakkepawothail, U.; Sreedharan, S.; Prakasan, P.; Moolakkariyil, J.; Sailas, B. Versatility Of Microbial Proteases. Advances in Enzyme Research, 2013, 1, 39-51.

(39) Schallenberger, M.; Niessen, S.; Shao, C.; Fowler, B.; Romesberg, F. Type I Signal Peptidase And Protein Secretion In Staphylococcus Aureus. J. Bacteriology 2012, 194, 26772686.

(40) Thallinger, B.; Prasetyo, E.; Nyanhongo, G.; Guebitz, G. Antimicrobial Enzymes: An Emerging Strategy To Fight Microbes And Microbial Biofilms. Biotechnology Journal 2013, 8, 97 109.

(41) Ramasamy, M.; Lee, J. Recent Nanotechnology Approaches For Prevention And Treatment Of Biofilm-Associated Infections On Medical Devices. BioMed Research Internat., 2016, 2016, 117.

(42) Park, J.; Lee, J.; Cho, M.; Herzberg, M.; Lee, J. Acceleration Of Protease Effect On Staphylococcus Aureus Biofilm Dispersal. FEMS Microbiology Letters 2012, 335, 31-38.

(43) Lequette, Y.; Boels, G.; Clarisse, M.; Faille, C. Using Enzymes To Remove Biofilms Of Bacterial Isolates Sampled In The FoodIndustry. Biofouling 2010, 26, 421-431.

(44) Boles, B.; Horswill, A. Staphylococcal Biofilm Disassembly. Trends in Microbiology 2011, 19, 449-455.

(45) Borovicka, J.; Stoyanov, S.; Paunov, V. Nanoantibiotic Particles For Shape And Size Recognition Of Pathogens. MRS Proceedings 2013, 1498, 127-132.

(46) Borovička, J.; Stoyanov, S.; Paunov, V. Cell Shape Recognition By Colloidal Cell Imprints: Energy Of The Cell-Imprint Interaction. Physical Review E, 2015, 92, 032730. DOI: 10.1103/physreve.92.032730.

(47) Tsang, L.; Cassat, J.; Shaw, L.; Beenken, K.; Smeltzer, M. Factors Contributing To The Biofilm-Deficient Phenotype Of Staphylococcus Aureus Sara Mutants. PLoS ONE 2008, 3, e3361.

(48) Mateo, C.; Palomo, J.; Fernandez-Lorente, G.; Guisan, J.; Fernandez-Lafuente, R. Improvement Of Enzyme Activity, Stability And Selectivity Via Immobilization Techniques. Enzyme and Microbial Technology 2007, 40, 1451-1463.

(49) Corîci, L.; Frissen, A.; van Zoelen, D.; Eggen, I.; Peter, F.; Davidescu, C.; Boeriu, C. Sol-Gel Immobilization Of Alcalase From Bacillus Licheniformis For Application In The Synthesis Of C-Terminal Peptide Amides. Journal of Molecular Catalysis B: Enzymatic 2011, 73, 90-97.

(50) Rodrigues, R.; Ortiz, C.; Berenguer-Murcia, Á.; Torres, R.; Fernández-Lafuente, R. Modifying Enzyme Activity And Selectivity By Immobilization. Chem. Soc. Rev. 2013, 42, 6290-6307.
(51) Tang, Z.; Qian, J.; Shi, L. Characterizations Of Immobilized Neutral Proteinase On Chitosan Nano-Particles. Process Biochemistry 2006, 41, 1193-1197.

(52) Wang, S.; Zhang, C.; Qi, B.; Sui, X.; Jiang, L.; Li, Y.; Wang, Z.; Feng, H.; Wang, R.; Zhang, Q. Immobilized Alcalase Alkaline Protease On The Magnetic Chitosan Nanoparticles Used For Soy Protein Isolate Hydrolysis. European Food Research and Technology 2014, 239, 1051-1059.

(53) Al-Awady, M.; Fauchet, A.; Greenway, G.; Paunov, V. Enhanced Antimicrobial Effect Of Berberine In Nanogel Carriers With Cationic Surface Functionality. J.Mater.Chem.B 2017, 5,78857897.

(54) Al-Awady, M.; Weldrick, P.; Hardman, M.; Greenway, G.; Paunov, V. Amplified Antimicrobial Action Of Chlorhexidine Encapsulated In PDAC-Functionalized Acrylate Copolymer Nanogel Carriers. Mater. Chem. Front. 2018, 2, 2032-2044.

(55) Weldrick, P.; Iveson, S.; Hardman, M.; Paunov, V. Breathing New Life Into Old Antibiotics: Overcoming Antibacterial Resistance By Antibiotic-Loaded Nanogel Carriers With Cationic Surface Functionality. Nanoscale 2019, 11, 10472-10485.

(56) Christensen, G.; Simpson, W.; Bisno, A.; Beachey, E. Adherence of Slime-Producing Strains of Staphylococcus epidermidis to Smooth Surfaces. Infection and immunity, 1982, 37, 318-326.

(57) O'Toole, G. Microtiter Dish Biofilm Formation Assay. Journal of Visualized Experiments, 2011, 47, 2437. DOI; $10.3791 / 2437$.

(58) Wilkinson, H.; McBain, A.; Stephenson, C.; Hardman, M. Comparing The Effectiveness Of Polymer Debriding Devices Using A Porcine Wound Biofilm Model. Advances in Wound Care 2016, 5, 475-485.

(59) Hoštacká, A.; Čižnár, I.; Štefkovičová, M. Temperature And Ph Affect The Production Of Bacterial Biofilm. Folia Microbiologica 2010, 55, 75-78.

(60) Mendes, A.; de Castro, H.; de S. Rodrigues, D.; Adriano, W.; Tardioli, P.; Mammarella, E.; de C. Giordano, R.; de L. C. Giordano, R. Multipoint Covalent Immobilization Of Lipase On Chitosan Hybrid Hydrogels: Influence Of The Polyelectrolyte Complex Type And Chemical Modification On The Catalytic Properties Of The Biocatalysts. Journal of Industrial Microbiology \& Biotechnology 2010, 38, 1055-1066.

(61) Lister, J.; Horswill, A. Staphylococcus Aureus Biofilms: Recent Developments In Biofilm Dispersal. Frontiers in Cellular and Infection Microbiology 2014, 4, 178.

(62) Freeman, D.; Falkiner, F.; Keane, C. New Method For Detecting Slime Production By Coagulase Negative Staphylococci. Journal of Clinical Pathology 1989, 42, 872-874.

(63) Lequette, Y.; Boels, G.; Clarisse, M.; Faille, C. Using Enzymes To Remove Biofilms Of Bacterial Isolates Sampled In The FoodIndustry. Biofouling 2010, 26, 421-431.

(64) Halbus, A.; Horozov, T.; Paunov, V. "Ghost" Silica Nanoparticles Of "Host"-Inherited Antibacterial Action. ACS Applied Materials \& Interfaces 2019, 11 (42), 38519-38530.

(65) Pavlukhina, S.; Kaplan, J.; Xu, L.; Chang, W.; Yu, X.; Madhyastha, S.; Yakandawala, N.; Mentbayeva, A.; Khan, B.; Sukhishvili, S. Noneluting Enzymatic Antibiofilm Coatings. ACS Applied Materials \& Interfaces 2012, 4, 4708-4716.

(66) Thallinger, B.; Prasetyo, E.; Nyanhongo, G.; Guebitz, G. Antimicrobial Enzymes: An Emerging Strategy To Fight Microbes And Microbial Biofilms. Biotechnology Journal 2013, 8, $97-$ 109. 
(67) Markland Jr, F.; Smith, E. Subtilisins: Primary Structure, Chemical and Physical Properties, The Enzymes, 1971, 3, 561608.

(68) Metcalf, D.; Bowler, P. Biofilm Delays Wound Healing: A Review Of The Evidence. Burns \& Trauma 2013, 1 (1), 5.

(69) Schultz, G.; Woo, K.; Weir, D.; Yang, Q. Effectiveness Of A Monofilament Wound Debridement Pad At Removing Biofilm And Slough: Ex Vivo And Clinical Performance. Journal of Wound Care 2018, 27 (2), 80-90.

(70) Omar, A.; Wright, J.; Schultz, G.; Burrell, R.; Nadworny, P. Microbial Biofilms And Chronic Wounds. Microorganisms 2017, 5 (1), 9.

(71) Johani, K.; Malone, M.; Jensen, S.; Dickson, H.; Gosbell, I.; Hu, H.; Yang, Q.; Schultz, G.; Vickery, K. Evaluation Of Short Exposure Times Of Antimicrobial Wound Solutions Against Microbial Biofilms: From In Vitro To In Vivo. Journal of Antimicrobial Chemotherapy 2017, 73 (2), 494-502.

(72) Vermeulen, H.; Westerbos, S.; Ubbink, D. Benefit And Harm Of Iodine In Wound Care: A Systematic Review. Journal of Hospital Infection 2010, 76 (3), 191-199.
(73) Bigliardi, P.; Alsagoff, S.; El-Kafrawi, H.; Pyon, J.; Wa, C.; Villa, M. Povidone Iodine In Wound Healing: A Review Of Current Concepts And Practices. International Journal of Surgery 2017, 44, 260-268.

(74) Percival, S.; Finnegan, S.; Donelli, G.; Vuotto, C.; Rimmer, S.; Lipsky, B. Antiseptics For Treating Infected Wounds: Efficacy On Biofilms And Effect Of pH. Critical Reviews in Microbiology 2014, 42 (2), 293-309.

(75) Edmiston, C., Bruden, B., Rucinski, M., Henen, C., Graham, M. \& Lewis, B. Reducing the risk of surgical site infections: Does chlorhexidine gluconate provide a risk reduction benefit? American Journal of Infection Control, 2013, 41(5), 49-55.

\section{Table of Contents artwork}

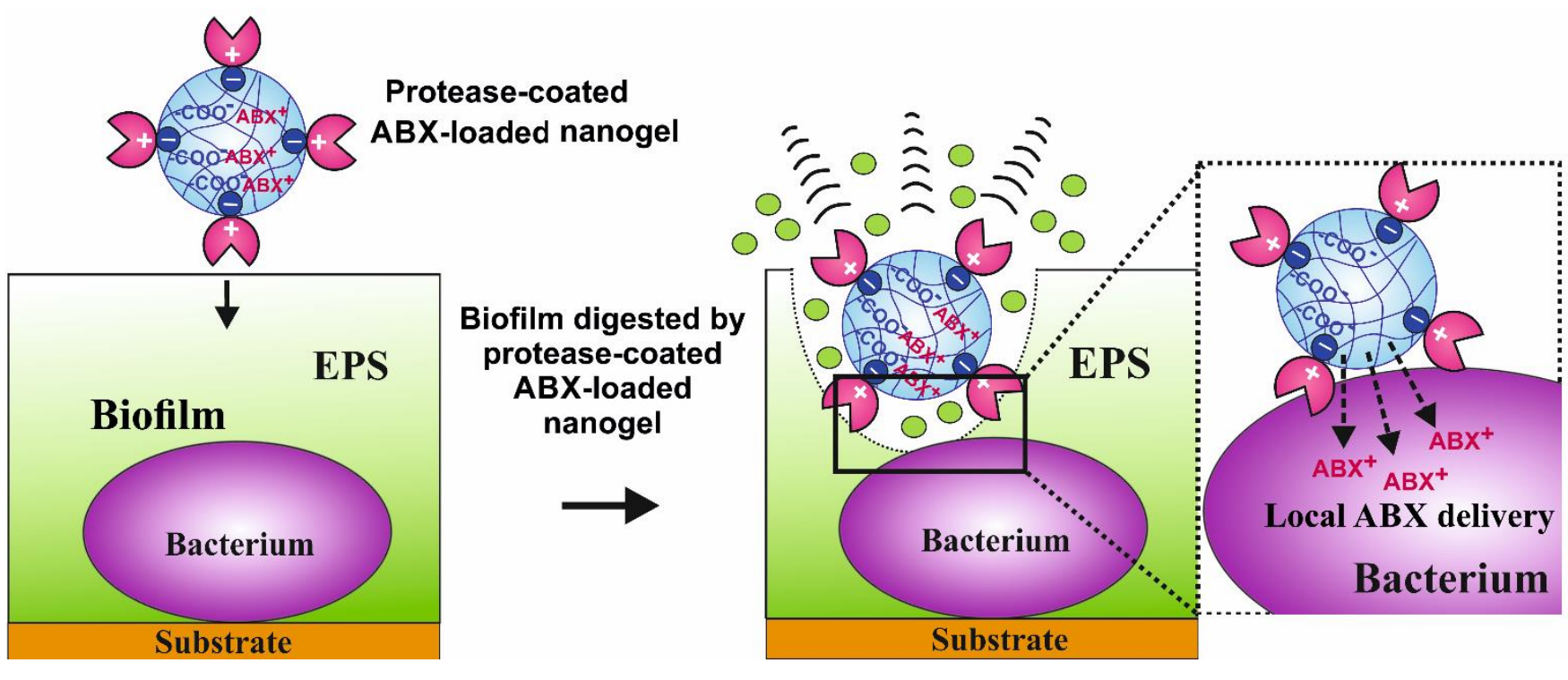




\title{
Supporting Information
}

\section{Enhanced Clearing of Wound Related Pathogenic Bacterial Biofilms Using Protease-Functionalized Antibiotic Nanocarriers}

\author{
Paul J. Weldrick, ${ }^{a}$ Matthew J. Hardman ${ }^{b}$ and Vesselin N. Paunov*a \\ ${ }^{a}$ Department of Chemistry and Biochemistry, University of Hull, Cottingham Road, Hull, UK \\ ${ }^{b}$ Centre for Atherothrombosis and Metabolic Disease, Hull York Medical School, Hull, UK \\ *Corresponding author: E-mail: v.n.paunov@hull.ac.uk, Phone: +44 (0)1482 465660
}

(ACS Appl. Mater. Interf. 2019)

\begin{tabular}{|c|c|c|}
\hline & Contents & $\begin{array}{l}\text { Page } \\
\text { number }\end{array}$ \\
\hline $\mathbf{i}$ & Schematic of the enzymatic degradation of peptide bonds in proteins by Alcalase 2.4 L FG & 2 \\
\hline ii & Comparison between bare Carbopol NPs and Alcalase coated Carbopol Aqua SF1 NPs & 2 \\
\hline iii & $\begin{array}{l}\text { Photographs of Carbopol Aqua SF1, Alcalase 2.4 L FG, and Carbopol Aqua SF1-0.6 Alcalase } 2.4 \\
\text { L FG NPs }\end{array}$ & 3 \\
\hline iv & $\begin{array}{l}\text { Fourier transform infra-red (FTIR) spectra of Carbopol Aqua SF1, Alcalase 2.4 L FG, Ciprofloxacin and } \\
\text { Carbopol encapsulated Ciprofloxacin coated with Alcalase NPs }\end{array}$ & 4 \\
\hline $\mathbf{v}$ & $\begin{array}{l}\text { EDX spectra of Carbopol Aqua SF1, Alcalase } 2.4 \text { L FG, Ciprofloxacin and } 0.6 \text { wt\% Carbopol- } \\
0.0032 \text { wt\% Ciprofloxacin-0.6 wt\% Alcalase NPs }\end{array}$ & 5 \\
\hline vi & Alcalase enzymatic characteristics & 5 \\
\hline vii & Enzymatic characteristics of Alcalase & 6 \\
\hline viii & Biofilm visual score & 6 \\
\hline ix & Relative activity of free Alcalase vs Alcalase-Carbopol & 6 \\
\hline $\mathbf{x}$ & Qualitative tube method of biofilm formation detection photographs & 7 \\
\hline $\mathbf{x i}$ & Congo Red Agar (CRA) biofilm detection method photographs & 7 \\
\hline xii & Photographs of 48-well plate biofilms after Crystal Violet staining and washing/drying & 8 \\
\hline xiii & Photographs of 48 -well plate biofilms after Congo Red staining and washing/drying & 9 \\
\hline xiv & Crystal Violet staining statistical analysis & 10 \\
\hline $\mathbf{x v}$ & Congo Red staining statistical analysis & 10 \\
\hline xvi & The zeta potential of treated bacterial cells & 11 \\
\hline xvii & Photographs of S. aureus biofilms surface after treated with Resazurin Sodium Salt reagent & 12 \\
\hline xviii & The concentration of ciprofloxacin encapsulated into 0.6 wt\% Carbopol Aqua SF1 nanogel & 12 \\
\hline xix & Standard calibration graphs of the absorption vs concentrations of ciprofloxacin hydrochloride & 13 \\
\hline $\mathbf{x x}$ & $\begin{array}{l}\text { The size and zeta potential of } 0.6 \text { wt\% Carbopol, } 0.6 \text { wt } \% \text { Carbopol encapsulating } 0.0032 \text { wt\% } \\
\text { ciprofloxacin and } 0.6 \text { wt\% Carbopol encapsulating } 0.0032 \text { wt\% ciprofloxacin with } 0.6 \text { wt } \% \\
\text { Alcalase coating }\end{array}$ & 13 \\
\hline xxi & Ciprofloxacin release kinetics & 14 \\
\hline xxii & Ciprofloxacin MIC ETEST ${ }^{\circledR}$ & 14 \\
\hline xxiii & Calibration curve of HaCaT cells. & 15 \\
\hline xxiv & HaCaT cell status after 24 hours of treatment & 15 \\
\hline $\mathbf{x x v}$ & Photographs of HaCaT cells & 16 \\
\hline xxvi & $\begin{array}{l}\text { Elemental analysis of Carbopol Aqua SF1, Alcalase } 2.4 \text { L FG, Ciprofloxacin, and Ciprofloxacin- } \\
\text { loaded Carbopol nanogel coated with Alcalase } 2.4 \text { L FG }\end{array}$ & 17 \\
\hline xxvii & Cell status of HaCaT cells measured using FITC Annexin staining kit and FACS & 17 \\
\hline xxviii & Statistical analysis of free ciprofloxacin vs encapsulated ciprofloxacin & 17 \\
\hline
\end{tabular}




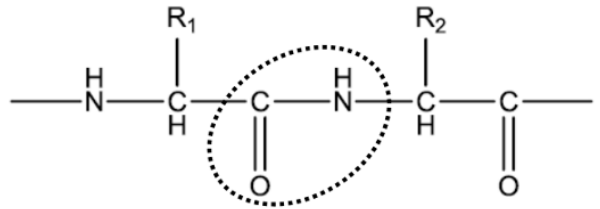

Peptide bond
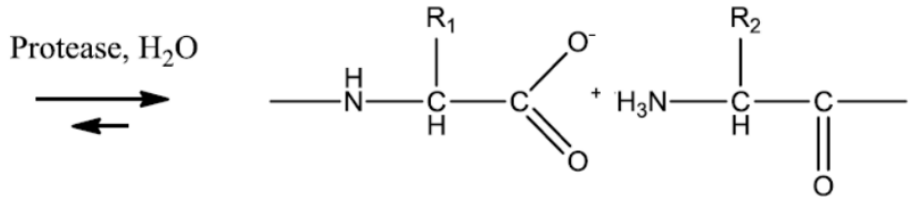

Hydrolysed amino acid chain

Figure S1. Schematic of the enzymatic degradation of peptide bonds in proteins by Alcalase 2.4 L FG. Alcalase 2.4 L FG acts as a hydrolases cleaving peptide chains. It also acts as esterase, enabling it to catalyse stereo-selective hydrolysis of some esters including carboxylic esters and amino esters.
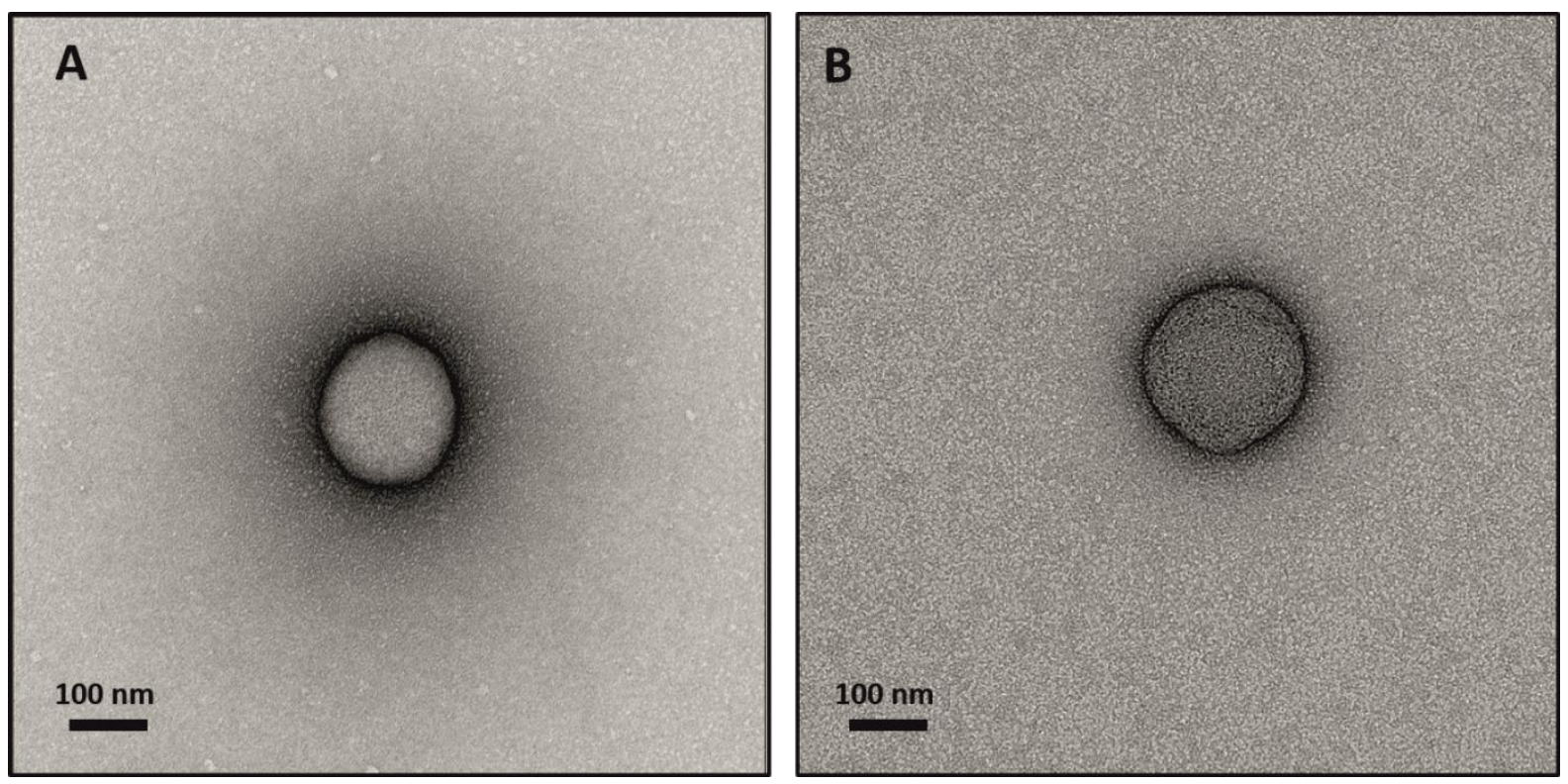

Figure S2. TEM images showing the comparison between (A) bare Carbopol Aqua SF1 nanogel particles and (B) Alcalase 2.4 L FG-coated Carbopol Aqua SF1 nanogel particles. As shown in the images, the coated NPs have a slight grainy and irregular surface texture caused by the coating with the protease. The coated NPs are also slight larger which is consistence with measurement taken by the Zetasizer Nano ZS. 

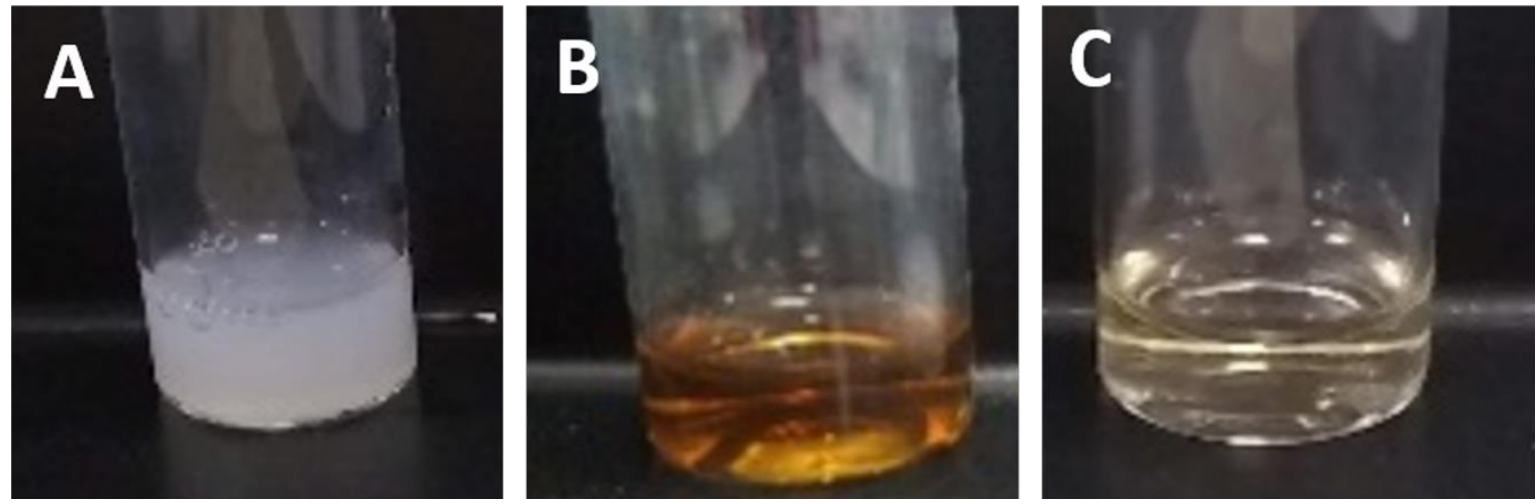

Figure S3. Photographs of (A) 0.6 wt Carbopol Aqua SF1, (B) $0.6 \mathrm{wt} \%$ Alcalase $2.4 \mathrm{~L} \mathrm{FG}$, and (C) $0.6 \mathrm{wt} \%$ Carbopol Aqua SF1-0.6 wt\% Alcalase 2.4 L FG NPs. 


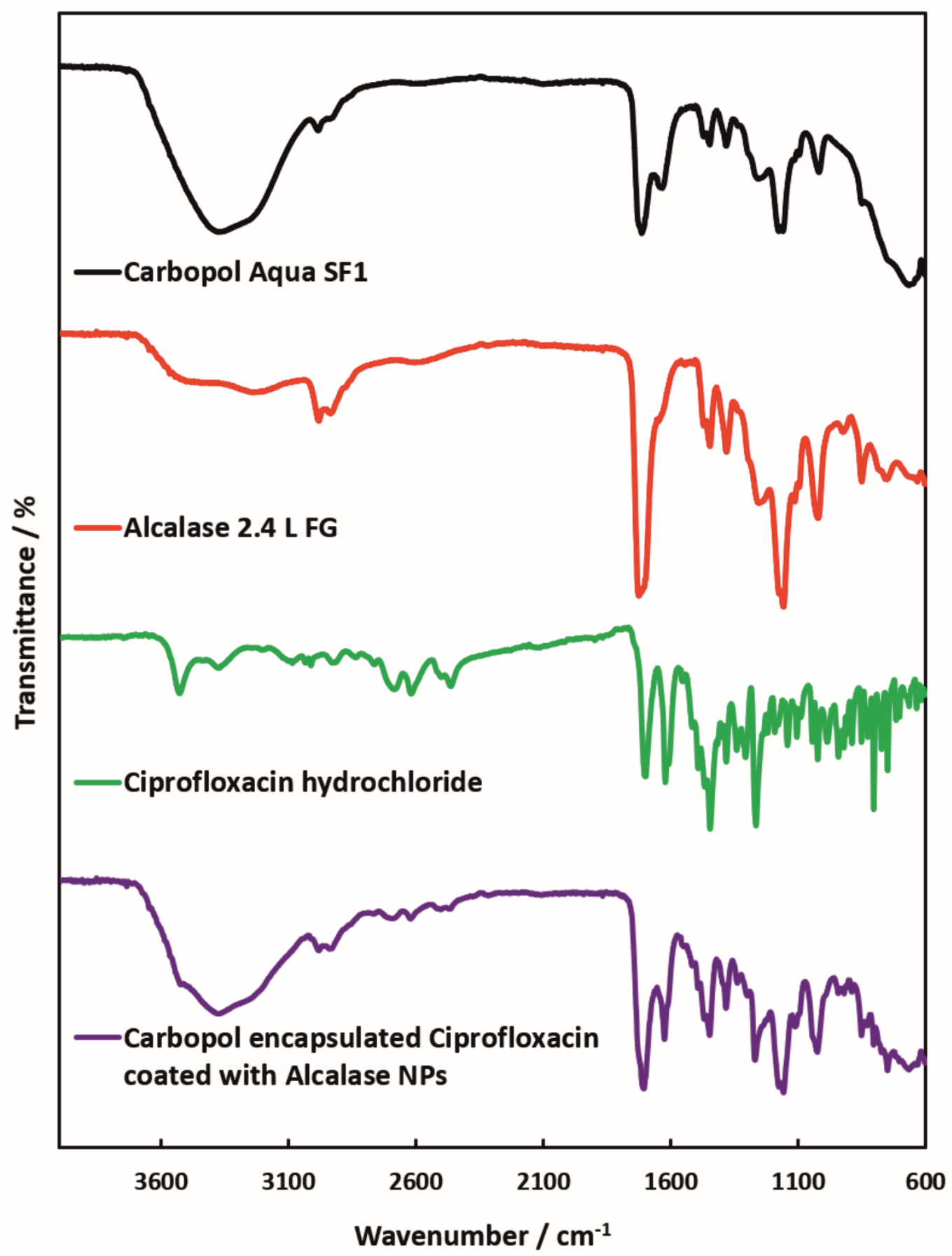

Figure S4. Fourier transform infra-red (FTIR) spectra of Carbopol Aqua SF1, Alcalase 2.4 L FG, Ciprofloxacin and Carbopol encapsulated Ciprofloxacin coated with Alcalase NPs. Samples were prepared by removing water using a Silica gel desiccant by in vacuum chamber for 1 day, then dried at $60^{\circ} \mathrm{C}$ for 2 days. The spectra was measured between $4000-600 \mathrm{~cm}^{-1}$ using PIKE ATR diamond settings. A spectrum was obtained with a blank of just air to reduce transmittance interference with the samples. 

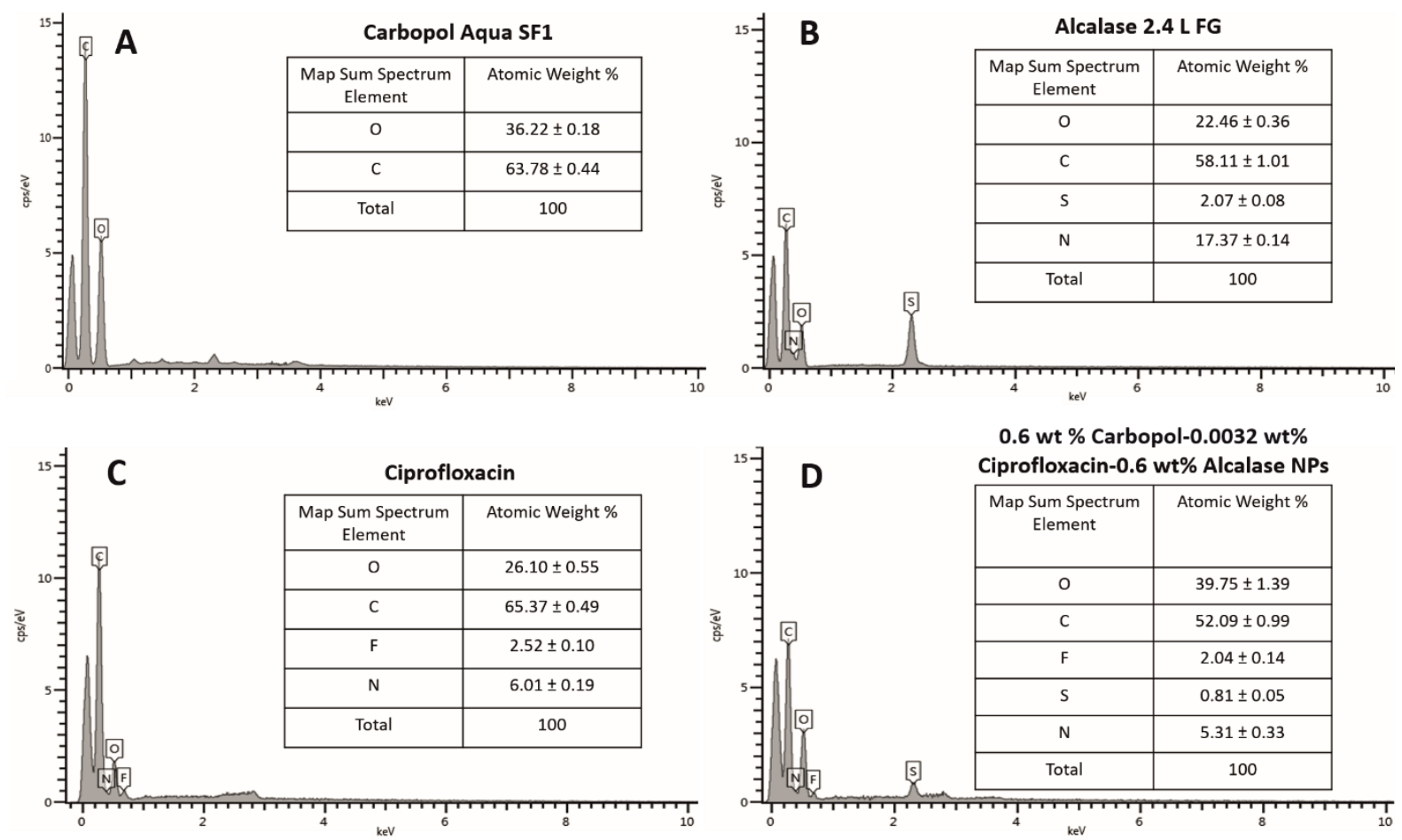

Figure S5. EDX spectra of (A) Carbopol Aqua SF1, (B) Alcalase 2.4 L FG, (C) Ciprofloxacin and (D) 0.6 wt\% Carbopol-0.0032 wt\% Ciprofloxacin-0.6 wt\% Alcalase NPs. The measurement for Carbopol, Alcalase and Ciprofloxacin was taken three separate locations and the data averaged. The measurement for the NP was taken in the centres of three separate NPs and averaged. A Hitachi TM3030Plus and Oxford Laboratories micF+ X-stream-2 EHX was used, and the data analysed using Aztec One v.3.3.
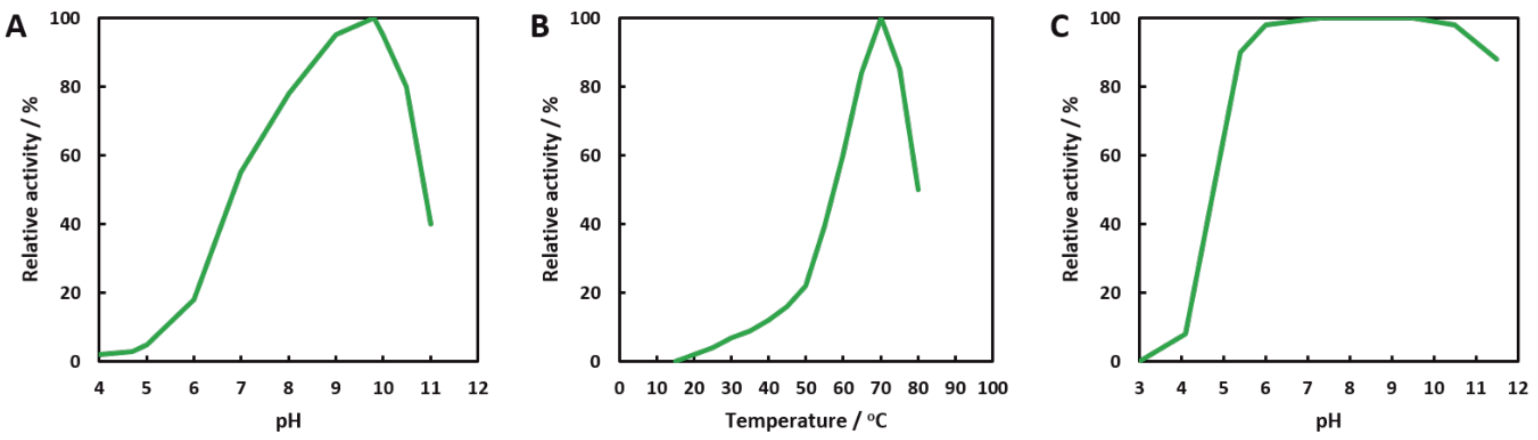

Figure S6. Alcalase 2.4 L FG enzymatic characteristics. (A) Effect of pH on Alcalase activity, (B) effect of temperature on Alcalase activity, (C) effect of $\mathrm{pH}$ on Alcalase stability. (Data obtained from Novozymes ${ }^{\circledR}$ ) 
Table S1. Enzymatic characteristics of Alcalase 2.4 L FG. (Data obtained from Novozymes ${ }^{\circledR}$ )

\begin{tabular}{|c|c|c|c|c|c|c|}
\hline $\begin{array}{c}\text { Product } \\
\text { name }\end{array}$ & $\begin{array}{c}\text { EC } \\
\text { Number }\end{array}$ & Type & Form & $\begin{array}{c}\text { Optimal Usage } \\
\text { Conditions }\end{array}$ & Activity & Applications \\
\hline $\begin{array}{c}\text { Alcalase 2.4 L } \\
\text { FG }\end{array}$ & 3.4 .21 .62 & $\begin{array}{c}\text { Serine endo- } \\
\text { peptidase } \\
\text { (mainly subtilisin } \\
\text { A) }\end{array}$ & Liquid & $30-65^{\circ} \mathrm{C}$ & $\mathrm{pH} 7-9$ & $2.4 \mathrm{AU}-\mathrm{A} / \mathrm{g}$ \\
\hline
\end{tabular}

Table S2. Biofilm formation visual score

\begin{tabular}{|l|l|}
\hline Bacteria Species & Biofilm score \\
\hline S. aureus & 3-strong \\
\hline P. aeruginosa & 3-strong \\
\hline S. epidermidis & 3-strong \\
\hline K. pneumoniae & 2-moderate \\
\hline E. coli & 2-moderate \\
\hline E. faecalis & 1-weak \\
\hline
\end{tabular}

The formation of biofilm by staining of adhered cells was scored as either 0-absent, 1-weak, 2 moderate or 3-strong.
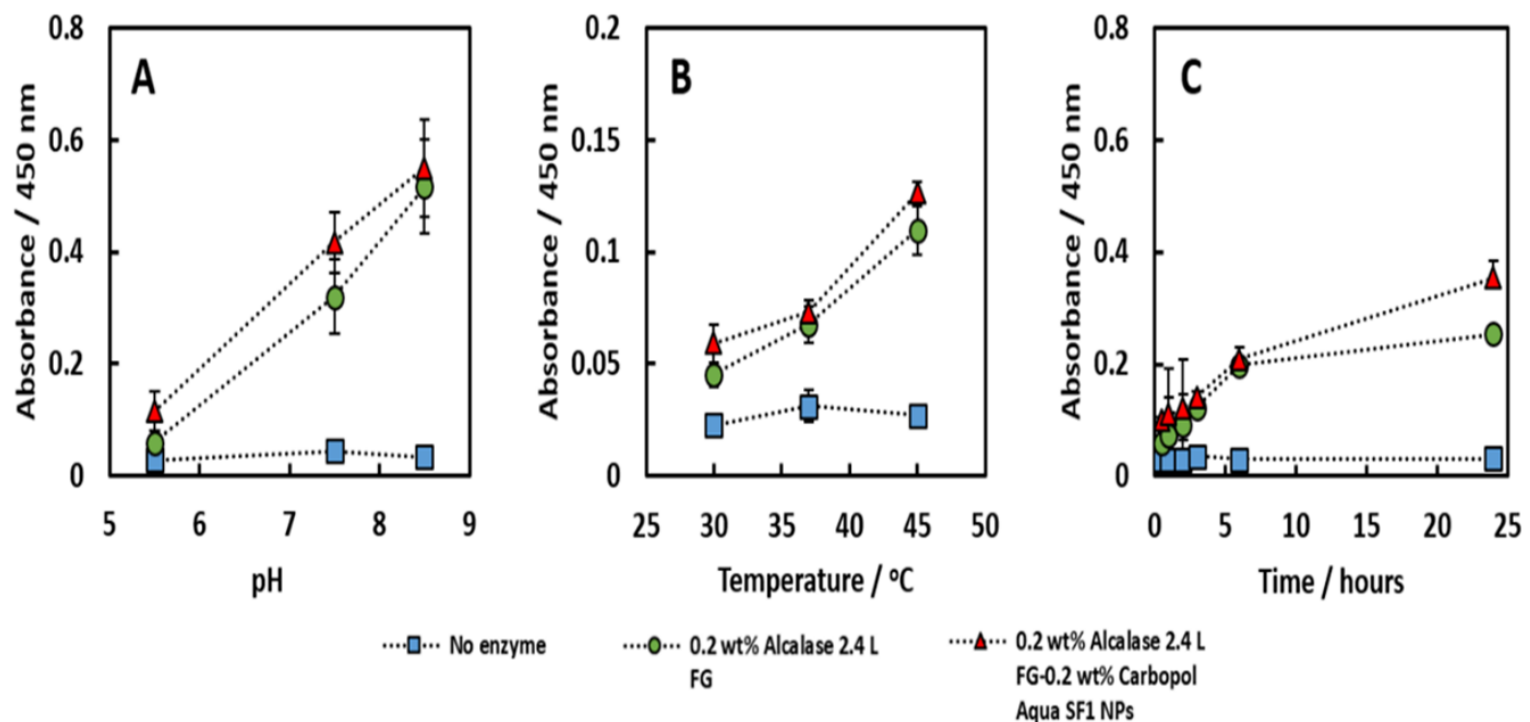

Figure S7. Relative activity of 0.2 wt\% free Alcalase 2.4 L FG vs $0.2 \mathrm{wt} \%$ Alcalase 2.4 L FG- $0.2 \mathrm{wt} \%$ Carbopol Aqua SF1 NPs. (A) shows the effect of pH, (B) temperature, and (C) time. Each value represents a triple replicate with $\pm S$. $D$. The lines are guides to the eye. 
S. aureus

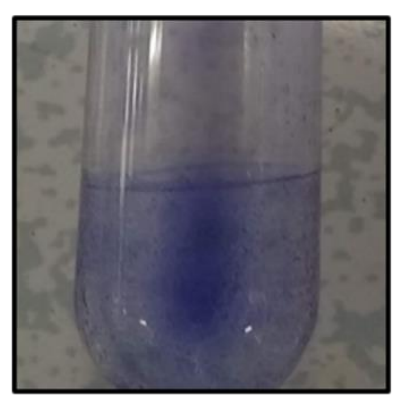

K. pneumoniae

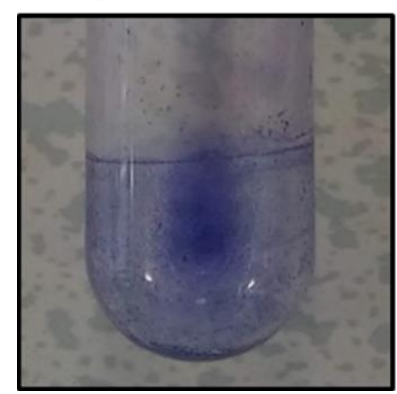

P. aeruginosa

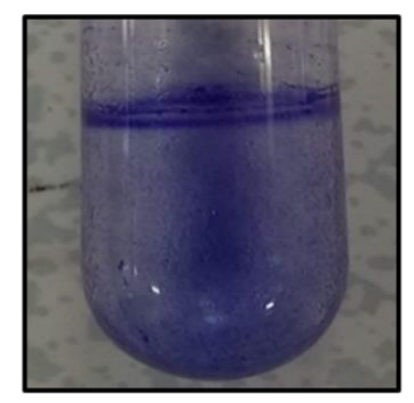

E. coli

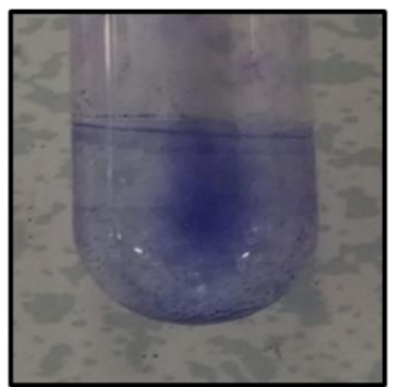

\section{S. epidermidis}

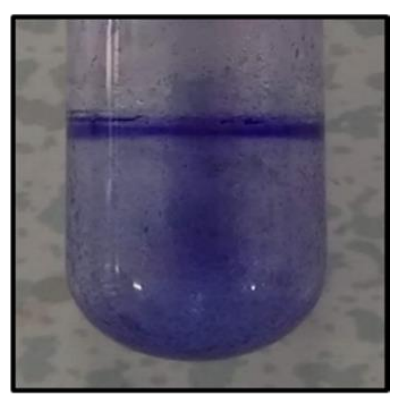

E. faecalis

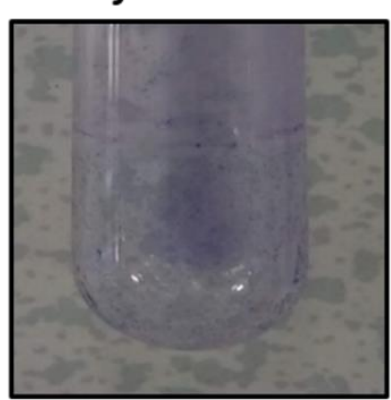

Figure S8. Qualitative tube method of biofilm formation detection photographs. Cells and biofilm mass are stained blue/purple by the Crystal Violet dye.

S. aureus

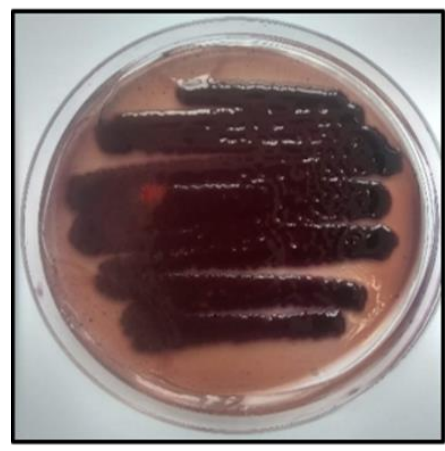

K. pneumoniae

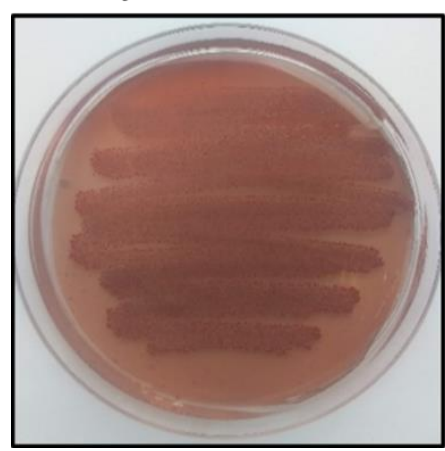

P. aeruginosa

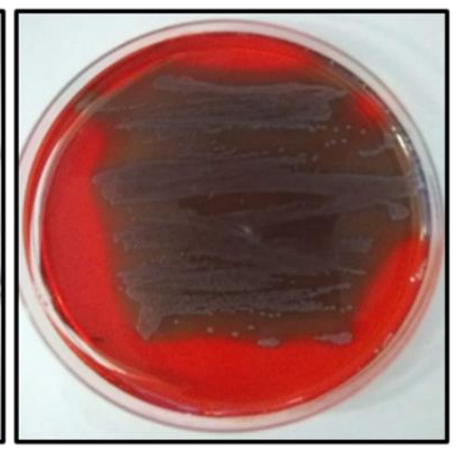

E. faecalis

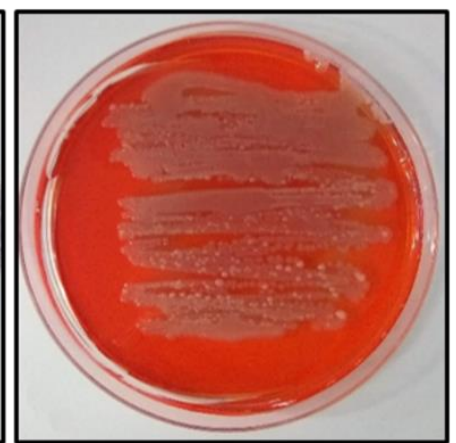

S. epidermidis

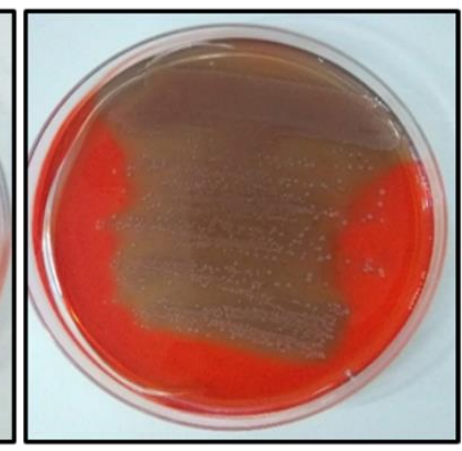

E. coli

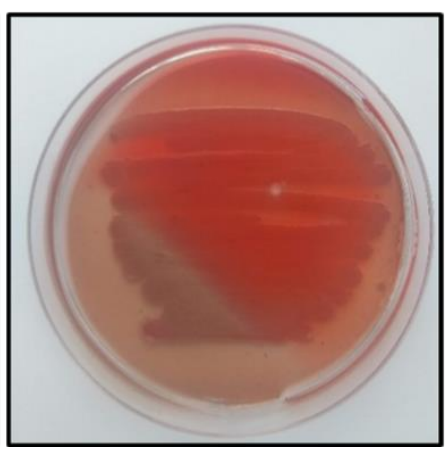

Figure S9. Congo Red Agar (CRA) biofilm detection method photographs. Black colonies indicated the species is a biofilm producer. Agar formulated using $37 \mathrm{~g} / \mathrm{L}$ Brain Heart Infusion agar, $0.8 \mathrm{~g} / \mathrm{L}$ Congo Red, and $6 \mathrm{~g} / \mathrm{L}$ sucrose. CRA has a very low sensitivity compared to other biofilm detection methods such as TM. 


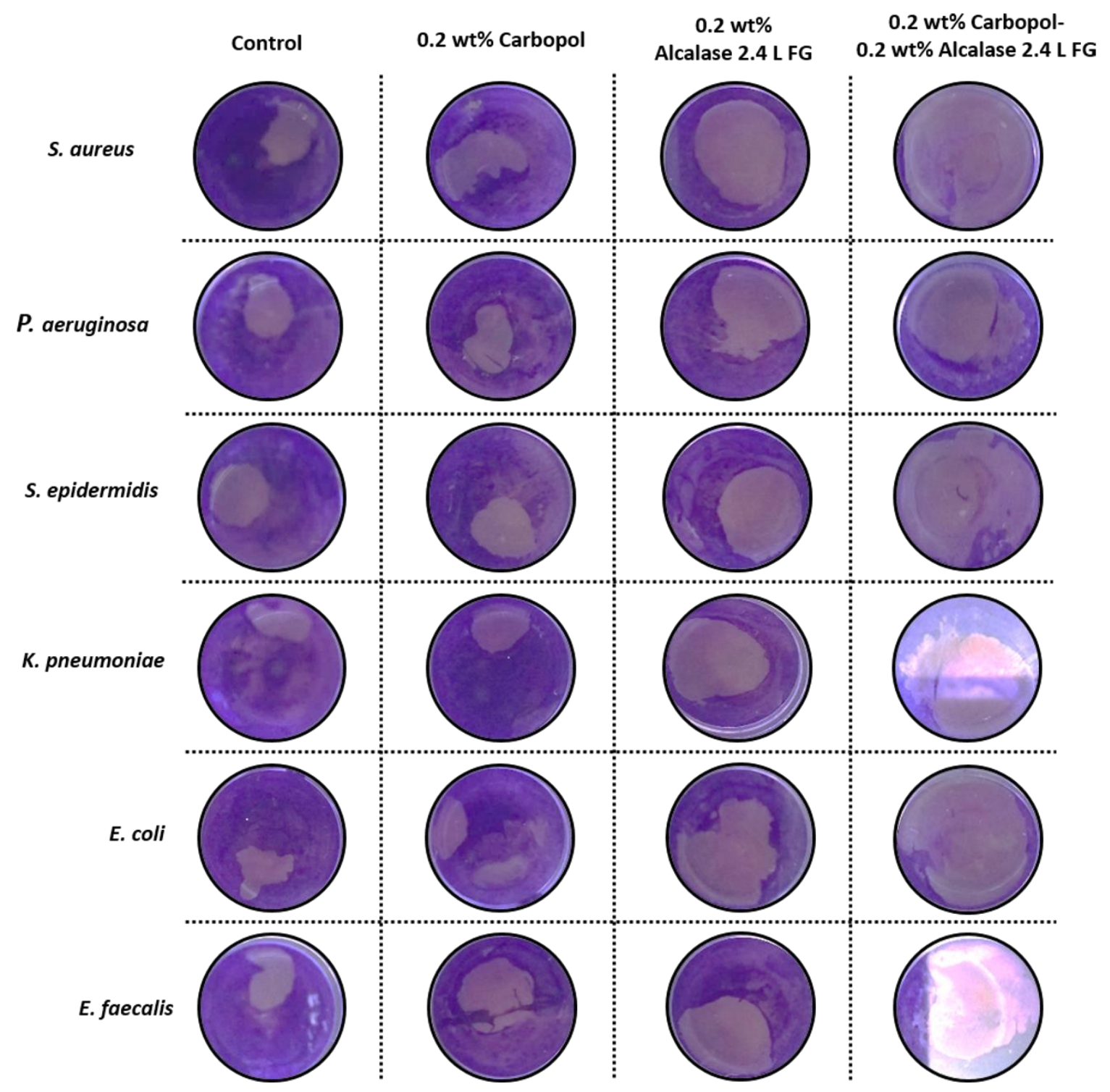

Figure S10. Photographs of 48-well plate biofilms after Crystal Violet staining and washing/drying. 


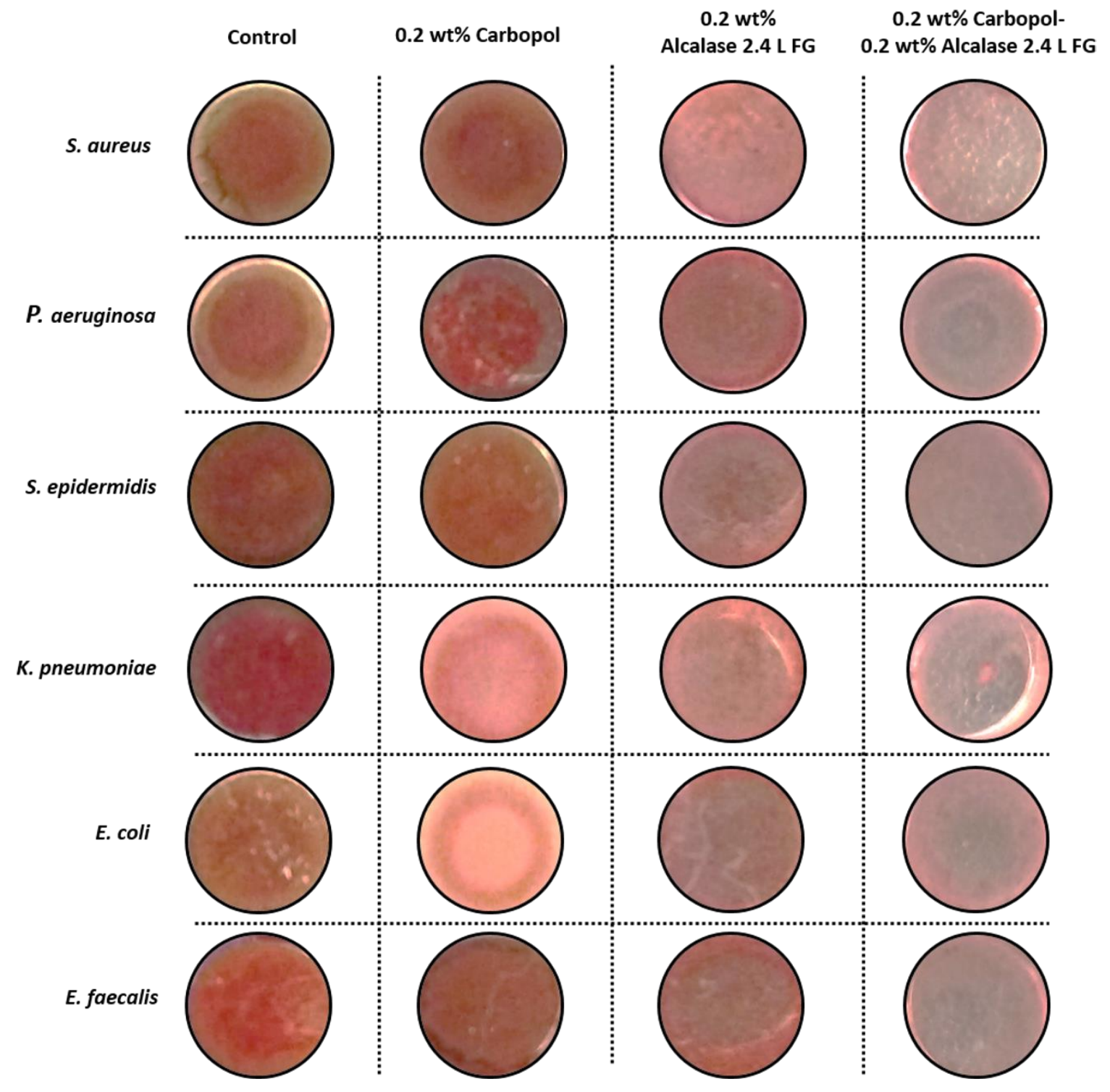

Figure S11. Photographs of 48-well plate biofilms after Congo Red staining and washing/drying. 
Table S3. Crystal Violet staining statistical analysis between $0.2 \mathrm{wt} \%$ Alcalase $2.4 \mathrm{~L} \mathrm{FG}$ and $0.2 \mathrm{wt} \%$ Alcalase 2.4. L FG-0.2 wt\% Carbopol Aqua SF1. Data were expressed as average values \pm standard deviations of the mean. $P$-values of less than 0.05 were considered significant. All Student's T-tests were performed in GraphPad v7.0.4.

\begin{tabular}{|l|l|c|c|}
\hline Species & Multiple Comparison & P-value & Significance \\
\hline S. aureus & $0.2 \mathrm{wt} \%$ Alcalase vs $0.2 \mathrm{wt} \%$ Alcalase-0.2 wt\% Carbopol & 0.015841 & $*$ \\
\hline P. aeruginosa & $0.2 \mathrm{wt} \%$ Alcalase vs $0.2 \mathrm{wt} \%$ Alcalase- $0.2 \mathrm{wt} \%$ Carbopol & 0.000579 & $* * *$ \\
\hline S. epidermidis & $0.2 \mathrm{wt} \%$ Alcalase vs $0.2 \mathrm{wt} \%$ Alcalase- $0.2 \mathrm{wt} \%$ Carbopol & 0.000387 & $* * *$ \\
\hline K. pneumoniae & $0.2 \mathrm{wt} \%$ Alcalase vs $0.2 \mathrm{wt} \%$ Alcalase- $0.2 \mathrm{wt} \%$ Carbopol & 0.014732 & $*$ \\
\hline E. coli & $0.2 \mathrm{wt} \%$ Alcalase vs $0.2 \mathrm{wt} \%$ Alcalase-0.2 $\mathrm{wt} \%$ Carbopol & 0.000264 & $* * *$ \\
\hline E. faecalis & $0.2 \mathrm{wt} \%$ Alcalase vs $0.2 \mathrm{wt} \%$ Alcalase- $0.2 \mathrm{wt} \%$ Carbopol & 0.001023 & $* *$ \\
\hline
\end{tabular}

$<0.05$ is considered significant. ${ }^{*} \mathrm{P}<0.05,{ }^{* *} \mathrm{P}<0.01,{ }^{* * *} \mathrm{P}<0.001$

Table S4. Congo Red staining statistical analysis between $0.2 \mathrm{wt} \%$ Alcalase $2.4 \mathrm{~L}$ FG and $0.2 \mathrm{wt} \%$ Alcalase 2.4. L FG-0.2 wt\% Carbopol Aqua SF1. Data were expressed as average values \pm standard deviations of the mean. $P$-values of less than 0.05 were considered significant. All Student's T-tests were performed in GraphPad v7.0.4.

\begin{tabular}{|l|l|c|c|}
\hline Species & Multiple Comparison & P-value & Significance \\
\hline S. aureus & $0.2 \mathrm{wt} \%$ Alcalase vs $0.2 \mathrm{wt} \%$ Alcalase- $0.2 \mathrm{wt} \%$ Carbopol & 0.00526 & $* *$ \\
\hline P. aeruginosa & $0.2 \mathrm{wt} \%$ Alcalase vs $0.2 \mathrm{wt} \%$ Alcalase- $0.2 \mathrm{wt} \%$ Carbopol & 0.001446 & $* *$ \\
\hline S. epidermidis & $0.2 \mathrm{wt} \%$ Alcalase vs $0.2 \mathrm{wt} \%$ Alcalase- $0.2 \mathrm{wt} \%$ Carbopol & 0.000657 & $* * *$ \\
\hline K. pneumoniae & $0.2 \mathrm{wt} \%$ Alcalase vs $0.2 \mathrm{wt} \%$ Alcalase- $0.2 \mathrm{wt} \%$ Carbopol & 0.007448 & $* *$ \\
\hline E. coli & $0.2 \mathrm{wt} \%$ Alcalase vs $0.2 \mathrm{wt} \%$ Alcalase- $0.2 \mathrm{wt} \%$ Carbopol & 0.004157 & $* *$ \\
\hline E. faecalis & $0.2 \mathrm{wt} \%$ Alcalase vs $0.2 \mathrm{wt} \%$ Alcalase- $0.2 \mathrm{wt} \%$ Carbopol & 0.000636 & $* * *$ \\
\hline
\end{tabular}

$<0.05$ is considered significant. ${ }^{*} \mathrm{P}<0.05,{ }^{* *} \mathrm{P}<0.01,{ }^{* * *} \mathrm{P}<0.001$ 


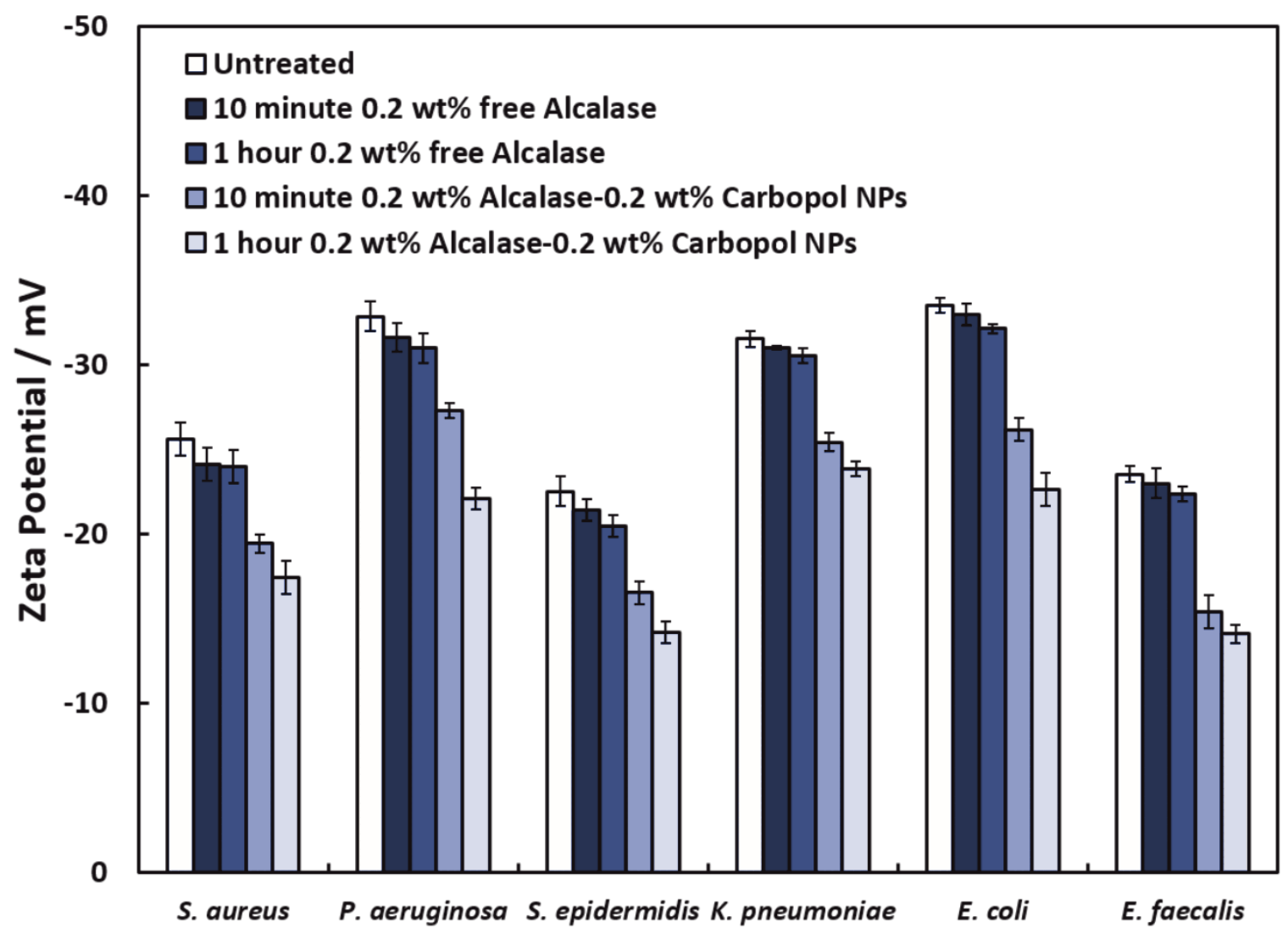

Figure S12. The zeta potential of bacterial cells treated with either $0.2 \mathrm{wt} \%$ free Alcalase or $0.2 \mathrm{wt} \%$ Alcalase- 0.2 wt $\%$ Carbopol NPs. The bacteria / treatment suspension was placed in a quartz cuvette and zeta potential was measured using the Dipstick probe and Malvern Zetasizer nano ZS. The refractive index was 1.384 and the absorption was $1.000 . \mathrm{N}=3$ with \pm S.D. 


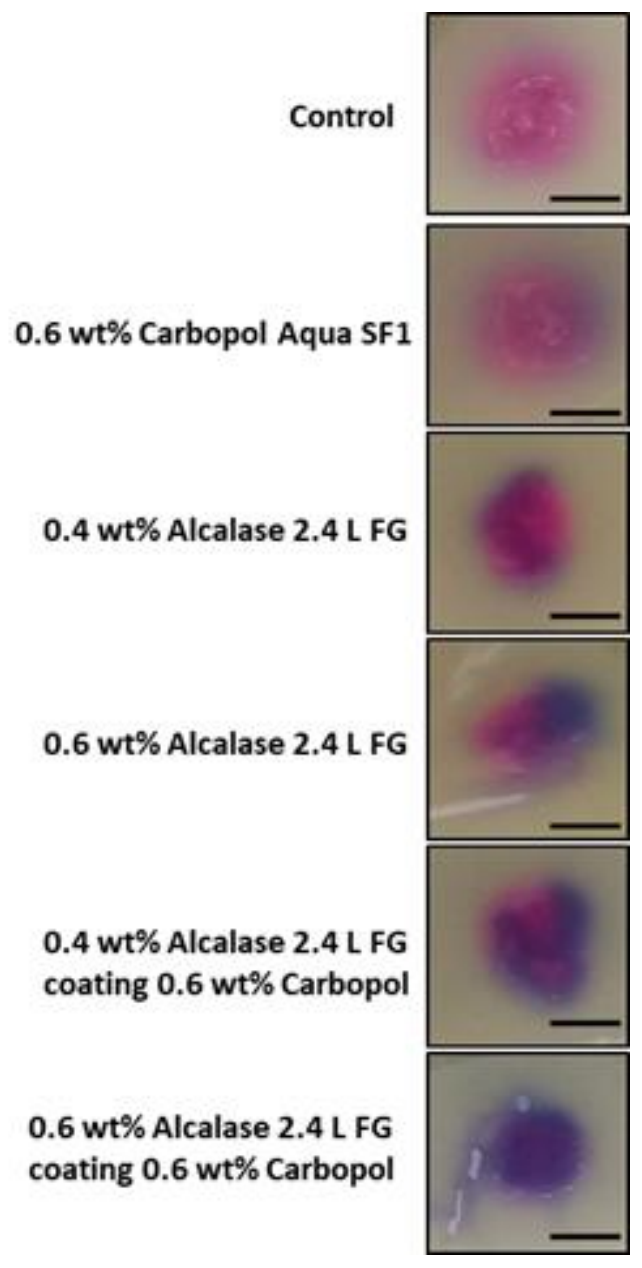

Figure S13. Photographs of $S$. aureus biofilms surface after treated with Resazurin Sodium Salt reagent. Pink indicates metabolising cells, purple non-metabolising cells. Black scale bar represents $1 \mathrm{~cm}$.

Table S5. The concentration of ciprofloxacin encapsulated into 0.6 wt\% Carbopol Aqua SF1 nanogel.

\begin{tabular}{|l|l|l|l|l|}
\hline $\begin{array}{l}\text { Carbopol- } \\
\text { ciprofloxacin } \\
\text { mixture } \\
\text { environment }\end{array}$ & $\begin{array}{l}\text { Total } \\
\text { ciprofloxacin } \\
\text { conc. attempted } \\
\text { to encapsulate / } \\
\text { wt\% }\end{array}$ & $\begin{array}{l}\text { Ciprofloxacin in } \\
\text { supernatant / } \\
\text { wt\% }\end{array}$ & $\begin{array}{l}\text { Ciprofloxacin } \\
\text { encapsulated / } \\
\text { wt\% }\end{array}$ & $\begin{array}{l}\text { Encapsulation } \\
\text { efficiency / wt\% }\end{array}$ \\
\hline $\begin{array}{l}\mathbf{3 0} \text { minutes } \\
\mathbf{3 7}{ }^{\circ} \mathrm{C} \\
\text { pH 7.5 }\end{array}$ & 0.0032 & 0.0008 & 0.0024 & 75 \\
\hline
\end{tabular}




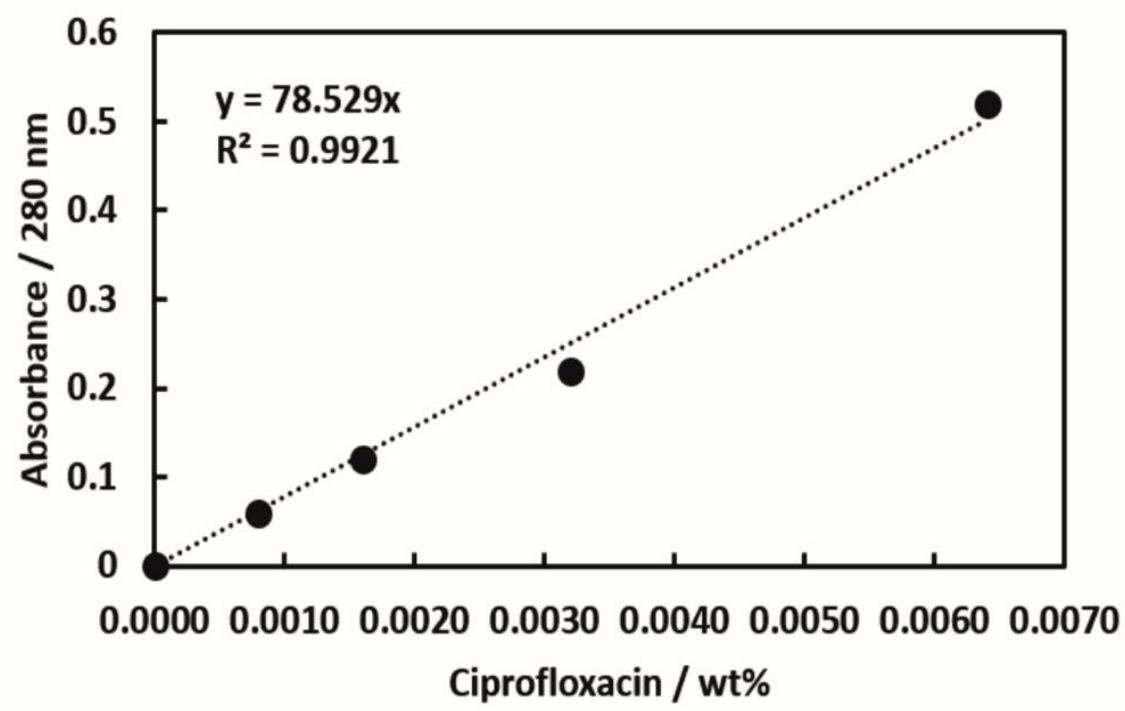

Figure S14. Standard calibration graphs of the absorption vs concentrations of ciprofloxacin hydrochloride. Absorbance was measured at $280 \mathrm{~nm}$. Aliquots were prepared by adding ciprofloxacin hydrochloride to $250 \mathrm{~mL}$ Milli-Q water (adjusted to $\mathrm{pH} 5.5$ using acetate buffer) at specific concentrations.
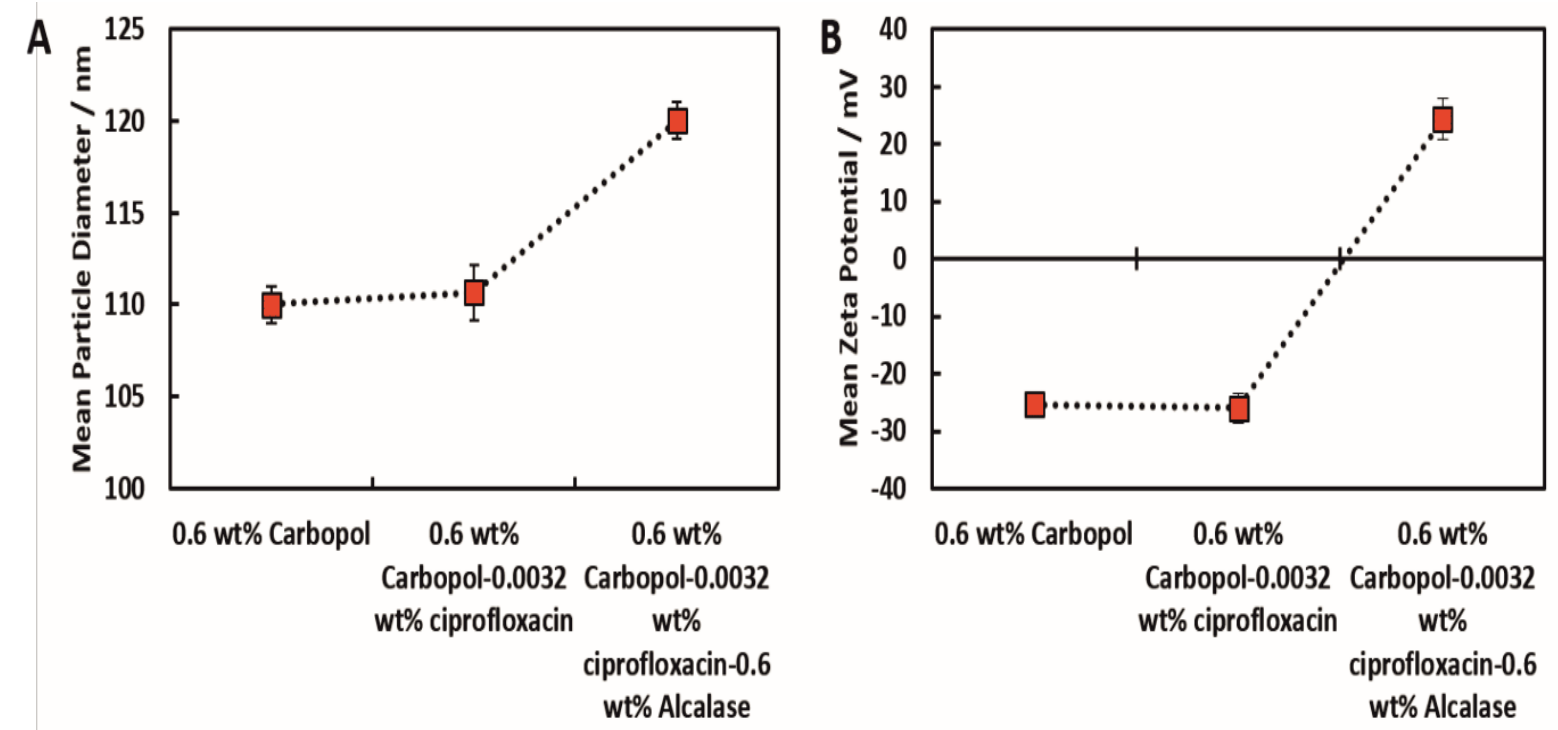

Figure S15. The (A) size and (B) zeta potential of $0.6 \mathrm{wt} \%$ Carbopol, $0.6 \mathrm{wt} \%$ Carbopol encapsulating 0.0032 wt\% ciprofloxacin and 0.6 wt\% Carbopol encapsulating $0.0032 \mathrm{wt} \%$ ciprofloxacin with $0.6 \mathrm{wt} \%$ Alcalase coating. All measurements were taken at $\mathrm{pH} 5.5$ (acetate buffer solution) with a RI of 1.450 at $25^{\circ} \mathrm{C}$. Each value represents a triple replicate with \pm S.D. The lines are guides to the eye. 


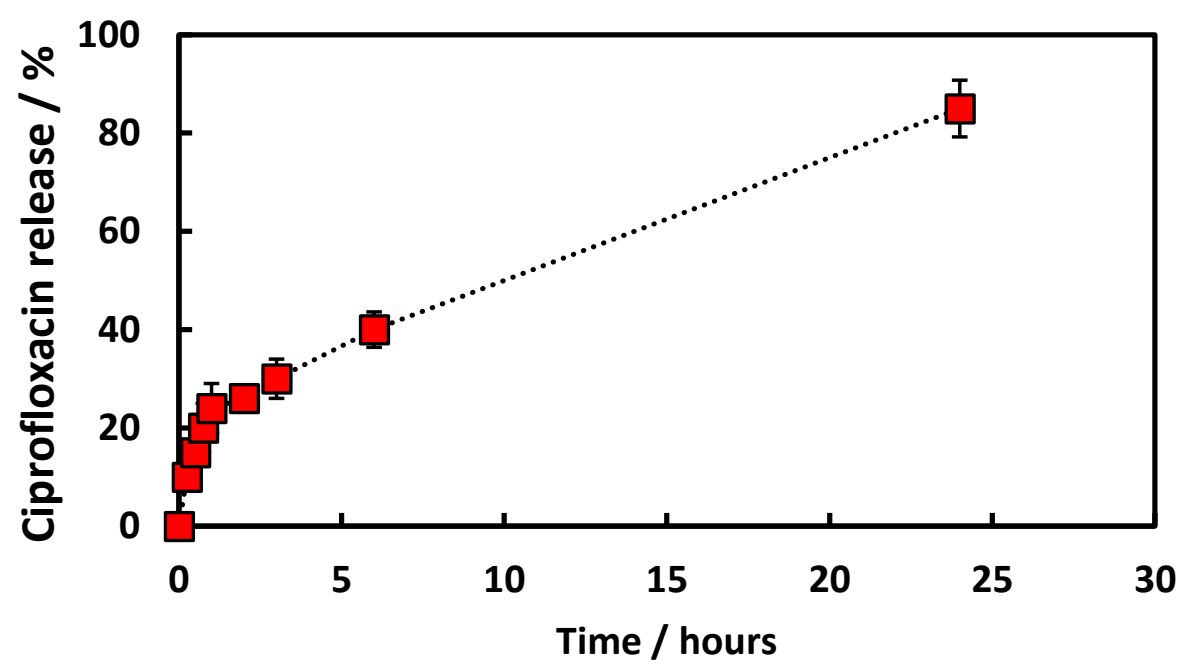

Figure S16. Ciprofloxacin release kinetics at $\mathrm{pH} 5.5$. $10 \mathrm{~mL}$ of $0.0032 \mathrm{wt} \%$ ciprofloxacin- $0.6 \mathrm{wt} \%$ Carbopol suspension was placed into a 10-12 kDa MWKO dialysis bag. The dialysis bag was submerged into $250 \mathrm{~mL}$ of pH 5.5 acetate buffer at $37^{\circ} \mathrm{C}$ whilst shaken at $100 \mathrm{rpm}$ shaking. $1 \mathrm{~mL}$ aliquots were taken at specific time points on the absorbance of the aliquot equated into the concentration of ciprofloxacin in the acetate buffer using a standard calibration curve. Absorption was measured at $280 \mathrm{~nm}$. Each value represents average triplicate measurements with error bars representing the \pm S.D. The lines are guides to the eye.

\section{S. aureus}

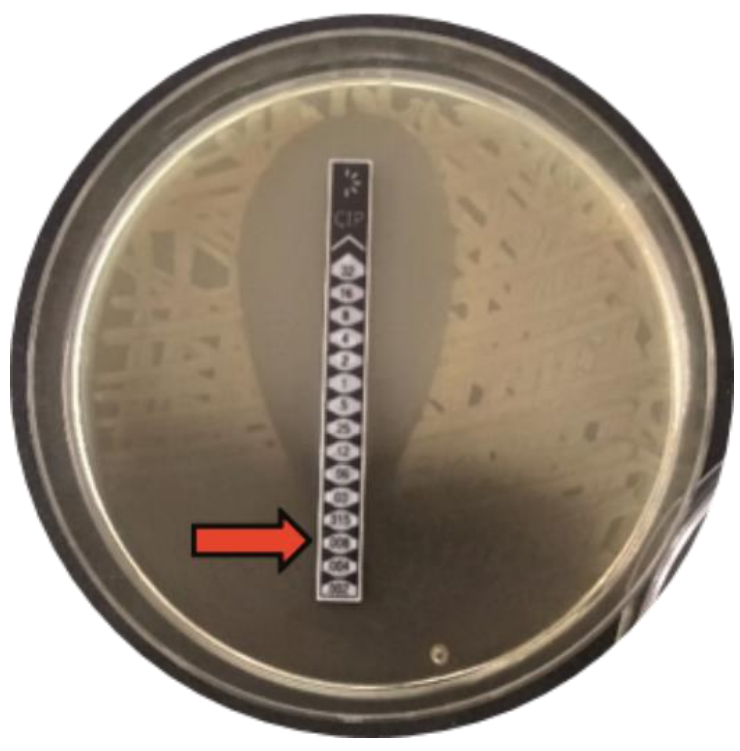

Figure S17. Ciprofloxacin MIC ETEST ${ }^{\circledR}$ Evaluator strips $32-0.002 \mu \mathrm{g} / \mathrm{mL}$ tested against $S$. aureus. Susceptibility is shown to be $0.08 \mathrm{ug} / \mathrm{mL}(0.000008 \mathrm{wt} \%)$. 


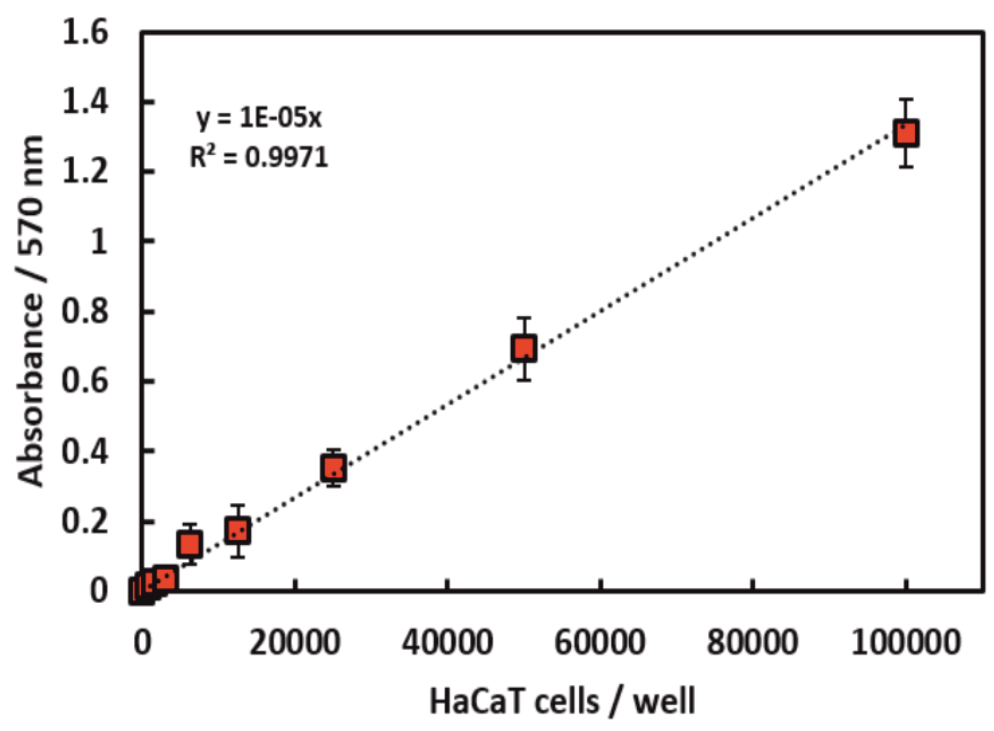

Figure S18. Calibration curve of HaCaT cells. Various cell concentrations were seeded in DMEM medium and absorption values obtained at $570 \mathrm{~nm}$. These data were used to calculate the number of cells in parallel treatment / untreated wells. $\mathrm{N}=3$ with \pm S.D.
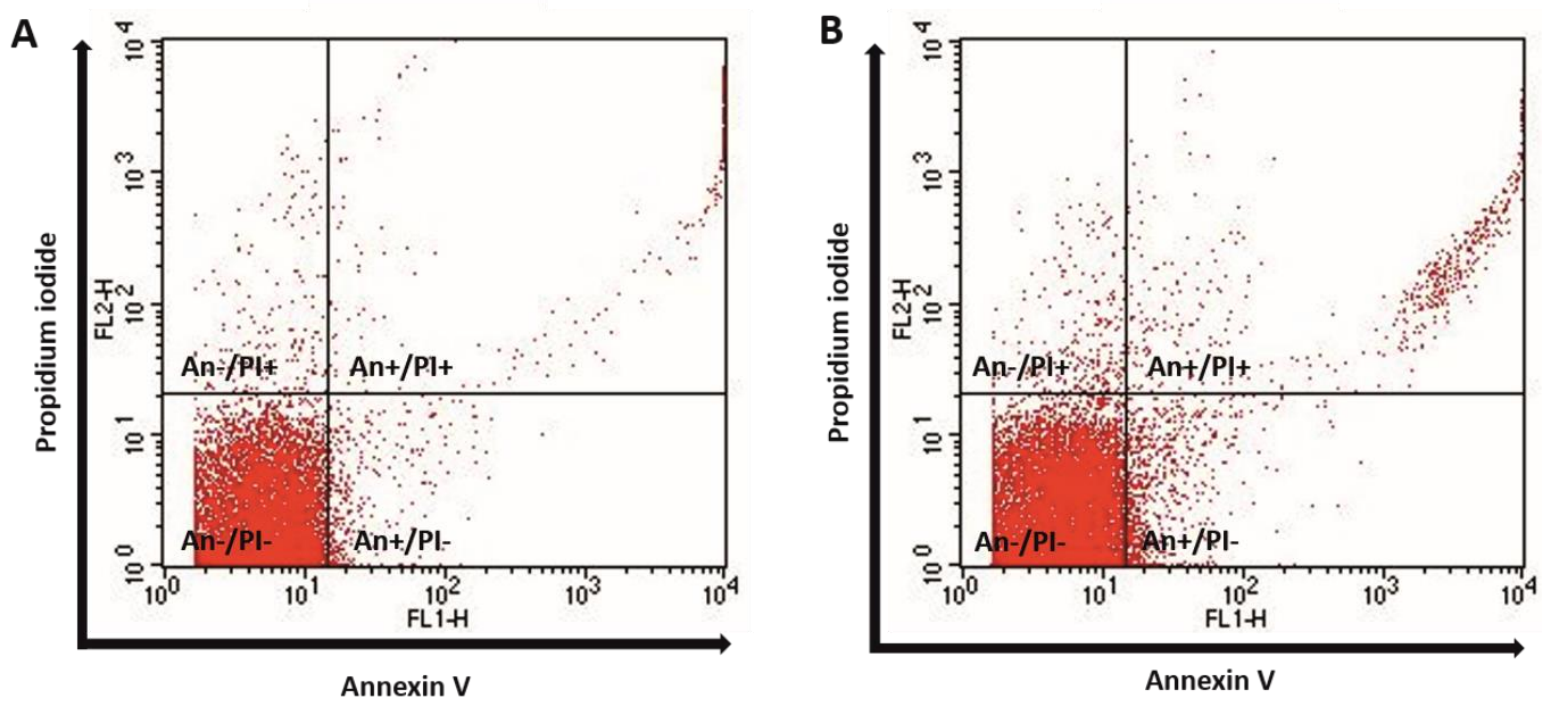

Figure S19. HaCaT cell status after 24 hrs of treatment with (A) $0.6 \mathrm{wt} \%$ Carbopol and (B) $0.6 \mathrm{wt} \%$ Alcalase. FACS dot plots of 10000 cells counted after $24 \mathrm{hr}$ treatment using a FITC Annexin V staining kit. 


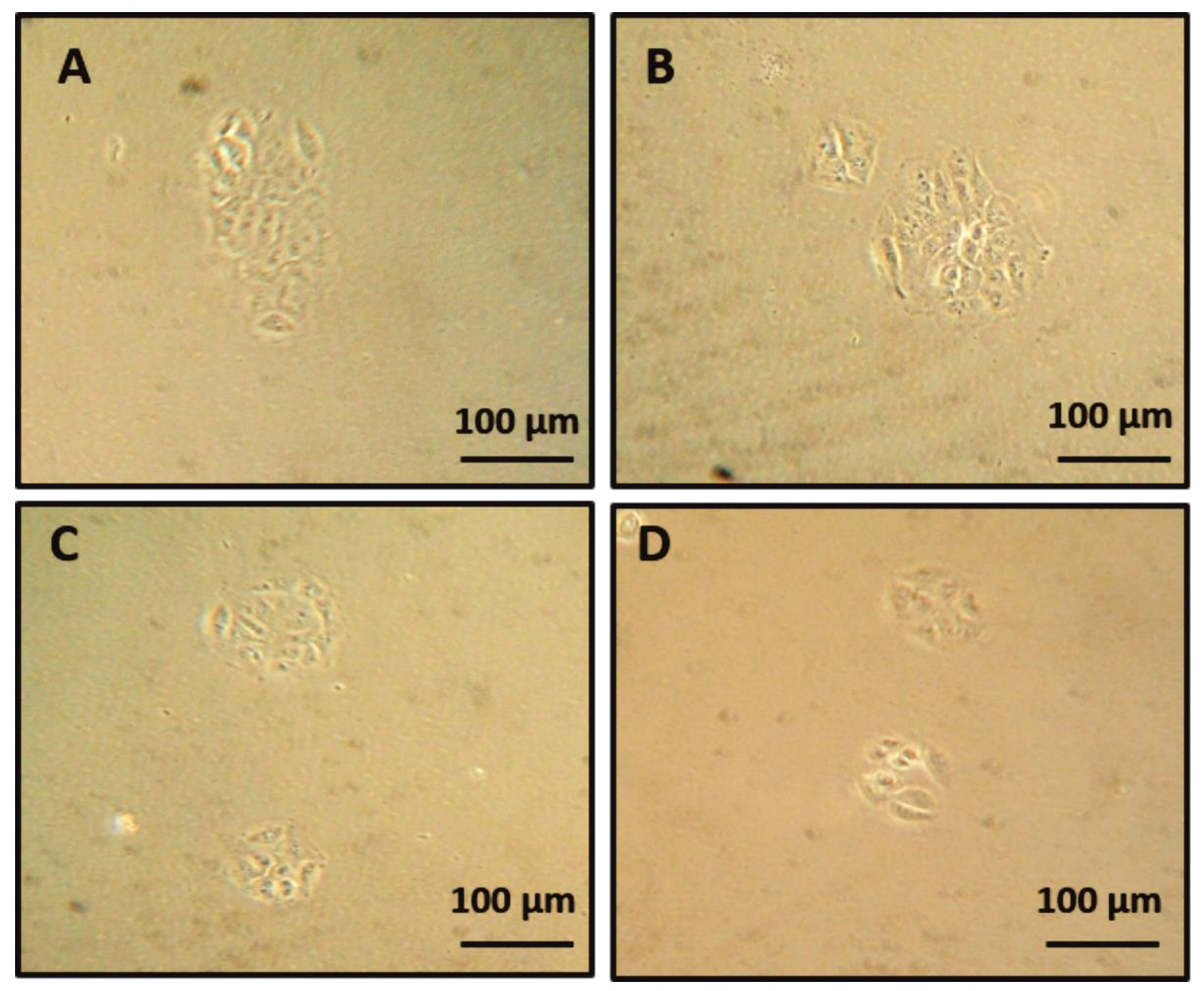

Figure S20. Photographs of HaCaT cells in 96-well plates after 24 hour treatment of (A) untreated control, (B) 0.6 wt\% Alcalase- 0.6 wt\% Carbopol NPs, (C) 0.6 wt\% bare Carbopol and (D) 0.6 wt\% free Alacalase. Photographs were taken immediately after treatment and before treatment infused DPBS was aspirated out. 
Table S6. The elemental analysis of Carbopol Aqua SF1, Alcalase 2.4 L FG, Ciprofloxacin, and Ciprofloxacin-loaded Carbopol nanogel coated with Alcalase 2.4 L FG.

\begin{tabular}{|c|c|c|c|c|}
\hline Element & $\begin{array}{c}0.6 \mathrm{wt} \% \text { Carbopol } \\
\text { Aqua SF1 / \% }\end{array}$ & $\begin{array}{c}0.6 \mathrm{wt} \% \text { Alcalase } \\
2.4 \mathrm{~L} \mathrm{FG} \mathrm{/ \%}\end{array}$ & $\begin{array}{c}0.0032 \mathrm{wt} \% \\
\text { Ciprofloxacin / \% }\end{array}$ & $\begin{array}{c}0.6 \mathrm{wt} \% \text { Carbopol Aqua SF- } \\
1-0.0032 \mathrm{wt} \% \\
\text { Ciprofloxacin-0.6 wt\% } \\
\text { Alcalase } 2.4 \mathrm{LFG} / \%\end{array}$ \\
\hline $\mathrm{C}$ & 35.93 & 47.60 & 51.08 & 41.19 \\
\hline $\mathrm{H}$ & 5.83 & 6.59 & 6.00 & 5.71 \\
\hline $\mathrm{N}$ & 0.0 & 16.58 & 10.60 & 7.57 \\
\hline $\mathrm{S}$ & 0.0 & 0.48 & 0.0 & 0.26 \\
\hline
\end{tabular}

Table S7. Cell status of HaCaT cells measured using FITC Annexin V staining kit and FACS.

\begin{tabular}{|c|c|c|c|}
\hline \multirow{2}{*}{ Treatment } & \multicolumn{3}{|c|}{ Cell status } \\
\cline { 2 - 4 } & Viable cells & Dead cells & Apoptotic cells \\
\hline Untreated cells & $87.4 \%$ & $7.2 \%$ & $5.4 \%$ \\
\hline 0.6 wt\% Carbopol-0.6 wt\% Alcalase NPs & $73.6 \%$ & $22.3 \%$ & $4.1 \%$ \\
\hline 0.6 wt\% Carbopol & $86.2 \%$ & $7.6 \%$ & $6.2 \%$ \\
\hline 0.6 wt\% Alcalase & $75.1 \%$ & $20.4 \%$ & $4.5 \%$ \\
\hline
\end{tabular}

Table S8. Statistical analysis of free ciprofloxacin vs encapsulated ciprofloxacin ( $0.6 \mathrm{wt} \%$ Alcalase-0.6 wt\% Carbopol formulation) at 1, 6 and 24 -hour time points. Data were expressed as average values \pm standard deviations of the mean. $P$-values of less than 0.05 were considered significant. All Student's T-tests were performed in GraphPad v7.0.4.

\begin{tabular}{|l|c|c|}
\hline Multiple comparison & P-value & Significance \\
\hline $\begin{array}{l}1 \text { hour free ciprofloxacin VS 1 hour encapsulated ciprofloxacin (0.6 } \\
\text { wt\% Carbopol-0.6 wt\% Alcalase NP) }\end{array}$ & 0.001952 & $* *$ \\
\hline $\begin{array}{l}\text { 6 hour free ciprofloxacin VS 1 hour encapsulated ciprofloxacin (0.6 } \\
\text { wt\% Carbopol-0.6 wt\% Alcalase NP) }\end{array}$ & 0.000314 & $* * *$ \\
\hline $\begin{array}{l}24 \text { hour free ciprofloxacin VS 1 hour encapsulated ciprofloxacin (0.6 } \\
\text { wt\% Carbopol-0.6 wt\% Alcalase NP) }\end{array}$ & 0.000499 & $* * *$ \\
\hline
\end{tabular}

$<0.05$ is considered significant. ${ }^{*} \mathrm{P}<0.05,{ }^{* *} \mathrm{P}<0.01,{ }^{* * *} \mathrm{P}<0.001$ 